
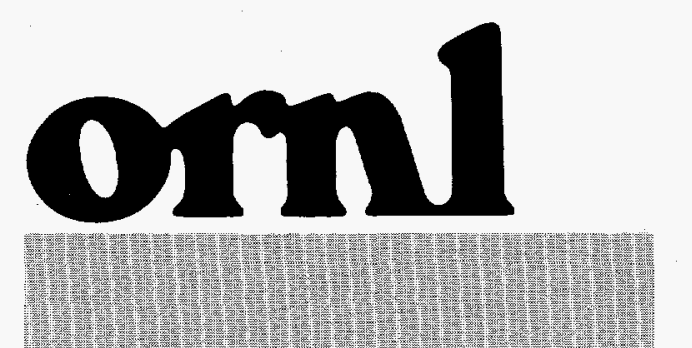

OAK RIDGE

NATIONAL

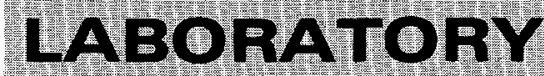

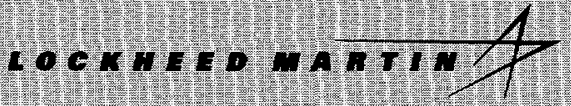

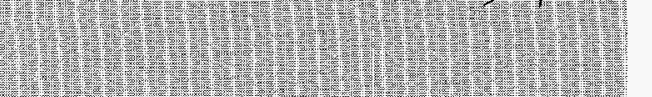

T)

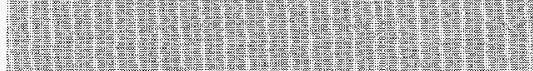

1.

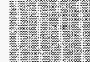

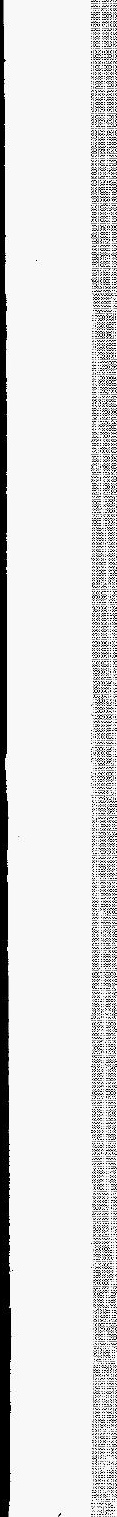

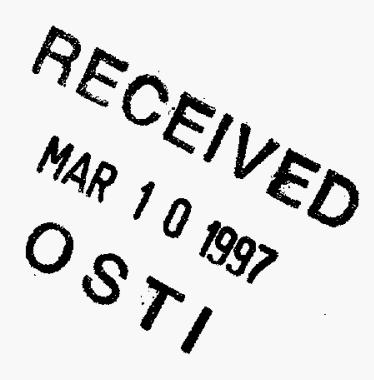

ORNL/TM-13382

\author{
W. E. Doll \\ R. D. Miller \\ J. Xia
}

Environmental Sciences Division

Publication Number 4645
"ASTFR H

DISTRIBUTION OF THIS DOCUMENT IS IMM MUTED 


\section{DISCLAIMER}

Portions of this document may be illegible in electronic image products. Images are produced from the best available original document. 
ORNLTM-13382

Environmental Sciences Division

\title{
Comparison of Seismic Sources for Imaging Geologic Structures on the Oak Ridge Reservation, Tennessee
}

\author{
W. E. Doll \\ Environmental Sciences Division \\ Oak Ridge National Laboratory \\ POB 2008, Oak Ridge, TN 37831-6400 \\ R.D. Miller and J. Xia \\ Kansas Geological Survey \\ Lawrence, KS 66046-2598 \\ Date Issued -- February, 1997 \\ Prepared by \\ Environmental Sciences Division \\ Lockheed Martin Energy Research \\ Prepared for the \\ U.S. Department of Energy \\ Office of Environmental Management \\ under budget and reporting code EU2010301 \\ Environmental Management Activities at the \\ OAK RIDGE NATIONAL LABORATORY \\ Oak Ridge, Tennessee 37831 \\ managed by \\ LOCKHEED MARTIN ENERGY SYSTEMS, INC. \\ for the \\ U.S. DEPARTMENT OF ENERGY \\ under contract DE-AC05-96OR22464
}




\section{ACKNOWLEDGMENTS}

John Mims and Julian Unger of Oyo Corporation provided the DAS instrument and prototype vibrator which were used in this project. Without their assistance, a less complete data set would have been collected. Jay and Nancy Bird of IVI brought the Minivib to our site and operated it at their expense. Brian Herridge of Bison Instruments loaned the EWG for testing purposes, and Rick Williams and John Hansen at the University of Tennessee provided the Failing vibrator. Well log data were acquired and interpreted by R. Kim Davis, Bob Kennard, and RaNaye Dreier. The assistance provided by Larry Musson during all phases of data acquisition is greatly appreciated. Les Beard, Phil Carpenter, and Kirk Hyder contributed in acquisition of the Mini-Sosie data. Allan Tucker and Brad Carr analyzed the VSP data that is provided in Figure 6. 


\section{EXECUTIVE SUMMARY}

Seismic reflection profiling is a technique that was developed by the petroleum industry to image geologic structures that define oil traps and thereby assist in the selection of drilling sites. Over the past twenty years, the technique has been adapted to image shallow geologic structures that are important in environmental studies. Previous work has shown that the success of shallow seismic reflection profiling depends on site conditions, the proper selection of energy sources, the geometrical arrangement of the source and receivers and appropriate processing of the data. Common seismic sources include sledge hammers, blasting caps or other high velocity explosives, shotgun shells, and a variety of vibrators and accelerated impact devices. A seismic source comparison was conducted in Melton Valley, near the Oak Ridge National Laboratory Waste Area Groupings (WAGs), in order to: 1) determine whether shallow seismic reflection was an appropriate technique in the area, 2) select the most effective source for subsequent seismic acquisition, considering the hazards that are associated with ground penetration at some locations in the area, and 3) evaluate processing techniques that might affect data acquisition procedures.

Non-invasive shallow seismic sources (i.e. those which do not require penetration of the ground surface with an auger or other device) might be preferred at hazardous waste sites for several reasons. First, many commonly used invasive shallow seismic sources are unacceptable for hazardous waste site investigations because they risk dispersal of soil contaminants, they add contaminants which are not allowed by regulations (e.g. lead), or they create new migration paths for contaminants. Invasive sources often use explosives which are inherently hazardous, and become more hazardous when detonated in contaminated soils. Furthermore, the success of swept sources for petroleum exploration suggested that the recently-developed high frequency vibrators might be a worthy alternative to the impulsive sources that have been commonly used in shallow seismic reflection work.

Non-invasive sources include both "swept" sources (vibrators) and impacting sources (e.g. weight drop devices). Recently developed high frequency vibrators, designed for shallow investigations, are more effective at some sites than the more commonly used (invasive and non-invasive) impacting sources because the range of frequencies that they generate can be controlled (and high frequencies can be enhanced) so that the resolution of resultant images can be improved. Many of these sources can also deliver more power with less surface damage, and because their energy is dispersed over a much longer time period, they will respond differently to random noise sources. This study differs from previous low energy source comparisons in that it: 1) includes swept sources, 2) is designed for a greater target depth, 3) was conducted in a very different geologic environment, and 4) generated a larger data set for each source.

In this study, five non-invasive swept sources, three non-invasive impulsive sources and one invasive impulsive source were compared in preparation for about eight miles of seismic reflection profiling in the vicinity of the hydrofracture facilities (WAG 10) on the Oak Ridge Reservation, Tennessee (Figure 1). Data were recorded at 95 geophone (receiver) groups from 125 source positions ("shot points") along a $1250 \mathrm{ft}$. test line (Figure 1). Source positions and geophone groups were spaced at $10 \mathrm{ft}$ intervals along the test line. Each of the nine data sets were processed in a consistent manner into common midpoint (CMP) seismic sections. These sections are images (nominally vertical) of geologic structures at depths ranging from a few hundred feet to 2000 feet or deeper beneath the profile line. Well log data are used to correlate geologic contacts with seismic reflections, and to generate synthetic seismograms for the site. 
Each source was also monitored with downhole receivers to provide a measure its efficiency by recording seismic waves that were transmitted from the surface to subsurface measuring points. Downhole data were obtained for each source with a string of 48 hydrophones at $5 \mathrm{ft}$ intervals between $200 \mathrm{ft}$ and $435 \mathrm{ft}$ depth in a hole near the center of the test line, and with a downhole geophone at $980 \mathrm{ft}$ depth near the west end of the line. The downhole geophone was used to determine transmission efficiency as a function of frequency for each source.

In general, each source is represented by five figures in this report. The CMP seismic sections (e.g. Figures 7 and 14c), as described above, reveal the level of detail (resolution) provided by each source (depending on the high frequency content of energy generated by the source), and the noise level that masks this detail. The best source will provide the greatest detail over the greatest range of depths with the lowest noise. A shot gather (e.g. Figure 14d), or plot showing the response of all 95 geophones for a single shot for a period of time following the shot, provides additional indications of the frequency content and noise level associated with a particular source. Reflected seismic waves appear as hyperbolae on shot gathers. If a reflection is apparent on a shot gather, it will be more apparent on a CMP seismic section. The frequency content of each source is represented by two spectral plots: one that represents the energy measured at one receiver for one shot (e.g. Figure 14e), and another which represents the average frequency content measured by the downhole geophone for all source positions at the surface (e.g. Figure $14 \mathrm{~g}$ ). Finally, noise levels and frequency content are represented by plotting the traces recorded by the downhole geophone as the source moved from one end of the profile line to the other. These plots are known as walkaway vertical seismic profiles (e.g. Figure 14f). For some sources, additional figures show the benefits of certain processing techniques (e.g. Figures $14 \mathrm{~b}$ and $14 \mathrm{c}$ ), and for other sources, acquisition constraints do not provide data required to generate some of the figures.

The CMP stacked images indicate that all of the sources were effective to some extent at this site, implying that it is a favorable site for shallow seismic reflection. This is even true of the sledge hammer, which provided low resolution images of the $200 \mathrm{~ms}$ reflection, which occurs at a depth of about 1200 feet on the basis of downhole velocity profile data acquired at the site.

The non-invasive seismic sources that provided the best resolution and signal to noise ratio for the nominal $1000 \mathrm{ft}$ target depth are the IVI Minivib (high frequency vibrator) and the Bison Elastic Wave Generator (weight drop). The figures that document the performance of these two sources are Figures 13 and 14 . The Minivib performed notably better than any other source when appropriate pre-correlation spectral whitening processing was applied. This is evidenced by the continuity and amplitude of the reflection at $100 \mathrm{~ms}$ and perhaps shallower reflections (Figure 14c) that are not evident or less apparent on images from the other sources.

Data acquired in this study also demonstrate the value of downhole measurements for identifying hydraulically conductive fractures or fracture zones. Hydrophone data from well 1920 (which is artesian) display tube waves emanating from depths of $280 \mathrm{ft}$ and $385 \mathrm{ft}$ (Figure 17). These tube waves indicate likely locations where fluid in the fractures or fracture zones is being squirted into the well due to the pressure of the seismic wave, and are therefore strong indicators of hydraulically conductive (active) fractures or fracture zones. Well logs acquired in well 1920 support the interpretation that these are conductive fractures. 


\section{CONTENTS}

ACKNOWLEDGMENTS

EXECUTIVE SUMMARY

ABBREVIATIONS V V V V V V

LIST OF FIGURES Vi

1. INTRODUCTION

2. DATA ACQUISITION

2.1 Pre-test 3

2.2 Source comparison procedures 3

2.3 Geophysical well logs and synthetic seismograms 7

2.4 Velocity profiles $\quad$. 7

3. DATA PROCESSING

3.1 Standard processing flow and spectral enhancement for CMP sections $\quad 11$

3.2 Interpreted CMP section 11

3.3 Resolution of CMP sections 13

$\begin{array}{ll}3.4 \text { Walkaway vertical seismic profiles } & 14\end{array}$

4. COMPARISON OF RESULTS FROM EACH OF THE SOURCES 16

4.1 Oyo Portable Vibrator $\quad 16$

$\begin{array}{ll}4.2 \text { Sledge Hammer } & 17\end{array}$

$\begin{array}{ll}\text { 4.3 Mini-Sosie } & 17\end{array}$

4.4 KGS Prototype Swept Impacting Source $\quad 17$

$\begin{array}{ll}4.5 \mathrm{KGS} \text { Auger Gun } & 17\end{array}$

4.6 Bison Elastic Wave Generator (EWG)

4.7 Industrial Vehicles Minivib 18

4.8 Bolt Land Air Gun 19

4.9 Failing Y-1100-A Vibrator 19

5. HYDROPHONE DATA

$\begin{array}{ll}\text { 6. CONCLUSIONS } & 60\end{array}$

$\begin{array}{ll}\text { 7. REFERENCES } & 61\end{array}$

8. FURTHER INFORMATION AND CONTACTS 63 


\section{ABBREVIATIONS}

$\begin{array}{ll}\text { AGC } & \text { Automatic Gain Control } \\ \text { CMP } & \text { Common Mid-Point } \\ \text { DAS } & \text { Digital Acquisition System } \\ \text { DOE } & \text { Department of Energy } \\ \text { EWG } & \text { Elastic Wave Generator } \\ \text { HFIR } & \text { High Flux Isotope Reactor } \\ \text { IVI } & \text { Industrial Vehicles International Inc. } \\ \text { KGS } & \text { Kansas Geological Survey } \\ \text { ORR } & \text { Oak Ridge Reservation } \\ \text { SAGC } & \text { Stretch Automatic Gain Control } \\ \text { VSP } & \text { Vertical Seismic Profile } \\ \text { VSW } & \text { Vibroseis Whitening } \\ \text { WAG } & \text { Waste Area Grouping }\end{array}$




\section{LIST OF FIGURES}

Fig. 1. Map view of the non-invasive source test site.

Fig. 2. Brute common midpoint stack of data acquired during the October pre-test.

Fig. 3. Three shot gathers from the pre-test, showing reflections when high-pass frequency filters are applied to the data.

Fig. 4. Selected well logs for well 1920.

Fig. 5. Synthetic seismograms generated from sonic logs of well 1920.

Fig. 6. Average velocities derived from surface to borehole measurements at wells 1920 and 1943.

Fig. 7. Interpreted seismic reflection data from the test line in Melton Valley.

Fig. 8. Annotated walkaway vertical seismic profile.

Fig. 9. $\quad$ Test results for the OYO portable vibrator.

Fig. 10. Test results for the sledge hammer.

Fig. 11. Test results for the Mini-Sosie.

Fig. 12. Test results for the KGS prototype swept impacting source.

Fig. 13. Test results for the KGS auger gun.

Fig. 14. Test results for the Bison Elastic Wave Generator.

Fig. 15. Test results for the IVI Minivib.

Fig. 16. Test results for the Bolt airgun.

Fig. 17. Test results for the Failing vibrator

Fig. 18. Hydrophone record for well 1920 with a Bison EWG source.

Fig. 19. Diagram showing the process by which tube waves are generated. 


\section{INTRODUCTION}

The Oak Ridge Reservation (ORR), located about 15 miles west of Knoxville, Tennessee, is a 35,000 acre $\left(143 \mathrm{~km}^{2}\right)$ U.S. Department of Energy operation which contains research facilities, production plants, waste disposal sites, and forests. The Reservation is located in the fold and thrust belt of the western Appalachians. Local geology consists of interbedded shales and limestones with strikes averaging $N 55^{\circ} \mathrm{E}$ and dips typically ranging between $20^{\circ} \mathrm{S}$ and $60^{\circ} \mathrm{S}$. Waste sites on the ORR contain a broad range of contaminants including radioisotopes and solvents. The waste sites and adjacent contaminated areas are operated under environmental regulations.

The new and old hydrofracture injection facilities (NHF and OHF, Figure 1) are located along a floodplain that receives runoff from waste sites, causing soil contamination in some areas. Hydrofracture waste disposal injections were conducted at these facilities between 1963 and 1984, During this time, 3.2 million gallons of low-level radioactive wastes were mixed with cement grout and injected in shales at a depth of approximately 940 feet. Seismic reflection profiling, planned as part of the remedial investigation of Waste Area Grouping 10 (Bechtel National and others, 1992), and conducted in 1996-1997 (subsequent to this test) was designed to image faults or fracture zones that might act as pathways for contaminants from the injected grouts to move into the overlying potable water system. The surface contamination around the facilities leads to restrictions in the choice of seismic sources (even on the roads) and constrains shot point and geophone locations. Before acquisition of the seismic profile data, a test was conducted in order to 1) determine whether shallow seismic reflection was an appropriate technique in the area, 2) select the most effective source for subsequent seismic acquisition, considering the hazards that are associated with ground penetration at some locations in the target area, and 3) evaluate processing techniques that might affect data acquisition procedures.

Because of the possibility of exposure to hazardous materials in the hydrofracture area, the test was conducted at a relatively quiet, uncontaminated site nearby, located along geologic strike in order to mimic the geologic setting of the hydrofracture area. The $1000 \mathrm{ft}$. target depth for this test is deeper than usual for many environmental surveys and shallower than is typical for petroleum investigations. Therefore, the test incorporated both environmental and petroleum sources.

Non-invasive shallow seismic sources (i.e. those that may cause compaction, but do not require penetration of the ground surface with an auger or other device) are generally preferred at hazardous waste sites for several reasons. First, many commonly used invasive shallow seismic sources are unacceptable for hazardous waste site investigations because they risk dispersal of soil contaminants, they add contaminants which are not allowed by regulations (e.g. lead), or they create new migration paths for contaminants. Invasive sources often use explosives which are inherently hazardous, and become more hazardous when detonated in contaminated soils. Furthermore, the success of swept sources for petroleum exploration suggested that the recentlydeveloped high frequency vibrators might be a worthy alternative to the impulsive sources that have been commonly used in shallow seismic reflection work.

Non-invasive sources include both "swept" sources (vibrators) and impacting sources (e.g. weight drop devices). Recently developed high frequency vibrators, designed for shallow investigations, are more effective at some sites than the more commonly used (invasive and non-invasive) 


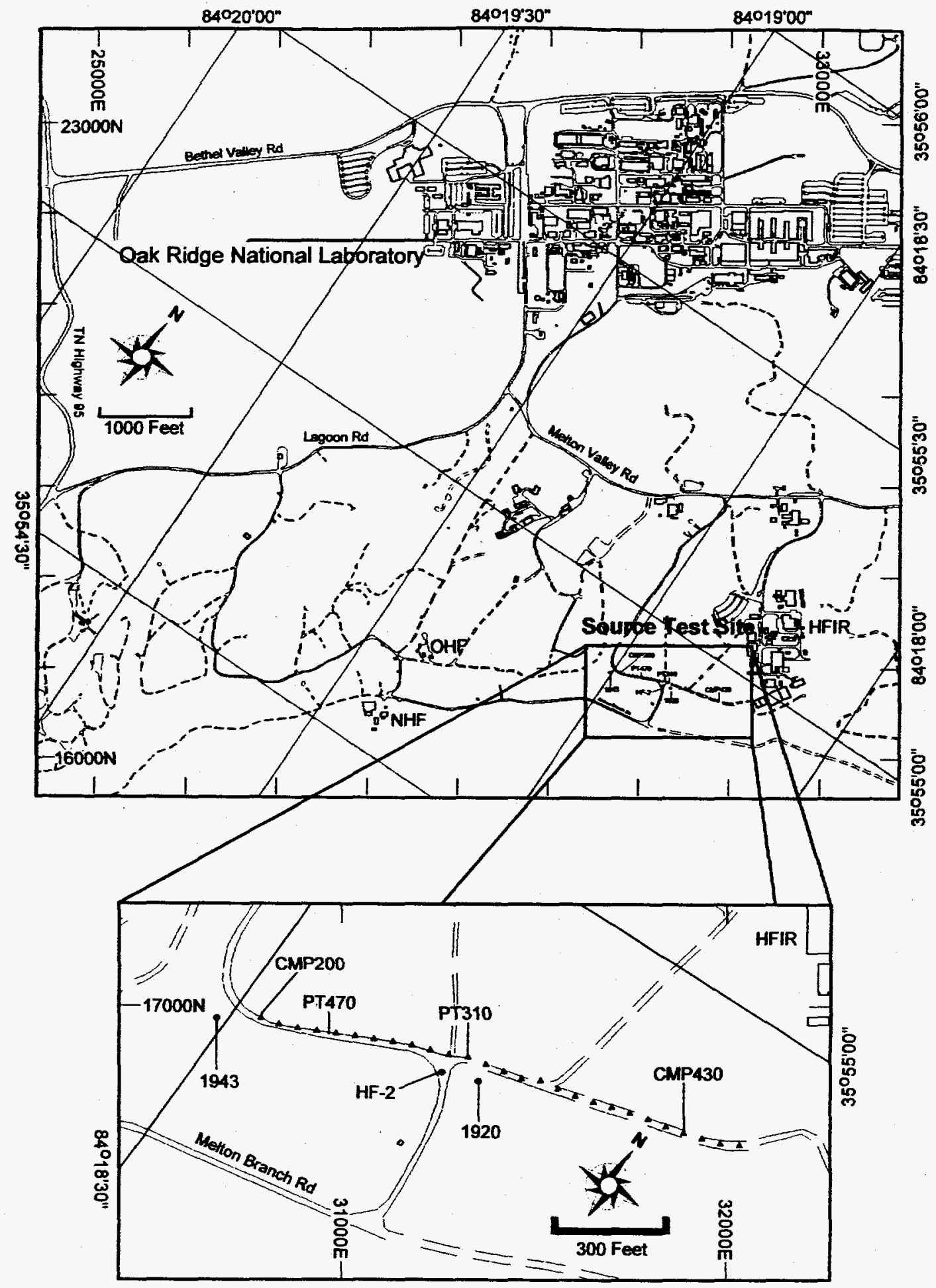

Figure 1. Map view showing the location of the source test site in relation to Oak Ridge National Laboratory. The inset view of the source test site shows locations of geophones and sources (triangles) and wells (circles). The end points of the common midpoint (CMP) and pre-test (PT) profiles are labeled for comparison with subsequent figures. 
impacting sources because the range and amplitude of frequencies that they generate can be controlled (i.e. high frequencies can be enhanced) so that the resolution of resultant images can be improved. Many of these sources can also deliver more total energy with less surface damage, and thereby reduce interference from random noise sources.

In this study, five non-invasive swept sources, three non-invasive impulsive sources and one invasive impulsive source were compared. Previous shallow seismic source tests (Miller and others, 1986, 1992, 1994) have established that site characteristics should be considered in determining the optimal source. These studies evaluated a number of "invasive" sources along with a few non-invasive impulsive sources. Several sources (particularly the high frequency vibrators) that were included in the ORR test were not available or not practical during previous tests, cited above. This study differs from previous source comparisons in that it 1) includes many swept sources, 2) is designed for a greater target depth, 3) was conducted in a very different geologic environment, and 4) generated a larger and more diverse data set (including high fold CMP sections and walkaway vertical seismic profiles) for each source.

This report is directed toward those who are familiar with the principles and methods of seismic reflection profiling. We recommend that readers who are unfamiliar with the seismic reflection technique read Steeples and Miller (1990) for background.

\section{DATA ACQUISITION}

The test site is centered around test injection well HF-2 (Fig. 1), between the southern end of Waste Area Grouping 5 (WAG 5) and the High Flux Isotope Reactor (HFIR). It is located about 0.6 mi east (along geologic strike) of the new and old hydrofracture injection facilities (NHF and OHF, Fig. 1). Dips measured at the surface average about $30^{\circ} \mathrm{S}$ in this area.

\subsection{Pre-test}

Acquisition parameters including receiver spacing, shot spacing, and sweep frequencies were selected on the basis of a pre-test which was conducted with a sledge hammer and auger gun at the western portion of the test line in October, 1993. Brute stacked sections from data collected during this pre-test (Fig. 2, common midpoints of the ends of the line labeled as PT310 and PT470 in Fig. 1) show numerous reflections including a very strong reflection at $195-200 \mathrm{~ms}$ (Fig. 2). In many of the shot gathers from the pre-test, the reflections were hidden in noise unless high pass filtered at $100 \mathrm{~Hz}$ to $200 \mathrm{~Hz}$ (Fig. 3). The reflections have an upper corner frequency of $150 \mathrm{~Hz}$ and a dominant frequency of about $120 \mathrm{~Hz}$ in the pre-test data.

\subsection{Source Comparison Procedures}

Test data were acquired during a two week period in November, 1993. Uniform weather conditions prevailed during the ten-day period when data were collected. Most days were characterized by heavy morning fog which cleared by mid-morning. Data were not collected when geophones were wet from dew or the light rains that fell a few times during the test period. Source-specific acquisition parameters were selected to maximize the performance of each source at this site while source-independent parameters were equivalent to the extent possible (e.g. background noise levels and water saturation conditions were very similar, but could not be rigidly controlled). To minimize the effects of ground compaction near each shot location on subsequent sources, the sources were sequenced from least disruptive to most disruptive. 


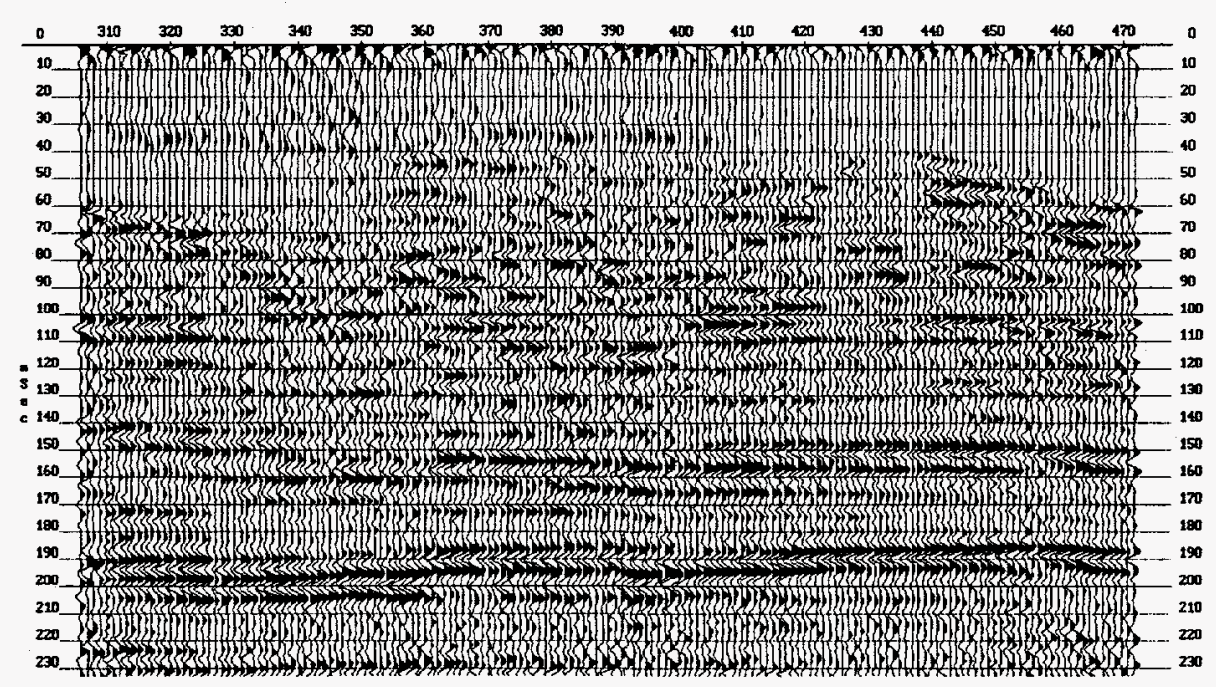

Figure 2. Brute common midpoint stack of seismic reflection data acquired during the October 1993 pre-test with an auger gun source between stations PT310 and PT470 (Figure 1). 

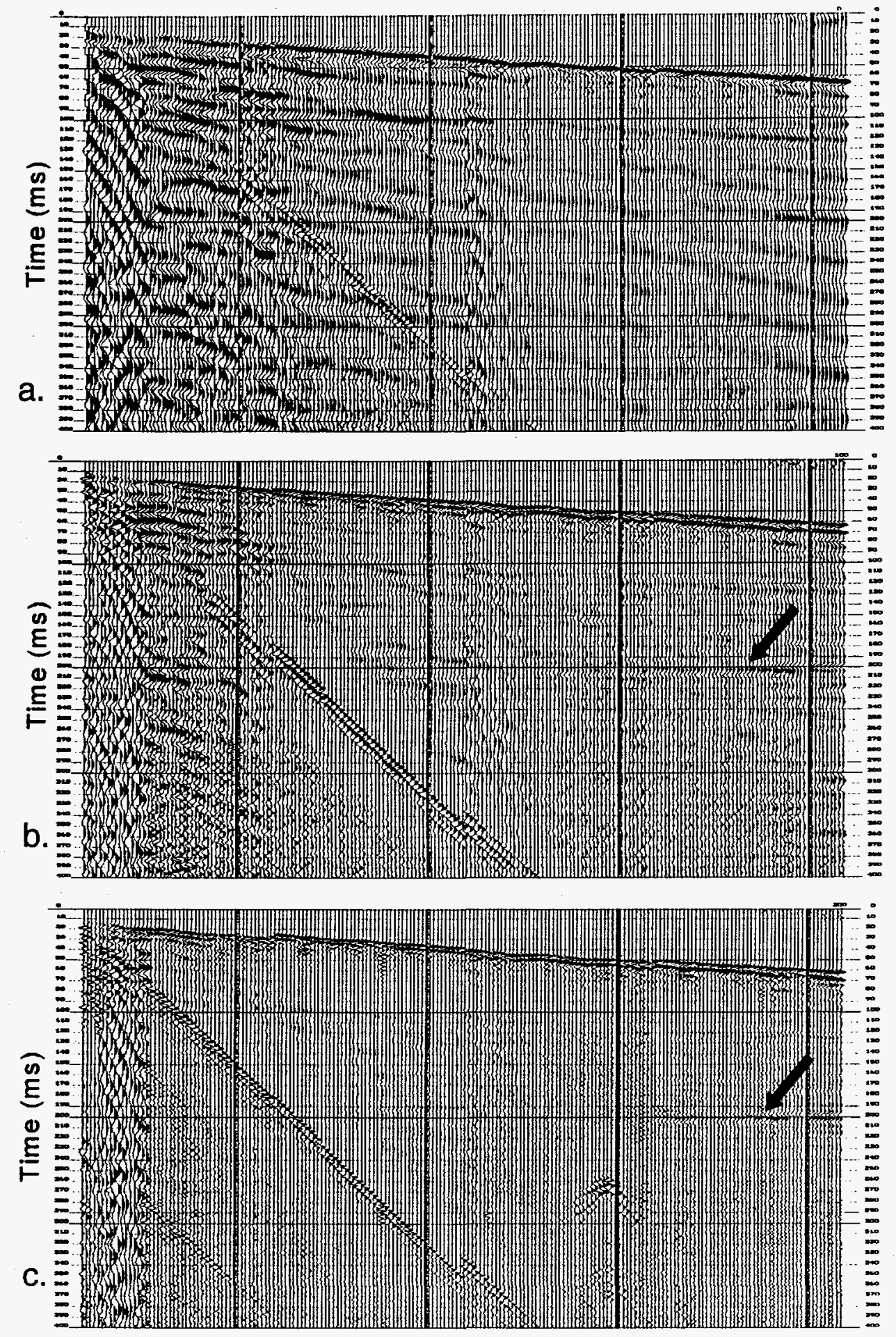

Figure 3. Three shot gathers from the October 1993 pre-test. a) raw data, b) data for the same shot as in a, but high pass filtered at $100 \mathrm{~Hz}$, and c) the same data high pass filtered at $200 \mathrm{~Hz}$. The $200 \mathrm{~ms}$ reflection is clearly seen in the filtered data, but not in the raw data. This demonstrates the need to use a source that can generate abundant energy at frequencies greater than $100 \mathrm{~Hz}$. 
In order, the nine sources tested were:

(1) $16 \mathrm{lb}(7.3 \mathrm{~kg})$ sledge hammer,

(2) Oyo prototype electrodynamic vibrator,

(3) Bison Elastic Wave Generator (EWG) Model EWG-1,

(4) Mini-Sosie,

(5) KGS auger gun (invasive),

(6) KGS Swept Impulsive Source prototype,

(7) IVI Minivib,

(8) Bolt Model LSS-3 land air gun, and

(9) Failing model Y1100A vibrator.

Vertical stacking is commonly used to improve the signal-to-noise ratio in seismic reflection data. However, vertical stacking may result in a loss of high frequency information (and therefore resolution potential), either because of imprecise triggering, or variations in the source wavelet (the wave train that propagates from the source) due to changes in the ground surface from compaction and changes in coupling between shots. For most sources the benefits will generally outweigh the detrimental effects. For swept sources in which uncorrelated data are stored in the field, vertical stacking is best done after correlation to preserve high frequency signal components. Five shots were vertically stacked at each source position for the non-invasive impulsive sources (hammer, EWG, air gun). To allow evaluation of pre-correlation enhancement techniques, we chose to store uncorrelated data for the swept sources. Data storage limitations made it necessary to limit uncorrelated swept source data to one file per shot point. To avoid loss of high frequency data, single sweeps of uncorrelated data were collected with the Failing vibrator and Minivib. Because the Oyo vibrator had low energy output relative to the other swept sources, five sweeps from each shot point were vertically stacked for this source and stored in uncorrelated format.

Linear sweeps, increasing from 100 to $500 \mathrm{~Hz}$ were used with the Oyo vibrator and Minivib. The Failing vibrator was mechanically incapable of generating frequencies much above $250 \mathrm{~Hz}$, and phase lock electronics became inadequate at even lower frequencies. The Failing Y1100A vibrators, and most other full size vibrators, are not designed to operate at frequencies higher than about $120 \mathrm{~Hz}$. For these reasons, Failing vibrator was operated with a linear sweep from 45 to $250 \mathrm{~Hz}$. For the Failing vibrator and the Minivib, the output from a baseplate accelerometer and an accelerometer attached to the vibrator mass were recorded as well as the synthetic input or "desired" sweep. By correlating the Failing data with the mass or baseplate, some of the discrepancies between the desired and resultant sweeps, that were evident when comparing the synthetics with the mass accelerometer, could be compensated. The Minivib computer also stores unfiltered and filtered ground force sweeps that are calculated from the mass and baseplate accelerometers, as alternatives for correlation. These are generally considered to be more reliable than either of the accelerometer traces. Accelerometer or ground force sweeps are often preferred over the input sweep because near surface conditions can cause the actual oscillatory motion input to the ground to differ from the electronically generated input sweep.

The test data were acquired at 125 shot locations for each source at $10 \mathrm{ft}(3.3 \mathrm{~m})$ spacing along a strike-parallel segment of road (Fig. 1). Each shot was recorded by a geophone spread consisting of 95 fixed geophone groups at $10 \mathrm{ft}(3.3 \mathrm{~m})$ spacing, a single fixed vertical component geophone in a well near the west end of the geophone spread, and 48 individual hydrophones at 5 foot $(1.5 \mathrm{~m})$ spacing suspended in an uncased water-filled well near the center of the geophone spread. Surface geophone groups consisted of three Mark Products L-28E $40 \mathrm{~Hz}$ geophones 
wired in series and separated by $1 \mathrm{ft}(0.3 \mathrm{~m})$ in an east-west (X-10 administrative grid) linear array. The 48 preamplified Innovative Transducers Model DF-5 hydrophones were deployed between 200 and 435 feet $(61 \mathrm{~m}$ and $132.6 \mathrm{~m})$ depth in Well 1920 (Fig. 1b). The vertical component of a Mark Products L-10-3D-SWC downhole geophone, located at $980 \mathrm{ft}(298 \mathrm{~m})$ depth in the uncased well 1943 was recorded for each shot. With the exception of Mini-Sosie, all data were recorded by a 48-channel Oyo DAS-1 seismograph with two 48-channel expansion units, for a total of 144 channels. Due to the unique hardware and software requirements of the Mini-Sosie technique, those data were recorded with an Input /Output model DHR-2400 24channel seismograph, and no downhole data were collected for that source.

Background noise tests were performed using a small array before and after each source was tested to assure consistency in near surface conditions, wind, and receiver plants, and to document any variations that might not have been obvious during the source test.

\subsection{Geophysical well logs and synthetic seismograms}

After all seismic reflection data were collected, the two wells that were used to record hydrophone and geophone data were logged to correlate observed reflections with log-confirmed lithologic contacts (Bechtel National, Inc., 1995). Digital logs that were acquired included neutron, dual spaced density, full waveform acoustic, caliper, natural gamma, temperature, spontaneous potential, single point resistance, and long/short-normal resistivity. Some of these logs for well 1920 , near the center of the CMP line, are shown with interpreted stratigraphy in Figure 4 . The well was open to a depth of 842 feet $(257 \mathrm{~m})$.

The SynSeis software package was used to produce synthetic seismograms from the log data from well 1920 (Figure 5). The four zero-phase source wavelets that were combined with the acoustic velocity log to calculate the synthetic seismograms had pass bands (low cutoff, low pass, high pass, high cutoff), in $\mathrm{Hz}$, of 40/60-120/150,60/80-150/200,45/70-250/300, and $100 / 120-450 / 500$. Times indicated are two-way travel times. Reflectivities in the first $100 \mathrm{~ms}$ are low $(-0.11<r<0.11)$ explaining the weak reflections that are observed in CMP images. The well logs from wells 1920 and 1943 do not extend to the depth of the dominant reflections in the CMP images, at $150 \mathrm{~ms}$ and $200 \mathrm{~ms}$, and so we cannot calculate the reflectivity of those interfaces from the synthetic seismograms. The weakness and intermittent character of reflections interpreted in the upper $100 \mathrm{~ms}$ of the stacked CMP sections that are shown later in this report is consistent with the synthetic seismograms. The synthetics also highlight the importance of high frequencies in improving resolution of finer features.

\subsection{Velocity profiles}

In a separate deployment, shots from a sledge hammer and downhole shotgun source were fired into the hydrophones and the downhole geophone as they were moved through a range of depths. The hydrophone data extended to $500 \mathrm{ft}(152 \mathrm{~m})$ depth in wells 1920 and 1943 , and the geophone data were acquired to 980 feet $(299 \mathrm{~m})$ depth in well 1943 . Source offsets of 57 feet were used in well 1920, and $50 \mathrm{ft}$ and $116 \mathrm{ft}$ in well 1943. Travel times for first arriving waves from the source to the downhole phones provides an estimate of the root-mean-square (RMS) velocity of the rocks from the surface to the measurement point that can be used to guide processing parameters for production seismic reflection data. A comparison of RMS velocities derived from two types of sensors for both wells is shown in Figure 6 . The black dots represent geophone measurements, which were acquired at $30 \mathrm{ft}$. and $60 \mathrm{ft}$. spacing in well 1943. 


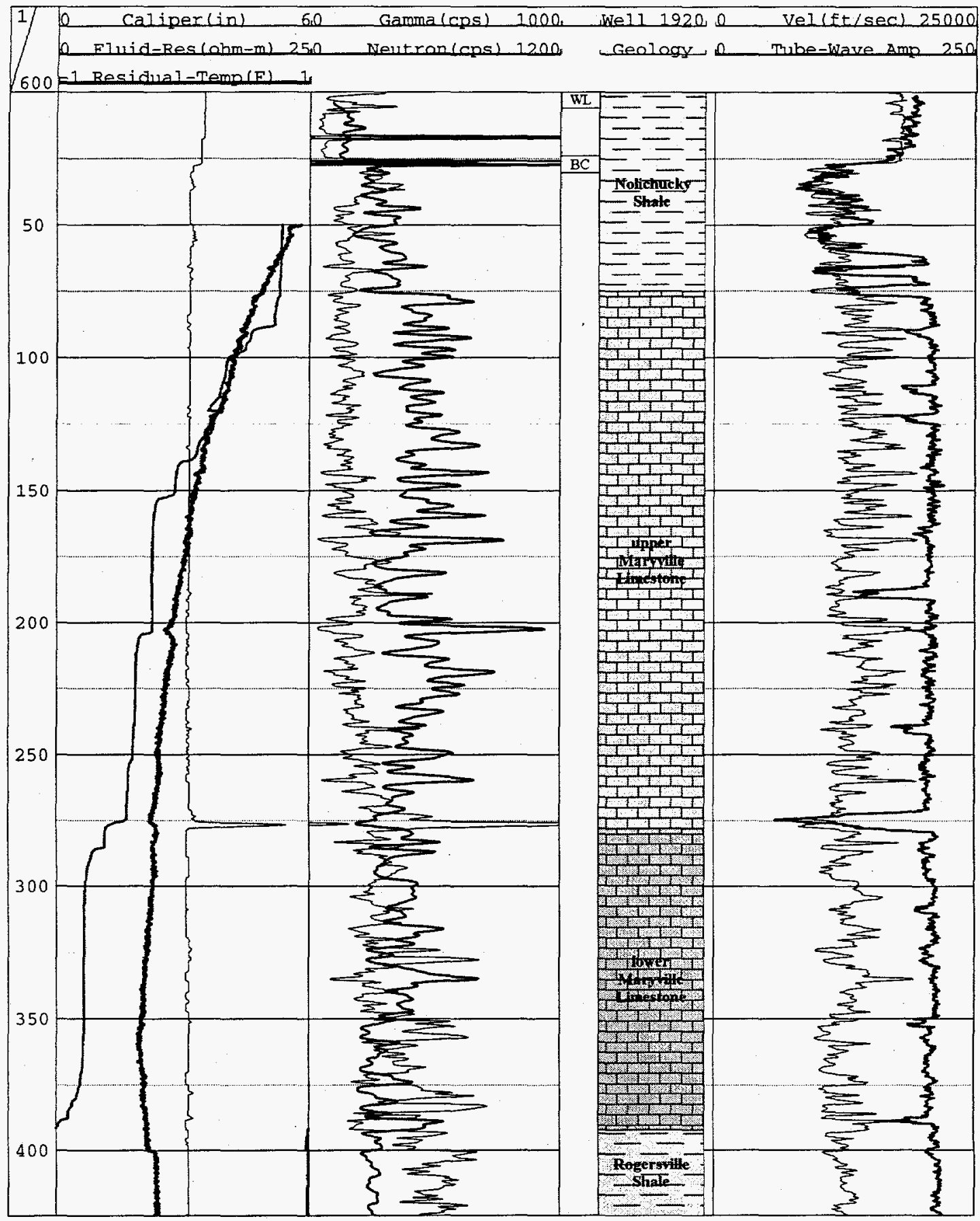

Figure 4. Selected well logs for well 1920. The acoustic logs were used to generate synthetic seismograms (Figure 5). 
SYNTHETIC SEISMOGRAMS DERIVED FROM SONIC LOG

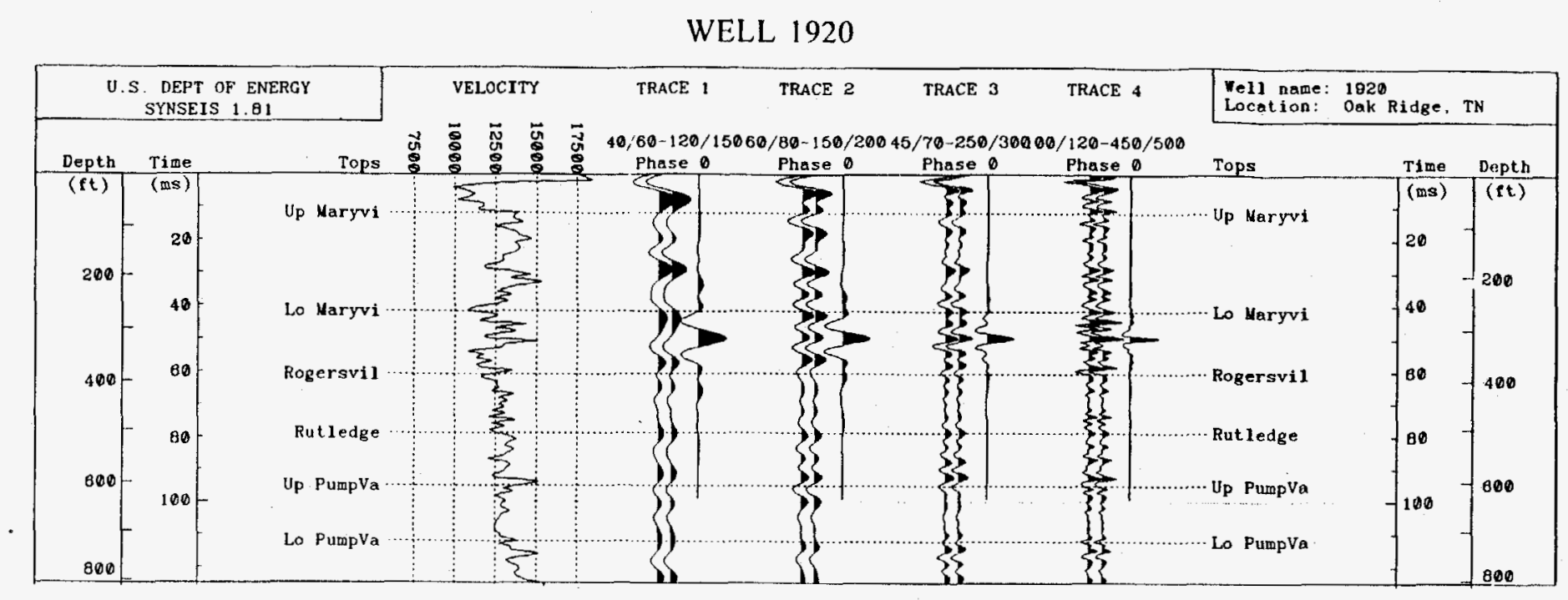

TWO-WAY TRAVEL TIMES TO 125 MS

FORMATION TOPS DETERMINED FROM NEUTRON AND GAMMA LOGS

Figure 5. Synthetic seismograms generated from sonic logs of well 1920. These allow seismic reflections to be related to stratigraphic intervals in the well. The sensitivity to many intervals is greatly improved by acquiring data with high frequency seismic sources. 


\section{Average Velocities}

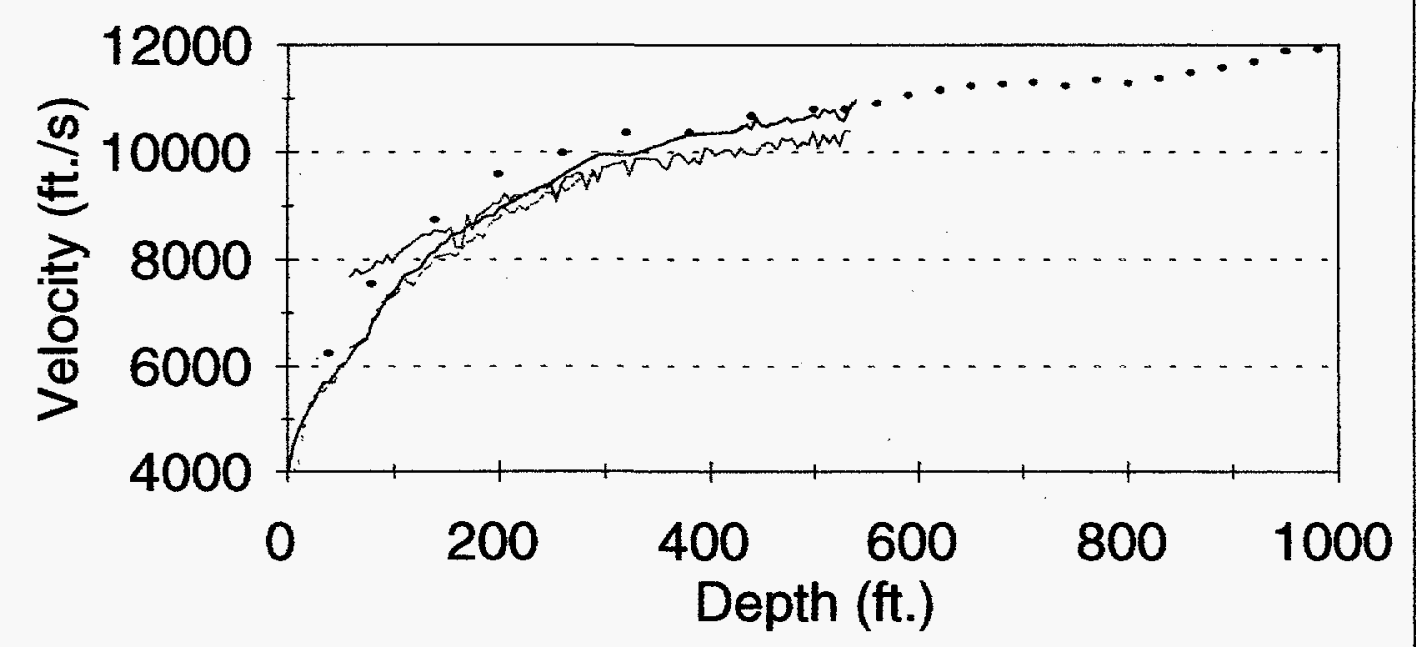

\section{Well1920 - 1943GEO - 1943A 1943b}

Figure 6. Average velocities derived from surface-to-borehole seismic data acquired at wells 1920 and 1943 (Figure 1). The source offset was $50 \mathrm{ft}$ for all data sets plotted except 1943A (solid red line) where it was $116 \mathrm{ft}$. Data have been corrected for well deviations. All velocities were derived from hydrophone data, with the exception of the "1943GEO" points, which were derived from downhole vertical geophone measurements. 
Hydrophone measurements were at $5 \mathrm{ft}$. spacing in both wells. The velocities have been corrected for well deviation from vertical.

\section{DATA PROCESSING AND PRESENTATION}

\subsection{Standard processing flow and spectral enhancement for CMP sections}

Processing steps that were used to generate the CMP stacked seismic reflection sections include:

1) Bandpass filtering $(40 / 80 / 240 / 300 \mathrm{~Hz})$

2) Automatic gain control $(70 \mathrm{~ms})$

3) Bad trace removal

4) first arrival mute (refraction and direct wave)

5) Surgical mute (air wave and ground roll)

6) Source and receiver geometry assignment

7) Common midpoint sort

8) Normal moveout velocity analysis

9) Correlation static correction (time window $90-230 \mathrm{~ms}, 3 \mathrm{~ms}$ maximum)

10) Wavelet editing

11) CMP stacking

12) Bandpass filtering $(40 / 80 / 240 / 300 \mathrm{~Hz})$

13) Automatic gain control (70 ms)

Where appropriate, spectral properties of the source wavelet were enhanced by applying prewhitening to data before the first step listed above. Prewhitening techniques are methods that are used in advance of the processing steps listed above (and sometimes before data are correlated) to equalize the amplitudes of all frequency components in the data. This is done to sharpen reflection peaks and therefore increase resolution (Doll and Çoruh, 1995). These improvements are consistent with Fourier theory, which states that equal amplitudes of all frequencies will produce an impulse, or spike, in time. In practice, prewhitening has the effect of increasing the amplitude of high frequency components, which are nearly always weaker than the lower frequencies. The three methods that were used for prewhitening were Vibroseis whitening (VSW), stretch AGC (SAGC), and spiking deconvolution. VSW is a method that can be applied to swept source data, and SAGC is a similar method designed for impulsive source data. Spiking deconvolution can be applied without SAGC or VSW, or it may be applied in sequence with them to either swept or impulsive source data. These methods were found to improve the resolution of data from swept sources, but seemed to have less benefit when applied to data from impulsive sources.

\subsection{Interpreted CMP section}

An annotated, representative CMP image of the test area from Minivib data is shown in Figure 7. The seismic data can be tied directly to the geologic formations at the site through correlation with well log data. The location of geologic contacts from Well 1920 are superimposed on the image in Figure 7. The Maryville, Rogersville, and Rutledge formations occur between about 50 and $600 \mathrm{ft}$. (15.2-183 m) depth at this location. Because the test data have their greatest redundancy (fold) between shot points 290 and 360 , we base our analysis and interpretations on that portion of the data. The CMP image in Figure 7 has many reflections in the depth range of interest. The $150 \mathrm{~ms}$ reflection is probably representative of the contact between the Pumpkin 


\section{Well 1920}

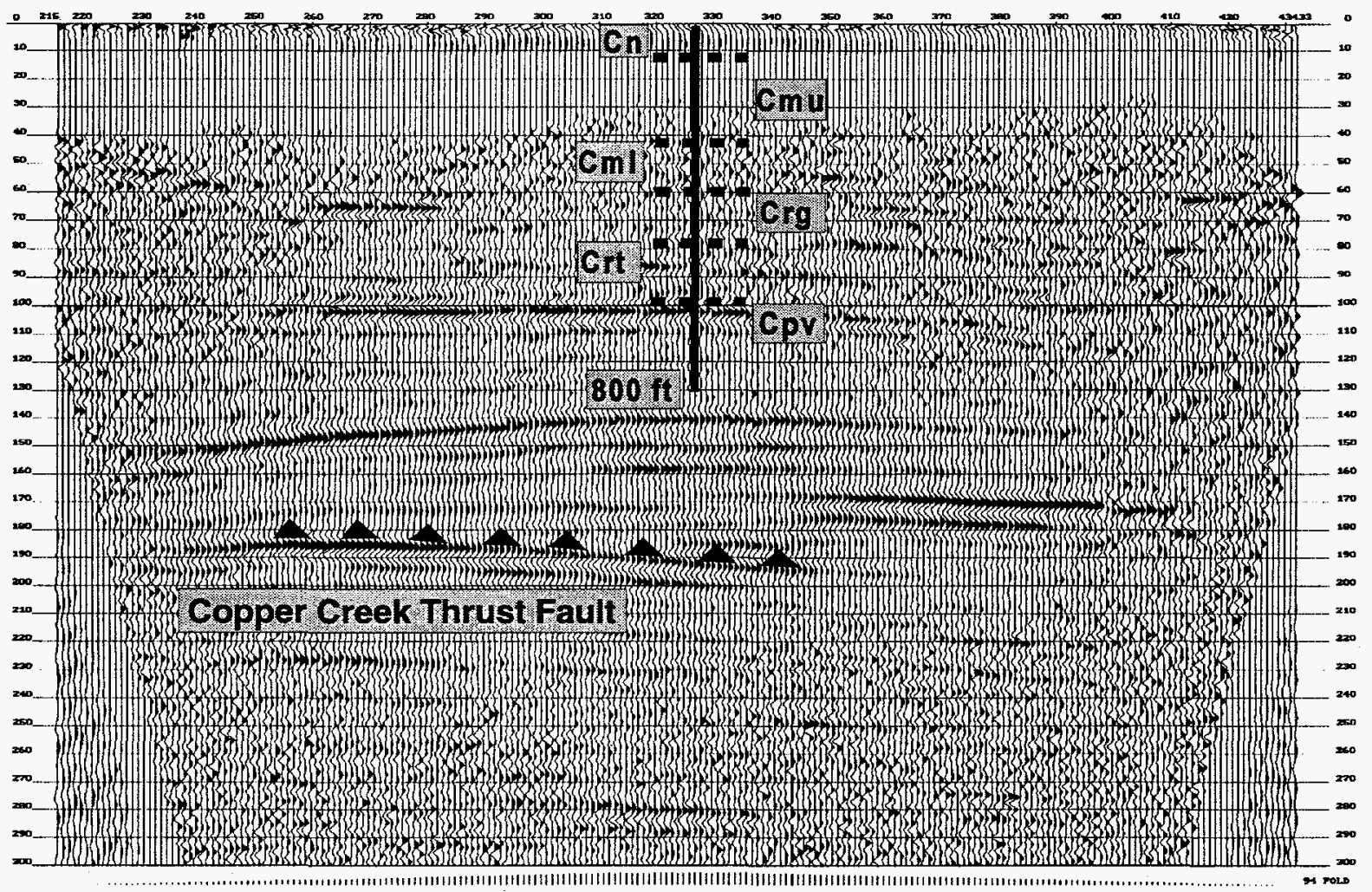

Figure 7. Interpreted seismic reflection data from the test line in Melton Valley. Data were acquired with a Minivib source and have been prewhitened and deconvolved (spiking deconvolution). The stratigraphy derived from logs of Well 1920 is overlain, and the location of the Copper Creek Thrust fault is shown. The total length of the line is about $1090 \mathrm{ft}$, and it extends to more than $1500 \mathrm{ft}$. in depth. The location of the line is shown in Figure 1. Common midpoint (CMP) numbers are shown across the top, labeled at $50 \mathrm{ft}$. increments, and time in milliseconds is shown on the vertical axis. The "fold", or level of vertical stacking, is shown across the bottom. The image is most reliable where the fold is highest. 
Valley shale and the Rome formation. The Rome formation consists of interbedded sandstone, siltstone, shale, and dolomite. The $200 \mathrm{~ms}$ reflection may represent the Copper Creek thrust fault. Note that many of the reflections occur within formations, rather than at contacts between geologic units. This is expected, and is due to changes in lithology within formations having greater velocity and/or density contrast than changes at formation contacts, which can be based on fossil content, color or texture. Boundaries between stratigraphic units that are based on such properties will likely have little or no seismic signature.

\subsection{Resolution of CMP sections}

The vertical resolution of seismic reflection images must be defined separately from horizontal resolution. Both are dependent upon the seismic velocity of the rocks and the dominant frequency of the processed reflection wavelet. Here, vertical resolution refers to the minimum thickness of individual, detectable stratigraphic units for which both the top and bottom of the unit can be detected. Theoretical vertical bed resolution is estimated to be one quarter of the dominant wavelength (Widess, 1974). In practice, however, the vertical resolution of shallow reflection data is best estimated to be around one-half wavelength (Miller and others, 1994). For the data presented in this report, we conservatively estimate the vertical resolution as about $15 \mathrm{ft}$ $(4.6 \mathrm{~m})$.

Vertical offset of a horizon can be detected with greater resolution than cited above for thin bed detection. However, careful interpretation is essential because small apparent offsets can occur. between adjacent traces due to processing uncertainties or incomplete correction for nearsurface effects. Furthermore, diffraction effects tend to cause horizontal smearing of real offsets over several adjacent traces. In general, evidence of fault zones that may be seen in seismic reflection data include 1) a series of diffraction hyperbolae occurring along a continuous line, 2) zones that are void of reflections that appear to be caused by disrupted geology, rather than noise, as viewed in the raw data, 3) a clear offset of several reflections, indicating an offset of stratigraphic interfaces, and 4) relatively abrupt flexures in a strong reflector along a line, where the flexure is a diffraction effect, particularly where the flexures appear in several reflections of a series and produce a faulting model that is geologically sound.

Horizontal resolution has classically been estimated using principles of optics, and is defined by the cross section of a cone within which all returned energy will have travel times that are less than one quarter period of the travel time for vertically incident energy at the dominant wavelength. This cross section, called the first Fresnel zone (Knapp, 1990), will increase in area with depth (as the cross sections of the cone increase with depth). In practice, the horizontal resolution of seismic reflection data is considered to be about half the radius of the first Fresnel zone (Sheriff, 1994). For the area discussed in this report, we estimate that the horizontal resolution increases from about $80 \mathrm{ft}(24 \mathrm{~m})$ at $200 \mathrm{ft}(61 \mathrm{~m})$ depth to $140 \mathrm{ft}(43 \mathrm{~m})$ at $600 \mathrm{ft}(183$ $\mathrm{m})$ depth. This means that the true horizontal position of a structure can occur anywhere within $80 \mathrm{ft}$ or $140 \mathrm{ft}$ (depending on depth) of the mapped reflection point.

Both horizontal and vertical resolution of seismic reflection data are improved by concentrating the energy of the source in the shortest possible time. The range of frequencies that can be generated and propagated by any seismic source are a function of the site and the source. The source wavelet will be reflected and refracted from each interface that it encounters. The dominant frequency of the wavelet will decrease as it propagates from the source, due to higher rates of absorption for high frequencies than low frequencies. Narrow bandwidth will produce 
source wavelets that consist of three or more peaks, causing each reflection to consist of multiple peaks. One goal of processing is to increase the bandwidth of the source wavelet, and to approximate a spike response as nearly as possible. This is the goal of the spectral whitening and deconvolution techniques that were discussed in Section 3.1.

With swept sources, the operator can control the range of frequencies that are generated and the energy distribution within the frequency range. The procedure for transforming the long (typically up to 10 seconds) sweep to a representative source wavelet is known as correlation. Routine correlation of swept source data produces a wavelet that is symmetric about the true travel time (i.e. some of the wavelet peaks occur before the energy would actually arrive at the geophone), a property which is referred to as "zero-phase". These wavelets will usually have their largest peak at the correct travel time, though they also have some early peaks. Zero-phase wavelets can be transformed to minimum phase wavelets (largest peak nearest to the actual initial energy arrival) during correlation, although in many cases, the data will have higher resolution if the data are not converted to minimum phase. For the images shown in this report, we have converted to minimum phase, in order to allow proper subsequent implementation of spiking deconvolution methods on portions of the data.

\subsection{Walkaway vertical seismic profiles}

Walkaway vertical seismic profiles (VSPS) can be formed by compositing the traces recorded by the downhole geophone as the source moved along the profile line, as shown in Figure 8 . These document the characteristics of the transmitted energy as well as some reflected energy for each source. At their closest approach, the sources were about $5^{\circ}$ from vertical, relative to the geophone, and at their greatest offset, they were at slightly greater than $45^{\circ}$ from vertical with respect to the geophone. The first arrivals (Pt, Figure 8 ) form a hyperbola in the VSPs, and the total energy of each source relative to the others is indicated by the amplitude of first breaks as the source moved further from the geophone. The bottom of Well 1943 at 980 feet corresponds to about $160 \mathrm{~ms}$ depth in the CMP section (Figure 7), based on the velocity determined from Well 1943 (Figure 6) or by doubling the (one-way) zero-offset VSP first arrival time of about $80 \mathrm{~ms}$.

This is roughly equal to the $150-160 \mathrm{~ms}$ (Pumpkin Valley/Rome contact?) reflection that would be extrapolated to Well 1943 off the left end of Figure 7. Reflected energy from this contact, if any, is presumably integrated with the transmitted energy. Reflections from the $200 \mathrm{~ms}$ reflection (Copper Creek Thrust?, Figure 7), labelled as the top of the Pr package of arrivals in Figure 8, would be expected to trail about $30-40 \mathrm{~ms}$ after the Pt first arrivals at zero offset in the VSPs. These reflected $P$ waves can be identified for some sources, but are masked by noise or low frequency signal in many of the VSPs in this report. At small offsets, very little direct shear wave energy would be expected because the particle motion would be orthogonal to the direction of maximum sensitivity of the geophone. At larger offsets, VSPs for many of the sources have high amplitude, low frequency arrivals with travel times that approximate those expected from shear waves that are either transmitted by, or mode-converted near the source (St, Figure 8). By comparing these arrivals for the different sources, one may obtain a qualitative sense for the amount of shear wave energy that each source generates. 


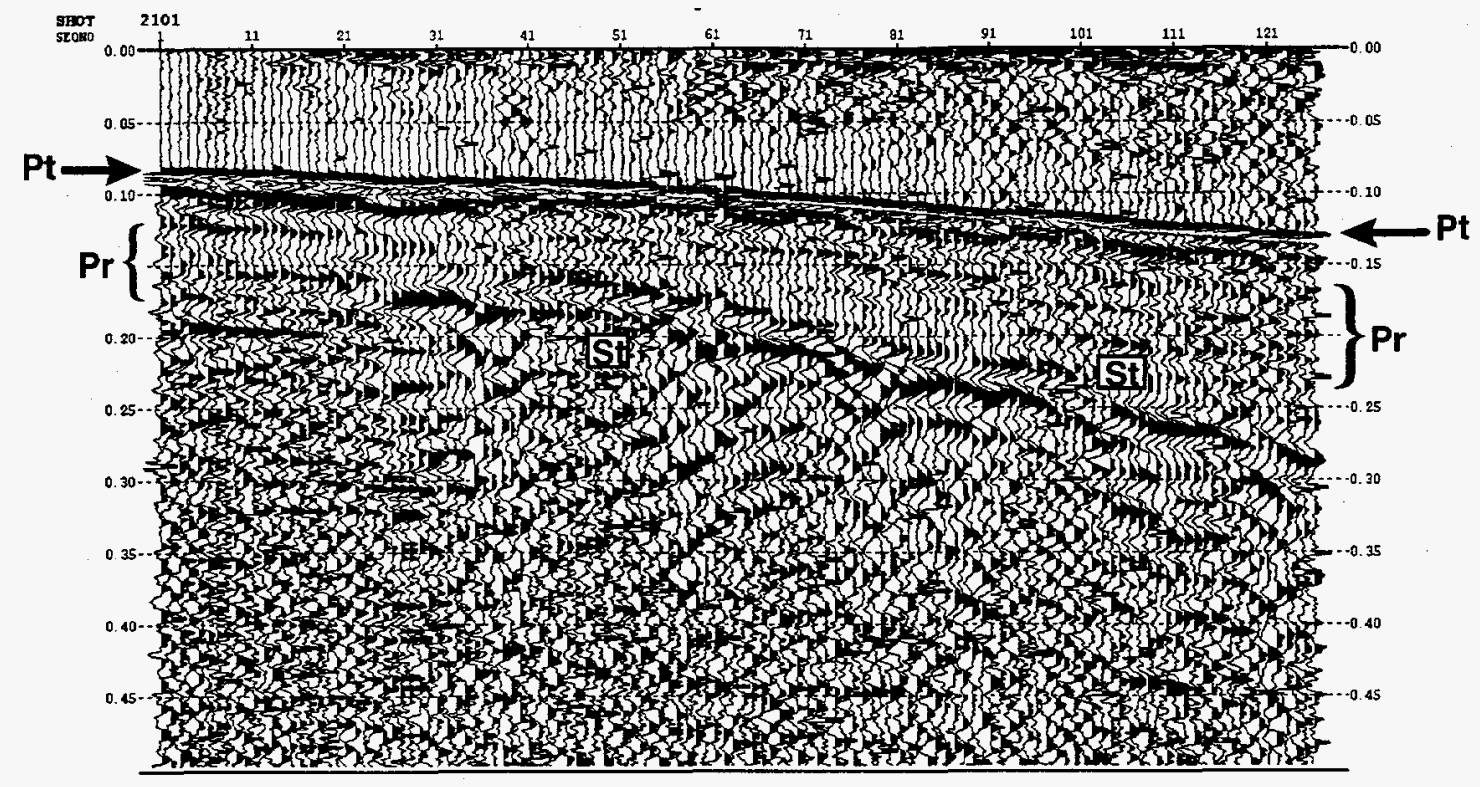

Figure 8. Annotated walkaway vertical seismic profile from the EWG source. These data have been bandpass filtered using a 5/30/250/300 $\mathrm{Hz}$ trapezoidal filter to enhance signal. The first breaks represent direct (transmitted) $\mathrm{P}$ waves, labelled $\mathrm{Pt}$. Reflected $\mathrm{P}$ waves are indicated in the 120-230 ms window by the brackets labelled Pr. Transmitted shear is labelled St. 


\section{COMPARISON OF RESULTS FROM EACH OF THE SOURCES}

Figures 9 through 17 show (in order) CMP processed seismic reflection sections, shot gathers, representative spectra for a single shot, plots of the downhole geophone data, and spectra of the downhole geophone data for each of the nine sources tested. In this section the attributes and limitations of each source are discussed. The discussion is generally organized from lowest energy to greatest energy sources, though some of the ordering is somewhat arbitrary.

The CMP images (e.g. Figure 15a-c), shot gathers (e.g. Figure 15d), and single shot spectra( e.g. Figure 15e) provide information on the effectiveness of each source for seismic reflection profiling. The best source for the site will most clearly image reflections on the CMP images over the broadest range of depths that are of interest. Reflection wavelets are best when they are most impulsive, i.e. they have one dominant peak rather than two or more. The lateral continuity of reflections on CMP images is also a good indicator of source effectiveness, since noise tends to make reflections appear less continuous, particularly at reflection times of less than $150 \mathrm{~ms}$. For three of the sources, additional CMP sections are included to demonstrate the improvements that are obtained by applying spectral whitening before the processing steps described in Section 3.1. The three sources that were processed in this manner were selected on the basis of their high data quality, using the criteria described above (EWG and Minivib) or an extreme need to improve signal bandwidth (Failing vibrator), so that the best source could be selected with greater confidence. None of the shot gathers that are shown have been prewhitened. These provide an indication of the signal to noise ratio and bandwidth of each source as observed before processing. The $200 \mathrm{~ms}$ reflection appears as a reflection hyperbola of varying clarity on all of the shot gathers. Plots of single shot spectra highlight the differences in the bandwidth of signal and/or noise for the sources.

To be most effective, the reflected energy must have high signal to noise ratio and high resolution. Low signal to noise ratio is generally the result of a source having low energy relative to natural background noise, or high levels of source-generated noise (e.g. shear waves or surface waves) that interferes with reflected $p$-wave energy. Low resolution is generally caused by a source that lacks bandwidth, or poor site conditions that don't permit transmission of part of the spectrum. Source energy and noise can be better understood by inspection of walkaway VSPs. The frequency spectrum of each VSP is plotted in two different ways for each source. At the bottom of each VSP spectral figure is an average spectrum for all traces. At the top of each figure is a color plot that shows how the frequency content of the downhole geophone traces vary with time. By measuring the frequency content in $200 \mathrm{~ms}$ time windows, the loss of high frequency energy with increasing time can be represented. The best source will maintain the greatest bandwidth for the longest time, assuming that the energy is signal and not noise.

\subsection{Oyo Portable Vibrator}

The Oyo Portable vibrator is a small (18 in high and 12 in diameter cylinder), lightweight (about $200 \mathrm{lb}$ or $100 \mathrm{~kg}$ ) low power vibrator designed for high resolution imaging (Matsubara and others, 1995 ), primarily within a few hundred feet of the surface. It is capable of generating seismic waves at frequencies beyond $1000 \mathrm{~Hz}$. This source should permit transmission of the highest frequencies possible through earth materials for surface seismic imaging above the background noise level, if it has adequate energy for the target. The CMP stacked section in Figure 9a shows that energy from this source was able to penetrate to the $200 \mathrm{~ms}$ reflector (approximately 1300 feet) at our site. The image has higher frequency content than any other source tested. 
However, the quality (signal-to-noise ratio) of the image is poorer than many of the other sources. Presumably, the signal is hidden in the ambient noise due to low source energy. The VSP and its spectrum in Figure 9d-e show that the energy penetrated to the $1000 \mathrm{ft}$ depth of the downhole geophone, but again shows that the energy is buried in random background noise. The spectrum of the VSP for the Oyo vibrator differs from that for the other sources because downhole data were not recorded for the last 40 shot points, and so it is based on only 81 shot points of data.

\subsection{Sledge Hammer}

The 16-lb sledge hammer (Fig. 10) generated a section (Fig. 10a) that has lower dominant and upper corner frequency content than the Oyo vibrator (compare Figs. 9c and 10c), and therefore poorer resolution. Because there is little that can be done to shape the bandwidth of the input spectra for a hammer source, and because it is generally considered to have too little power to propagate beyond a few hundred feet on the Oak Ridge Reservation, the performance of the hammer at this site is better than anticipated. The data from the hammer is a clear indicator of the favorable seismic attributes of this site.

\subsection{Mini-Sosie}

The Mini-Sosie data (Fig. 11) were acquired with three earth compactors and an I/O DHR-2400 24 channel recording system instead of the Oyo DAS-1 144-channel acquisition system. Approximately 2000 impacts were recorded at each shot point. The Mini-Sosie technique is typically chosen for shallow imaging at sites where there is a high level of cultural noise (Knapp and Steeples, 1986). The stacked section clearly shows the $200 \mathrm{~ms}$ reflection and portions of the $150 \mathrm{~ms}$ reflection, but all of the shallower reflections are hidden in narrow bandwidth noise. It is possible that additional filtering or spectral whitening, designed for this source, could pull shallower reflections from these data. The frequency content of the $200 \mathrm{~ms}$ reflection (Fig. 11c) is between that of the Oyo vibrator and the sledge hammer. Some of the difference between Mini-Sosie images and those from other sources could be due to the lower redundancy in these data. The Mini-Sosie data have nominal twelve-fold redundancy in comparison with greater than forty-fold redundancy when data were recorded on the Oyo DAS-1. Because a separate recording system was required to record the Mini-Sosie, no downhole data were recorded for that source.

\subsection{KGS Swept Impulsive Source Prototype}

The CMP image for the KGS prototype coded source (Figure 12, described in Park and others, 1996) was of much lower signal-to-noise ratio than any of the others. By applying more elaborate processing, the $200 \mathrm{~ms}$ reflection could be imaged with this source, though with lower resolution than any of the other sources. Because of the experimental nature of the source and poor results, we have not provided a more complete set of images to compare with the other sources.

\subsection{KGS Auger Gun (8-gauge blank shotgun shells)}

The auger gun (Figure 13) provided a comparison of a commonly used "invasive"and explosive source to the non-invasive impacting and swept sources. The CMP image from this source (Fit. 13a) shows better depth penetration than the first four sources, as indicated by the continuity and 
amplitude of the $200 \mathrm{~ms}$ reflection. Shallower reflections were not imaged as coherently as those evident on data from the vibrators and Elastic Wave Generator. The $150 \mathrm{~ms}$ reflection becomes discontinuous and diffuse beyond CMP 275, and shallower reflections are not interpretable. The downhole record (Figure 13d) shows a very peculiar "shingling" appearance that could be caused by time-zero errors or could be due to real structural features that become obvious when a source generates the frequencies of the auger gun and/or when energy is released below the ground surface. This is a phenomenon that we cannot currently explain.

\subsection{Bison Elastic Wave Generator (EWG)}

The EWG performed better than any of the other impulsive sources tested at this site (Figure 14). Both the $150 \mathrm{~ms}$ and $200 \mathrm{~ms}$ reflections are imaged clearly and continuously with indications of shallower reflections, though they are more diffuse or unfocussed. Figure 14b shows the EWG CMP section with stretch AGC (SAGC) and spiking deconvolution (Doll and Çoruh, 1995) applied before filtering and stacking. For this source, these spectral whitening techniques added high frequency noise, reducing the sharpness of the $150 \mathrm{~ms}$ and $200 \mathrm{~ms}$ reflections. These techniques appear to enhance reflections in the first $100 \mathrm{~ms}$, but these may be artifacts and not real reflections (e.g. comparison with Fig. 14c for the Minivib source). The downhole spectrum of the EWG (Fig. 14f) shows that its spectral content is flat between 80 and $280 \mathrm{~Hz}$, and analysis of the time-frequency plot shows that the energy spectra remains relatively flat throughout the first $200 \mathrm{~ms}$. This is likely part of the reason for the high quality of the image.

\subsection{Industrial Vehicles Inc. (IVI) Minivib}

The IVI Minivib was the most effective of the sources tested at this site for the range of depths that are important to this study. Three different CMP stacked sections are shown. The first (Fig. $15 a)$ has not had any pre-correlation processing or spectral whitening applied to the data. A phase correction was, however, applied to the data upon correlation to produce minimum phase wavelets. The image in Figure 15b was prewhitened using Vibroseis whitening (VSW, Doll and Çoruh, 1995), and the image in Figure 15c was prewhitened with both VSW and spiking deconvolution. The image that was not prewhitened (Fig. 15a) is similar to the image derived from the EWG source (Fig. 14a), except that the EWG wavelet is closer to minimum phase. This minimum phase property makes the $150 \mathrm{~ms}$ reflection appear as a single distinct set of peaks on prewhitened images (Fig. 15c), whereas the reflection has two peaks in the image that had no prewhitening (Fig. 15a). Both sources are effective at imaging the $150 \mathrm{~ms}$ and $200 \mathrm{~ms}$ reflections across the entire section and seem to show shallower reflections as well. When prewhitening is applied to the Minivib data, it reveals a strong, continuous, high frequency reflection at about 100 ms (Fig. 15c). This reflection is not nearly as evident on images from any of the other sources. There are indications of even shallower reflections in the image in Figure 15c. These events that are shallower than 100 ms must be considered artifacts, at least until confirmed through drilling, log correlation, or other means. The prewhitening processes are seen to be much more effective with the Minivib than with the EWG, perhaps because the pass band of the vibrator can be controlled, and can be forced to generate energy over a broad range of frequencies in order to boost deficiencies in the spectra, whereas the EWG may generate or propagate relatively little useable energy in the higher frequency portion of the spectrum. If the amplitudes of certain frequencies are too weak in the raw data, prewhitening will serve only to increase the noise level in the data and lower the quality of the image. 


\subsection{Bolt Land Air Gun}

The Bolt Land Air Gun is an impacting source that is typically used for petroleum exploration to image to depths of more than a mile. For this reason, it has lower frequency content than most of the other sources. The CMP image for the airgun (Figure 16a) has reflections from $150 \mathrm{~ms}$ and $200 \mathrm{~ms}$ that have very high amplitude, but very narrow bandwidth (the reflected wavelet has several peaks, lasting perhaps $30-40 \mathrm{~ms}$ ). Although the reflections in the depth range of interest lack the resolution of other sources, there are reflections at $300 \mathrm{~ms}$ and deeper that do not appear on images from the less energetic sources.

\subsection{Failing Y-1100-A Vibrator}

The Failing vibrator is a swept source that generates relativley large amounts of energy, like the impulsive air gun, and is typically used for petroleum exploration. Three stacked sections are shown with this source, as with the Minivib. When the data were not prewhitened (Figure 17a), the CMP stacked image is quite similar to that from the air gun, with high amplitude narrow band reflections and penetration to $300 \mathrm{~ms}$ and deeper. Prewhitening by VSW leads to a significant improvement in the resolution of individual reflections (Figure 17b). When spiking deconvolution is added to the prewhitening sequence (Figure $17 \mathrm{c}$ ), the $150 \mathrm{~ms}$ and $200 \mathrm{~ms}$ reflection wavelets have much more bandwidth and a higher upper corner frequency. 


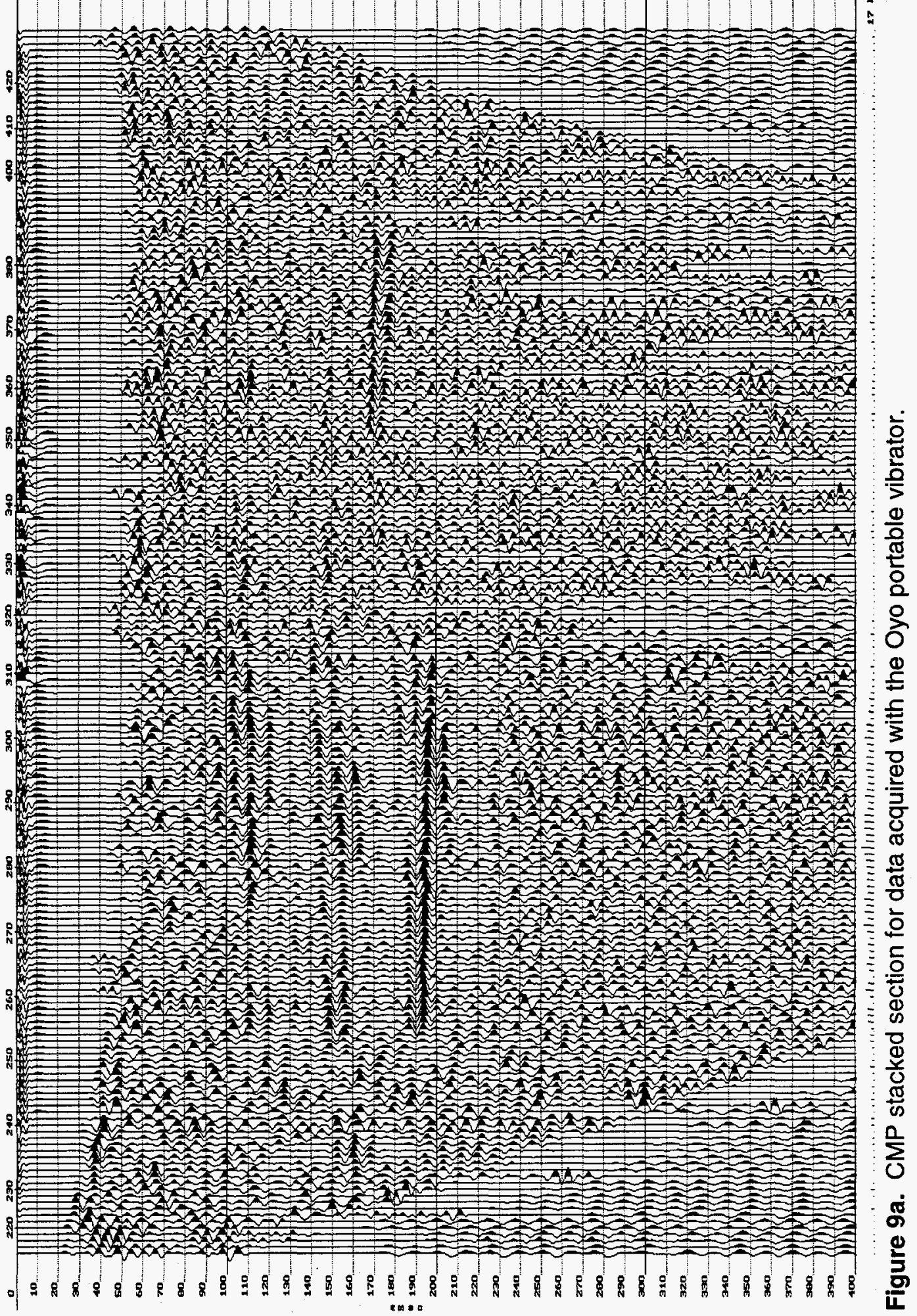




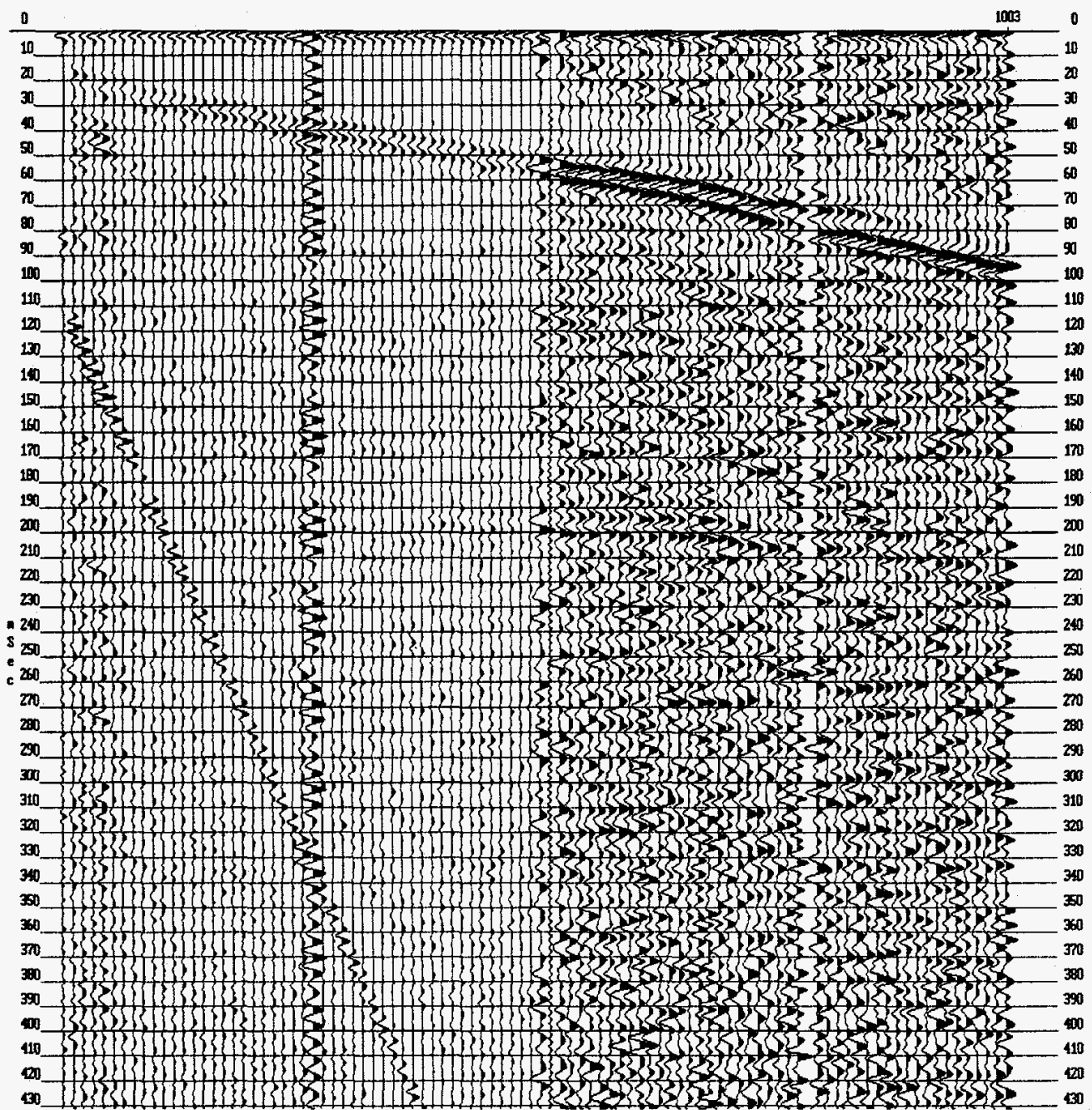

Figure $9 \mathrm{~b}$. Shot gather for one shot for the Oyo portable vibrator. The first 48 channels were recorded at lower gain by the Oyo representative to avoid clipping. 


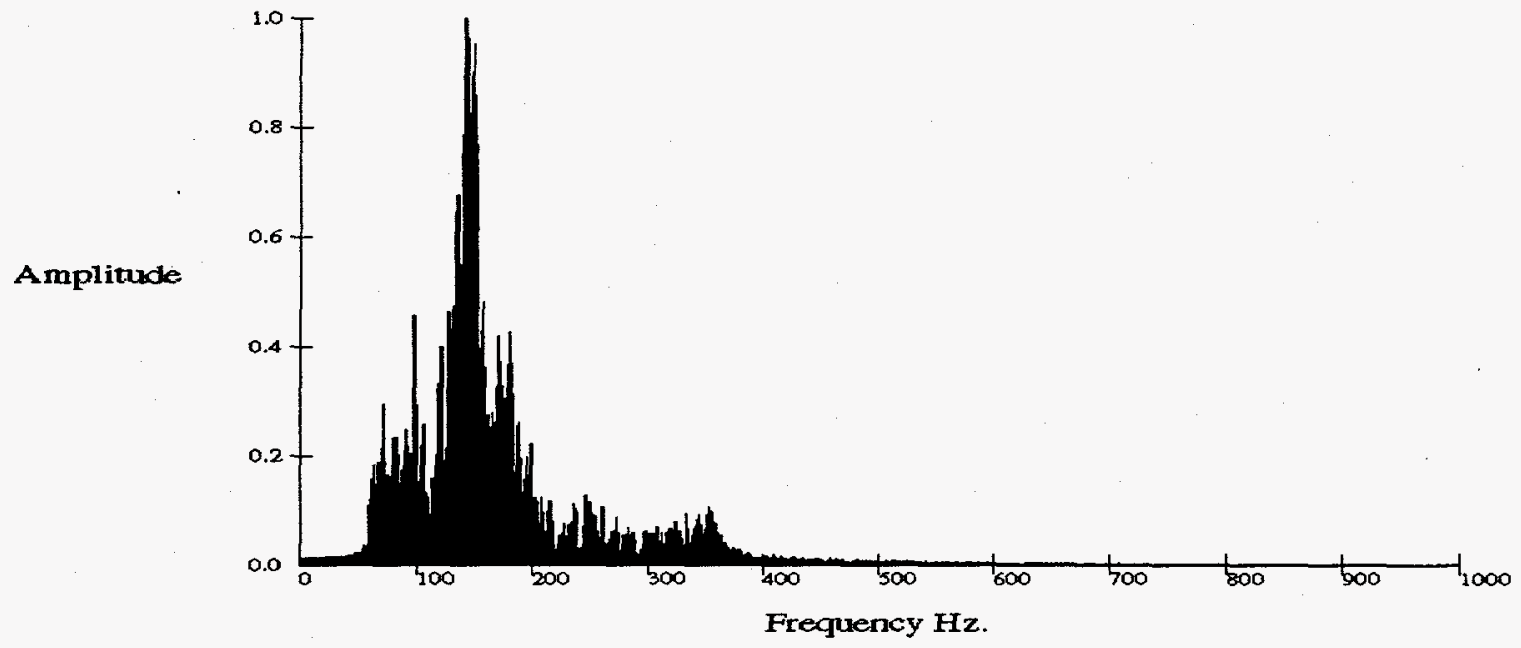

Figure 9c. Spectrum of trace 63, shot 1003 (Fig. 8b) for the Oyo portable vibrator.

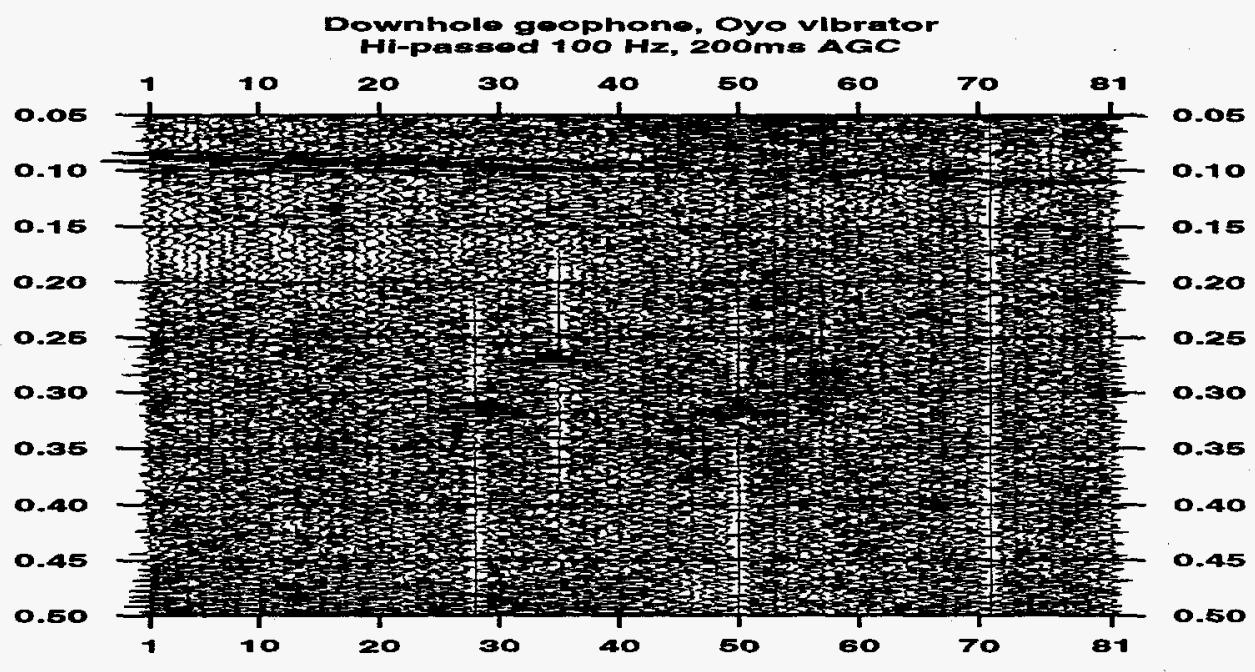

Figure 9d. Oyo portable vibrator shots from all shot stations, recorded by the downhole vertical geophone in well 1943 at the west end of the geophone spread. 

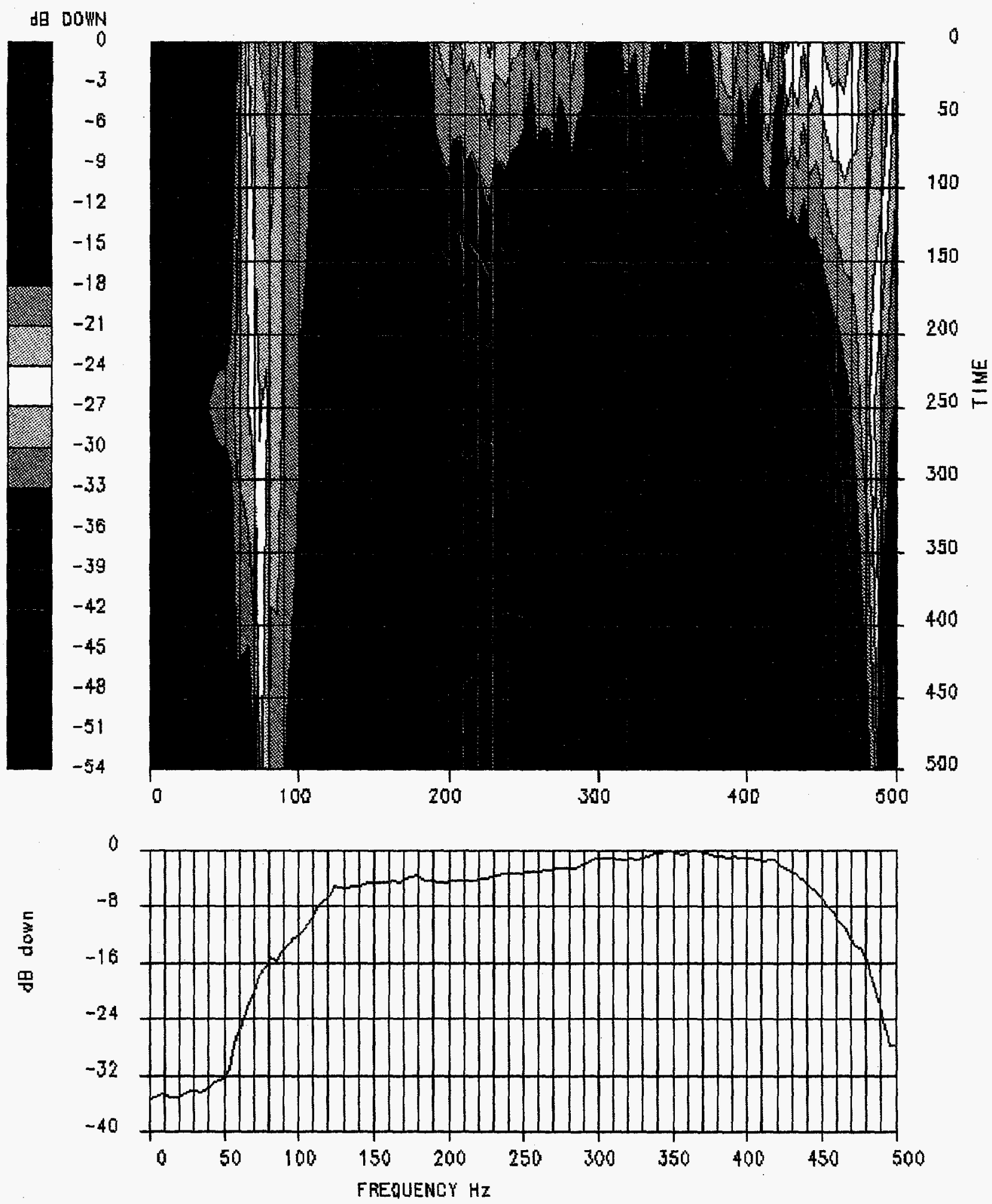

Figure 9e. Spectrum of Oyo downhole geophone data after applying a 50/100 high pass filter to the data. 


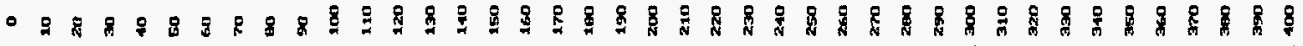

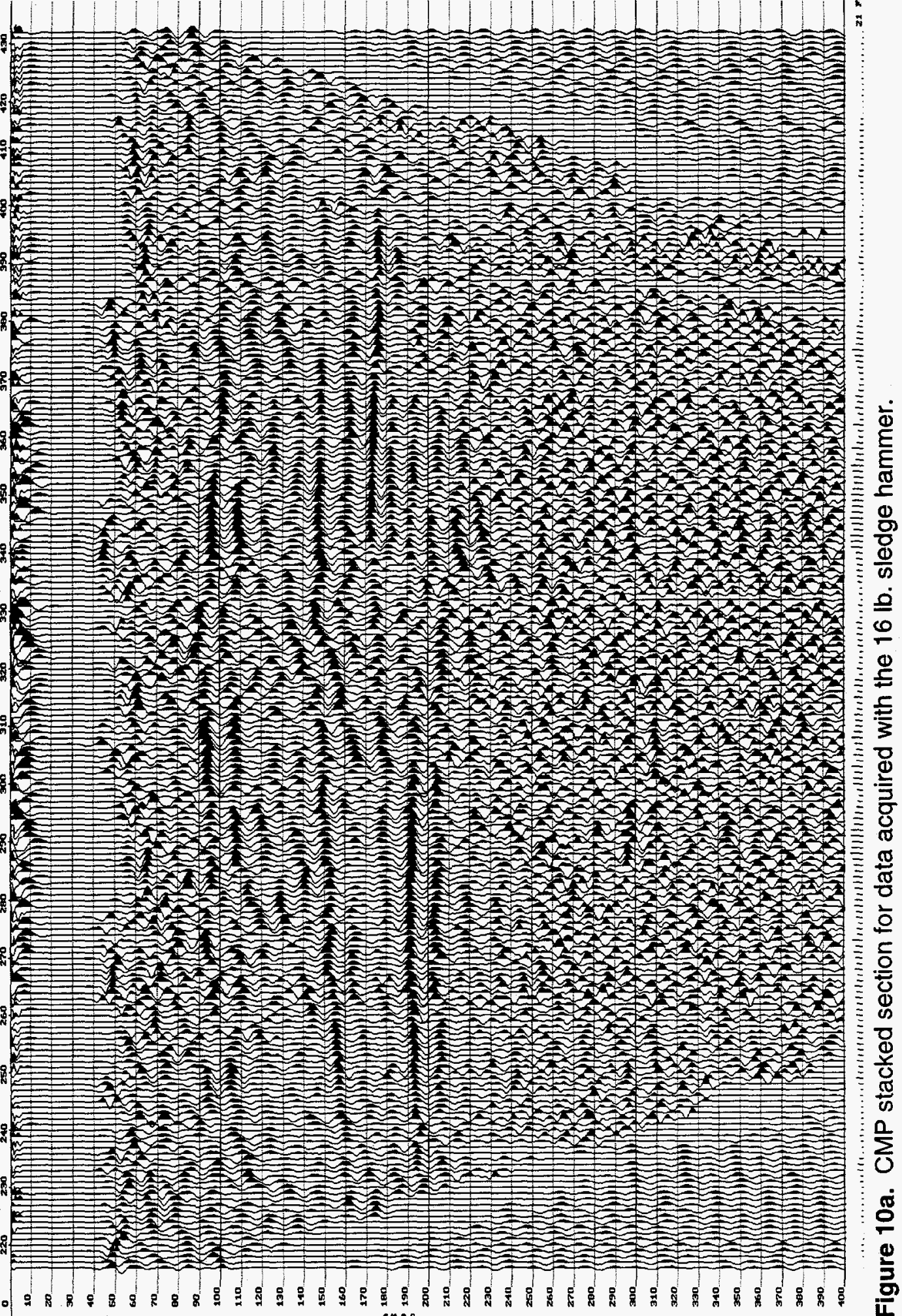




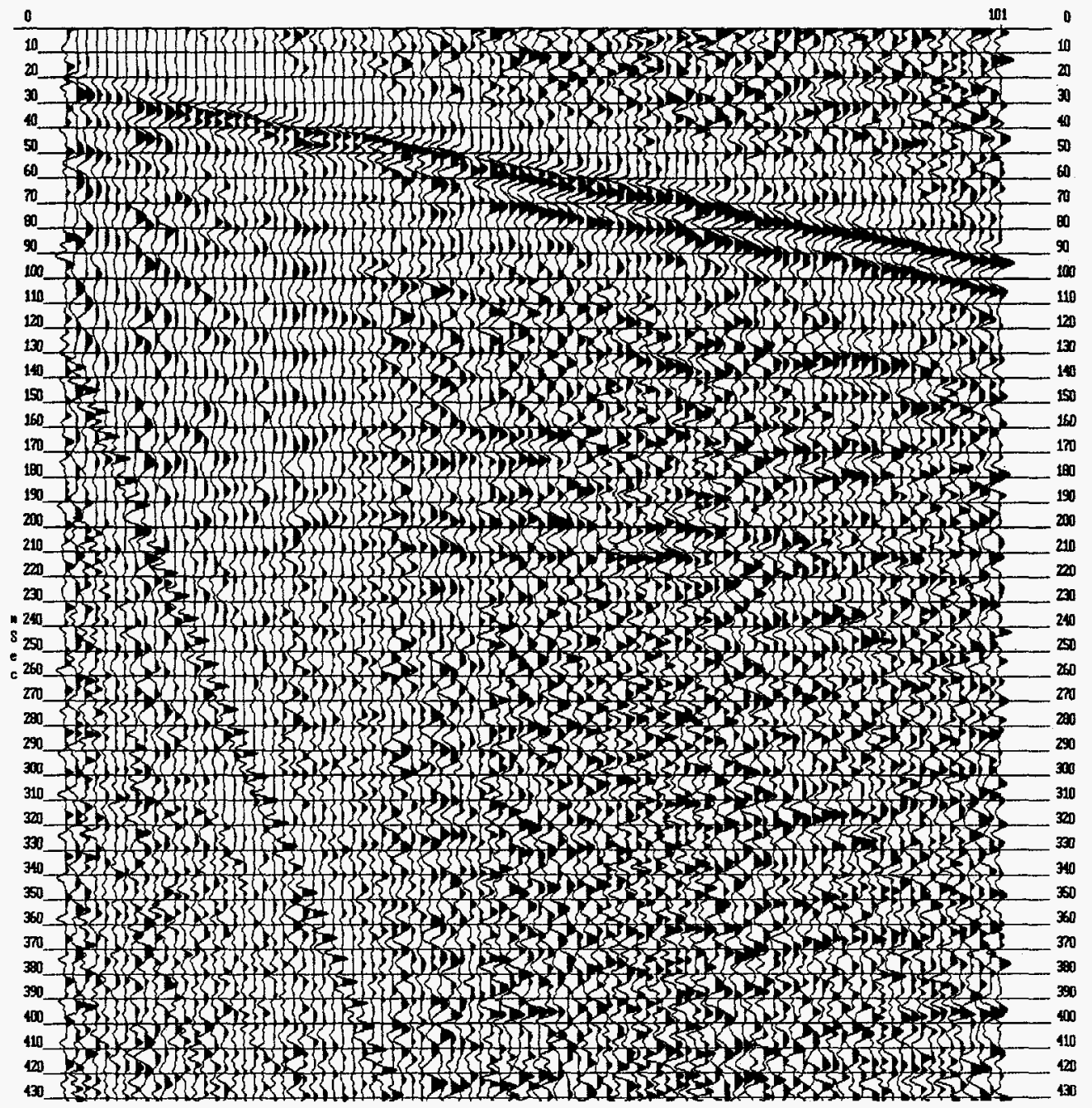

Figure 10b. Shot gather for one shot for the sledge hammer. 


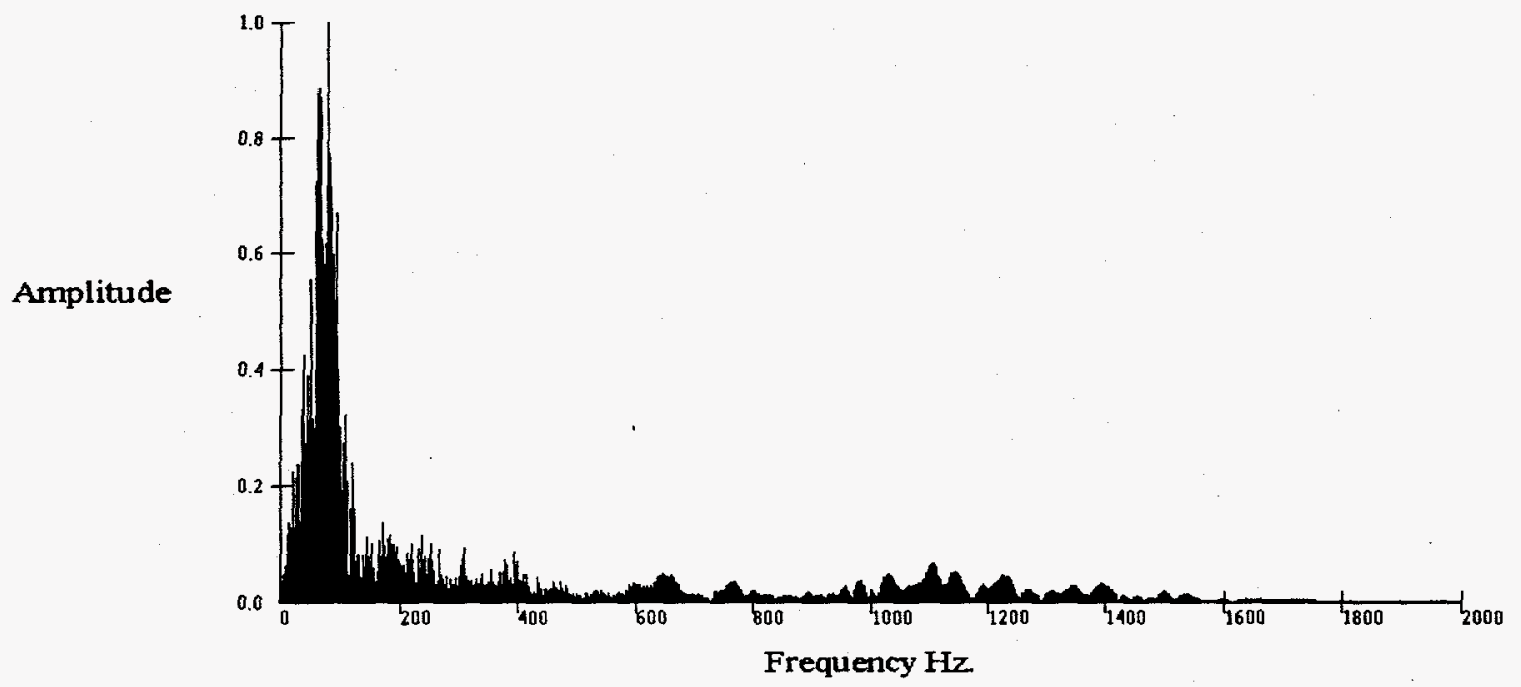

Figure 10c. Spectrum of trace 63, shot 1101 (Fig.10b) for the sledge hammer

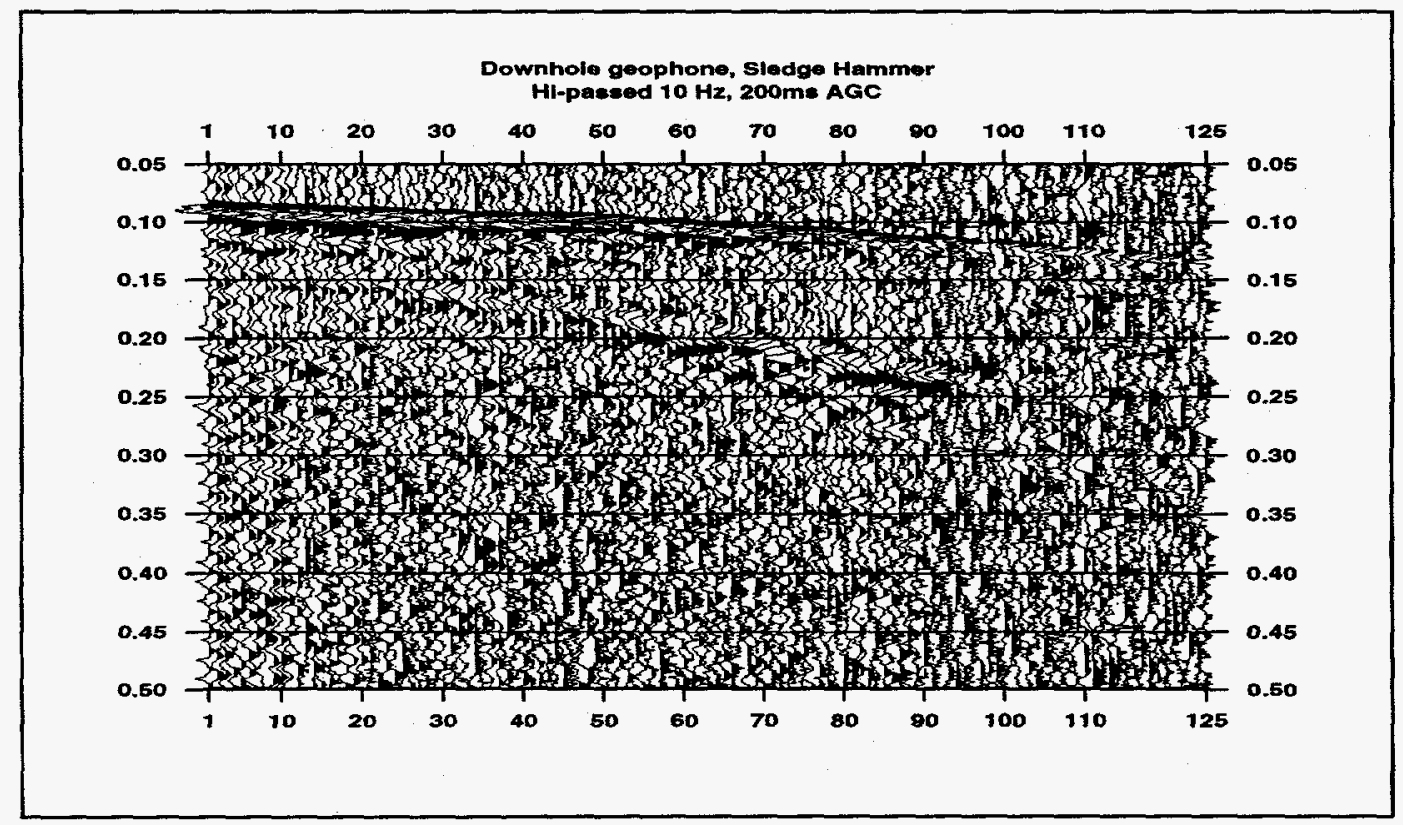

Figure 10d. Sledge hammer shots from all shot stations, recorded by the downhole vertical geophone in well 1943 at the west end of the geophone spread. 

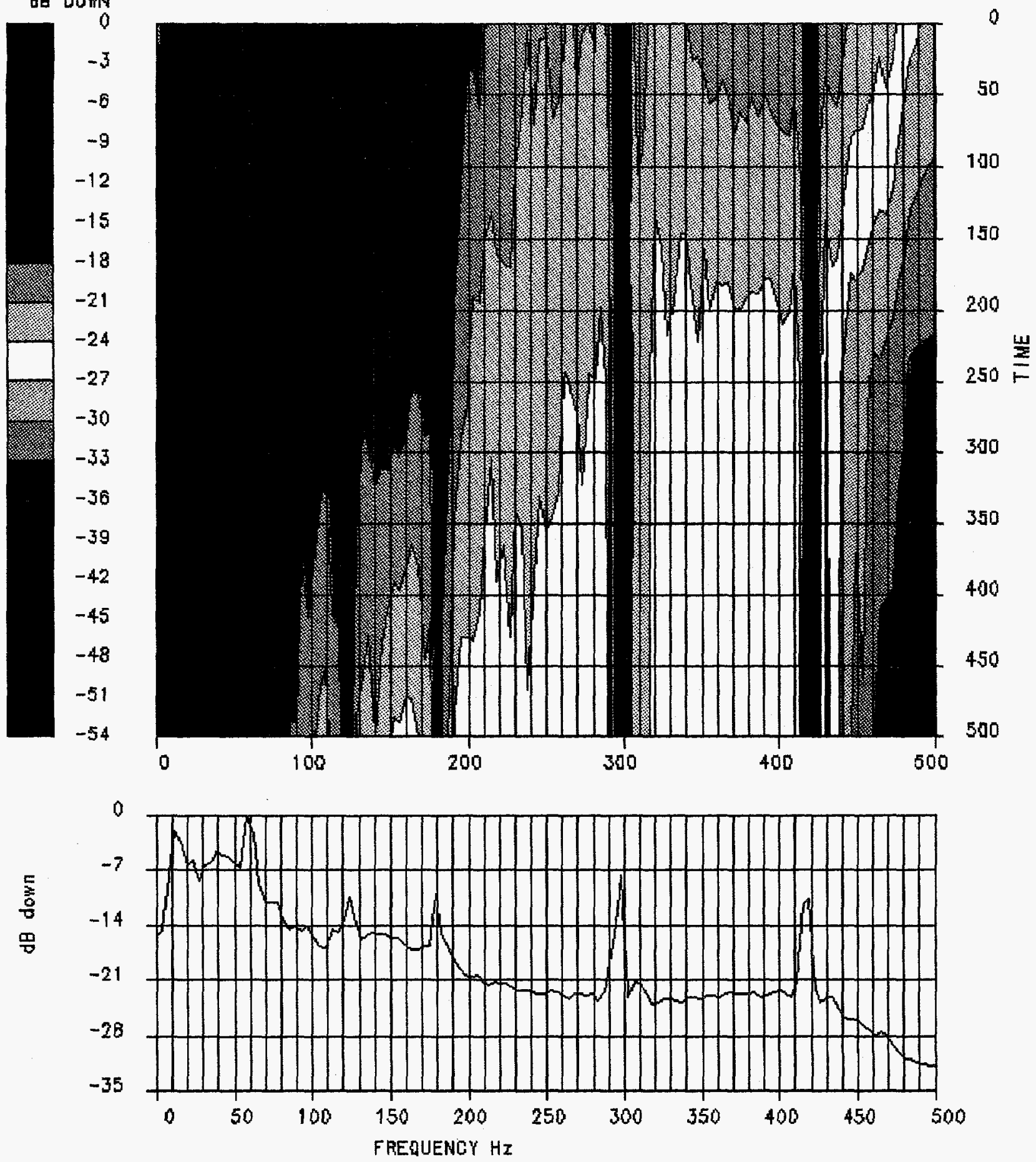

Figure 10e. Spectrum of unfiltered shots recorded by the downhole geophone with the sledge hammer source. The color display shows how the frequency content varies with time, and an average spectrum for the entire record is shown at the bottom. 


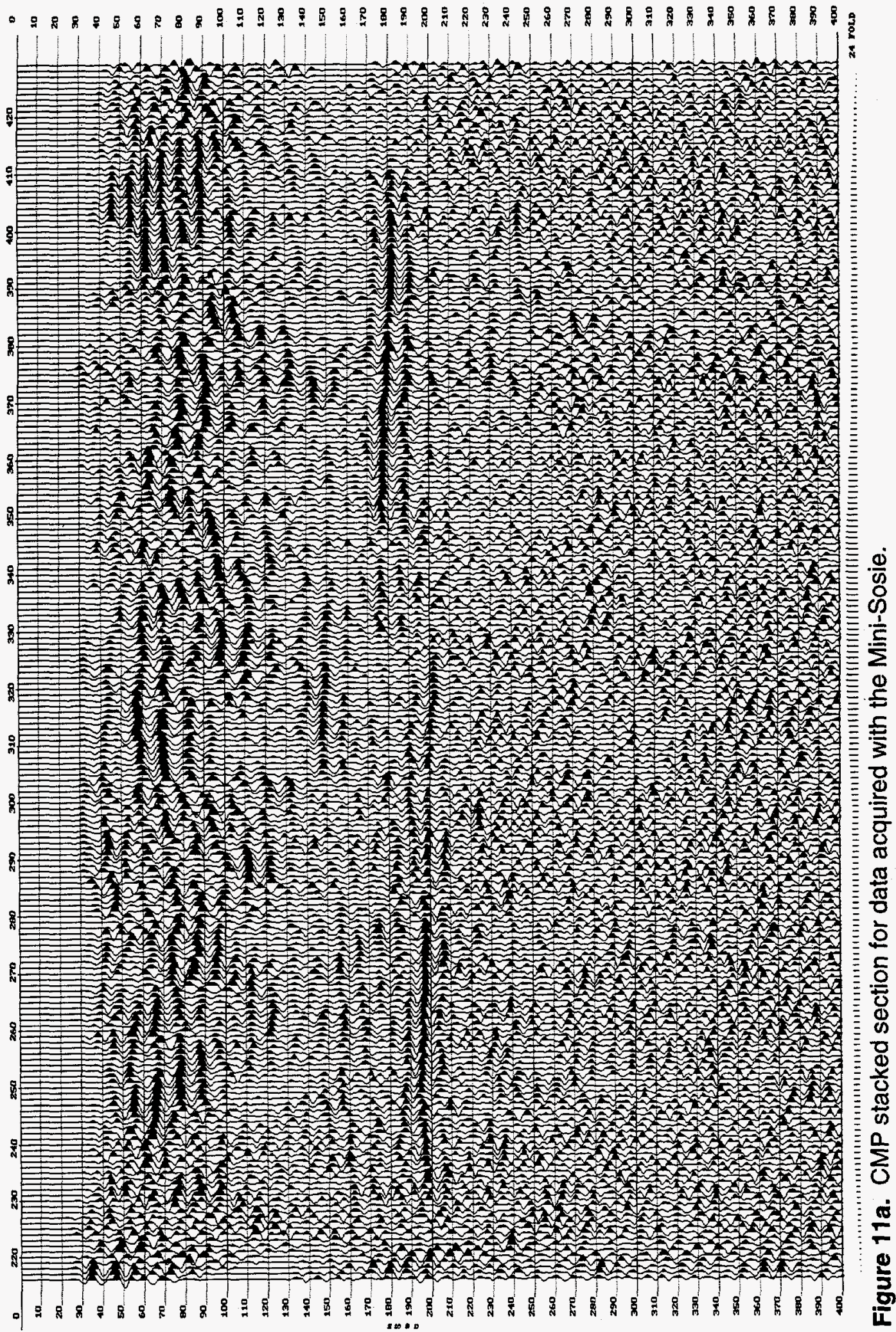




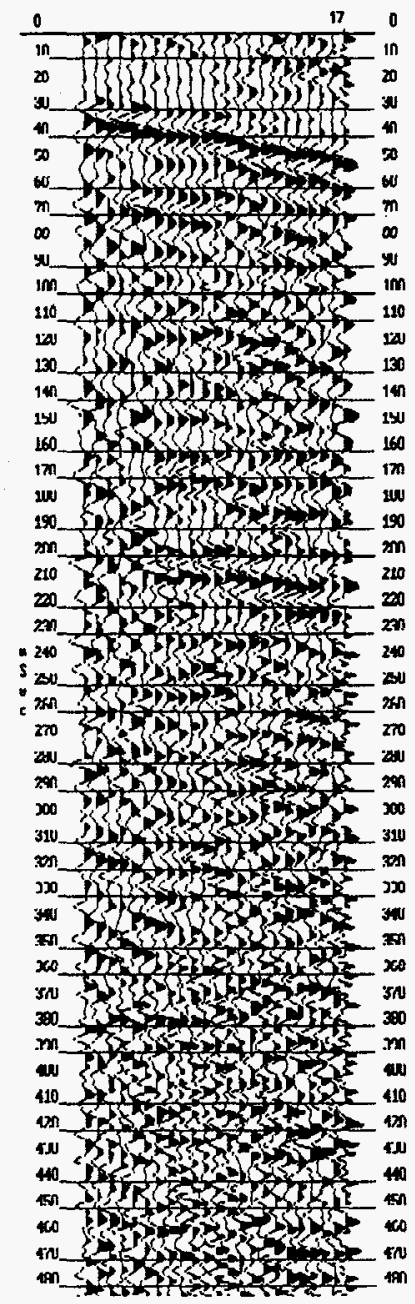

Figure 11b. Shot gather for one shot for the Mini-Sosie. 


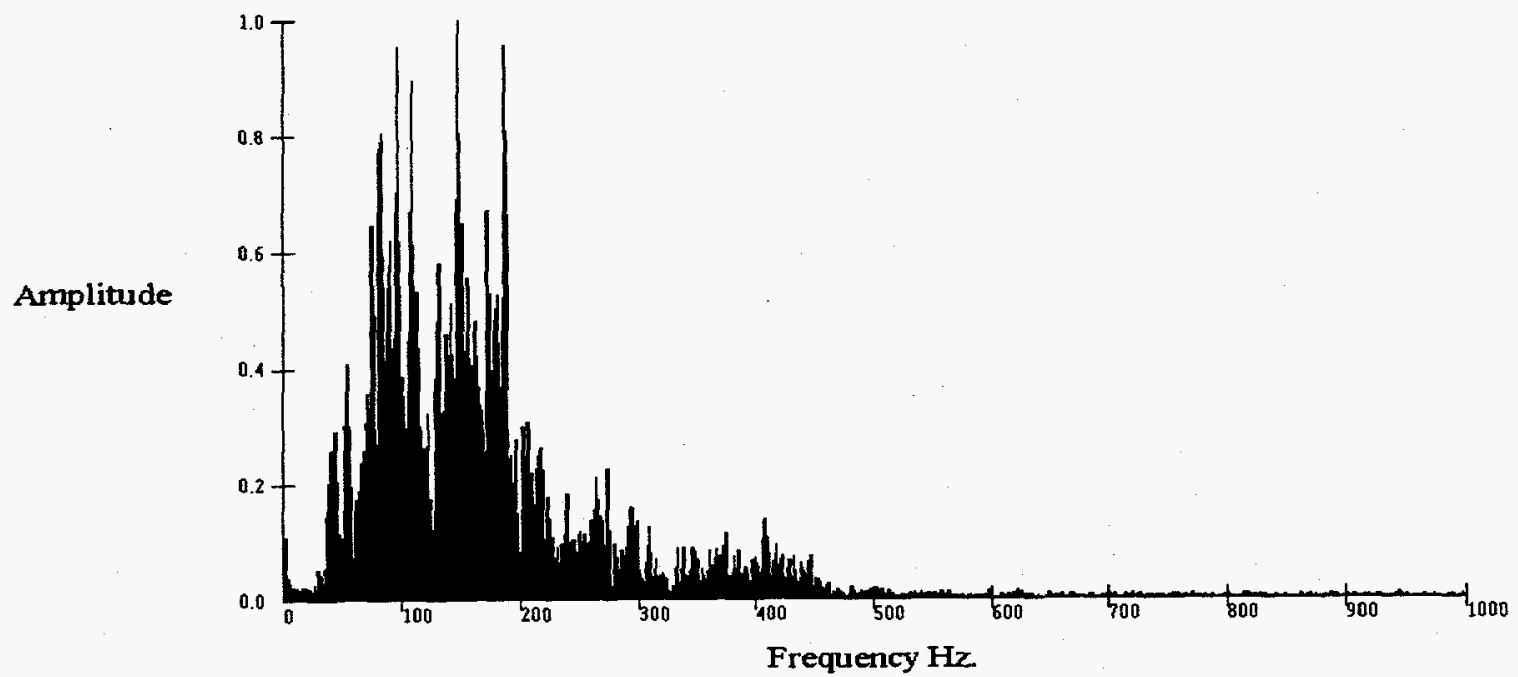

Figure 11c. Spectrum of trace 12, shot 17 (Fig. 11b) for the Mini-Sosie. 


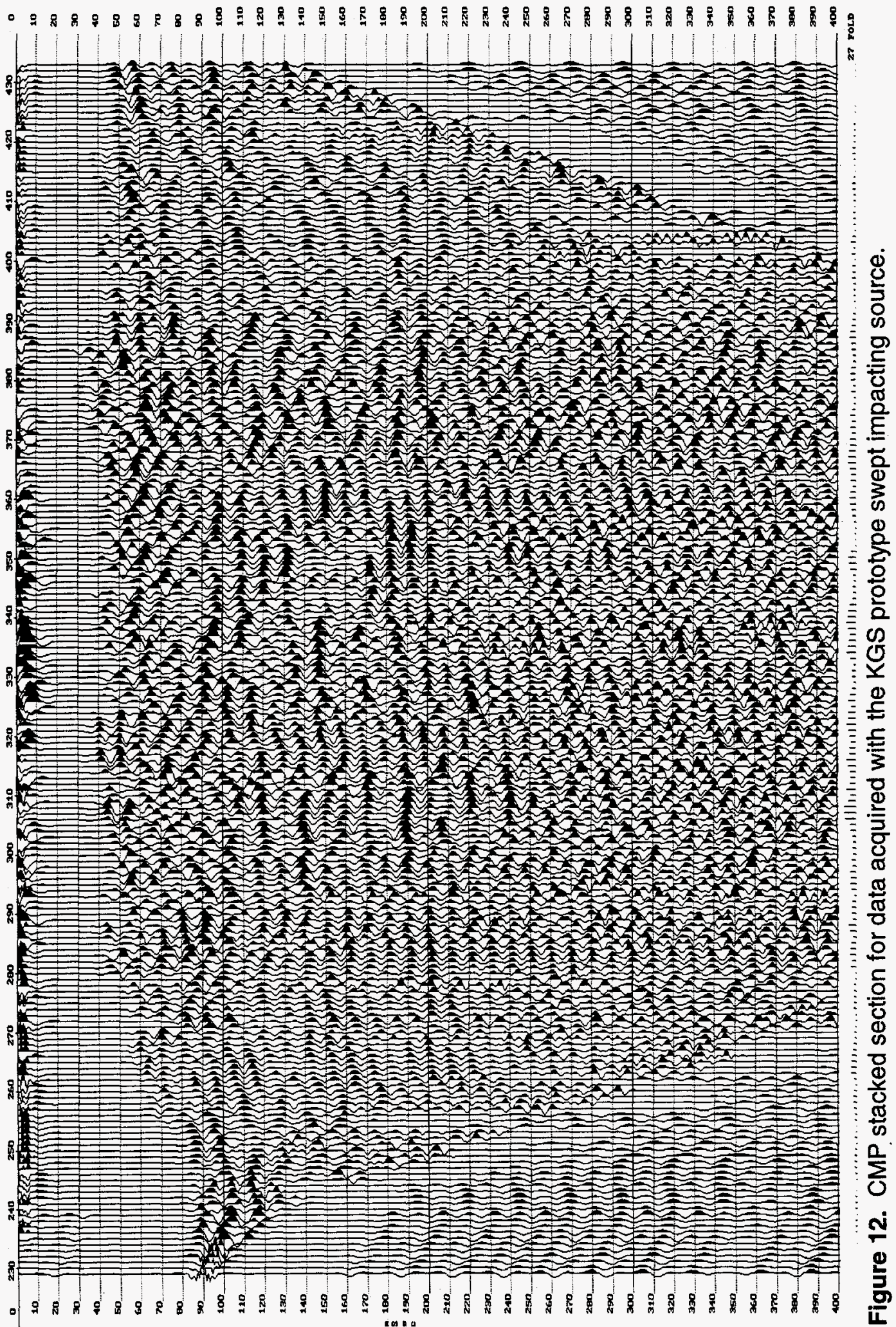




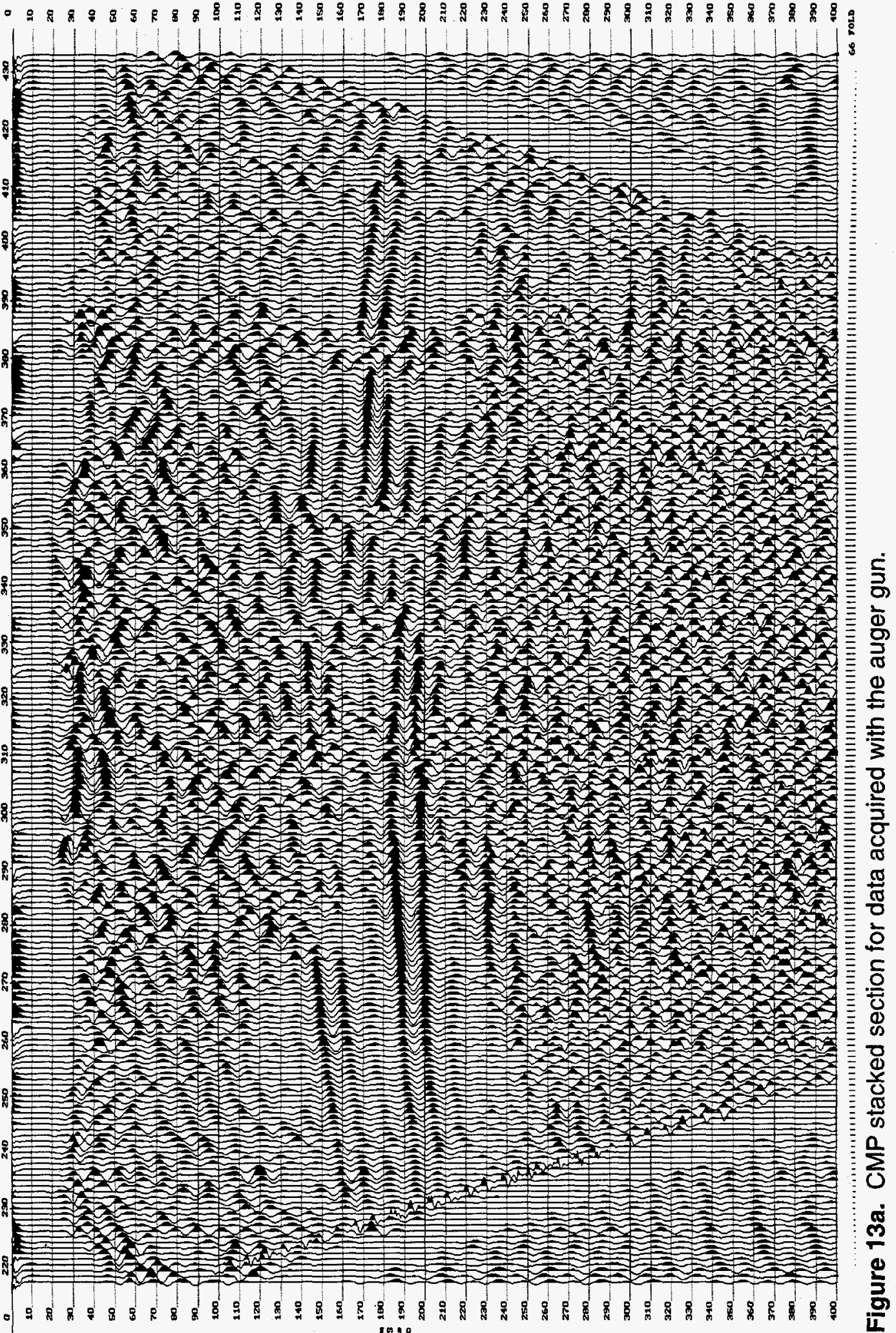




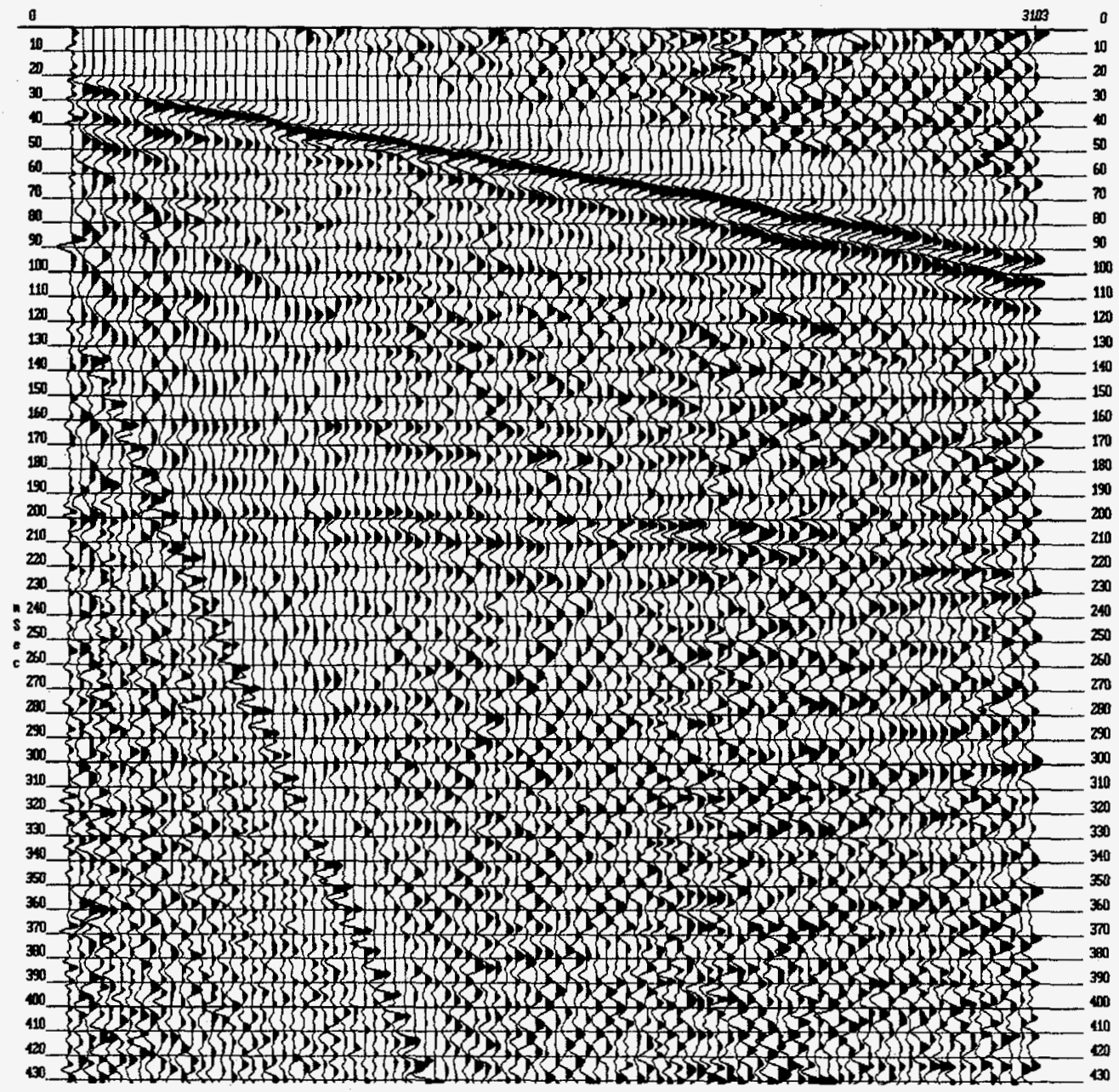

Figure 13b. Shot gather for one shot of the auger gun. 


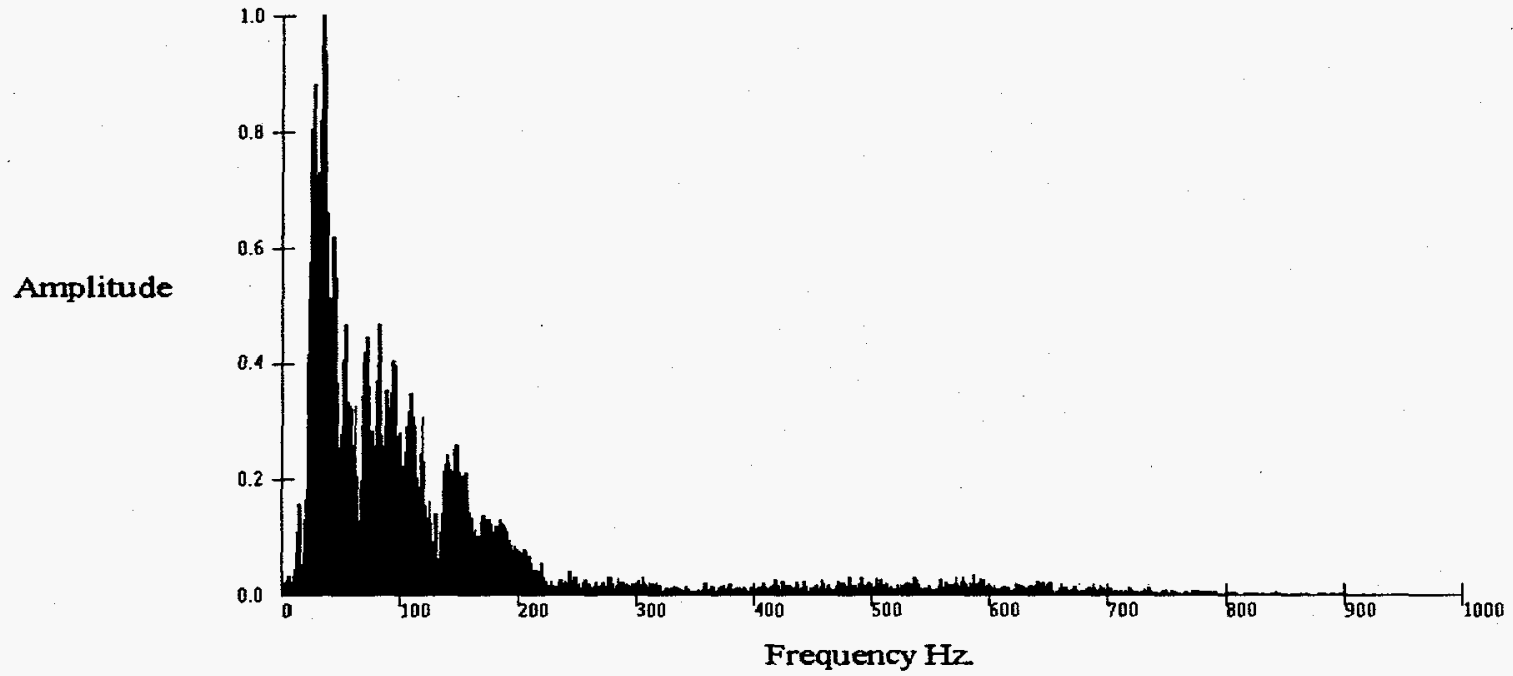

Figure 13c. Spectrum of trace 57, shot 3103 (Figure 13b) for the auger gun.

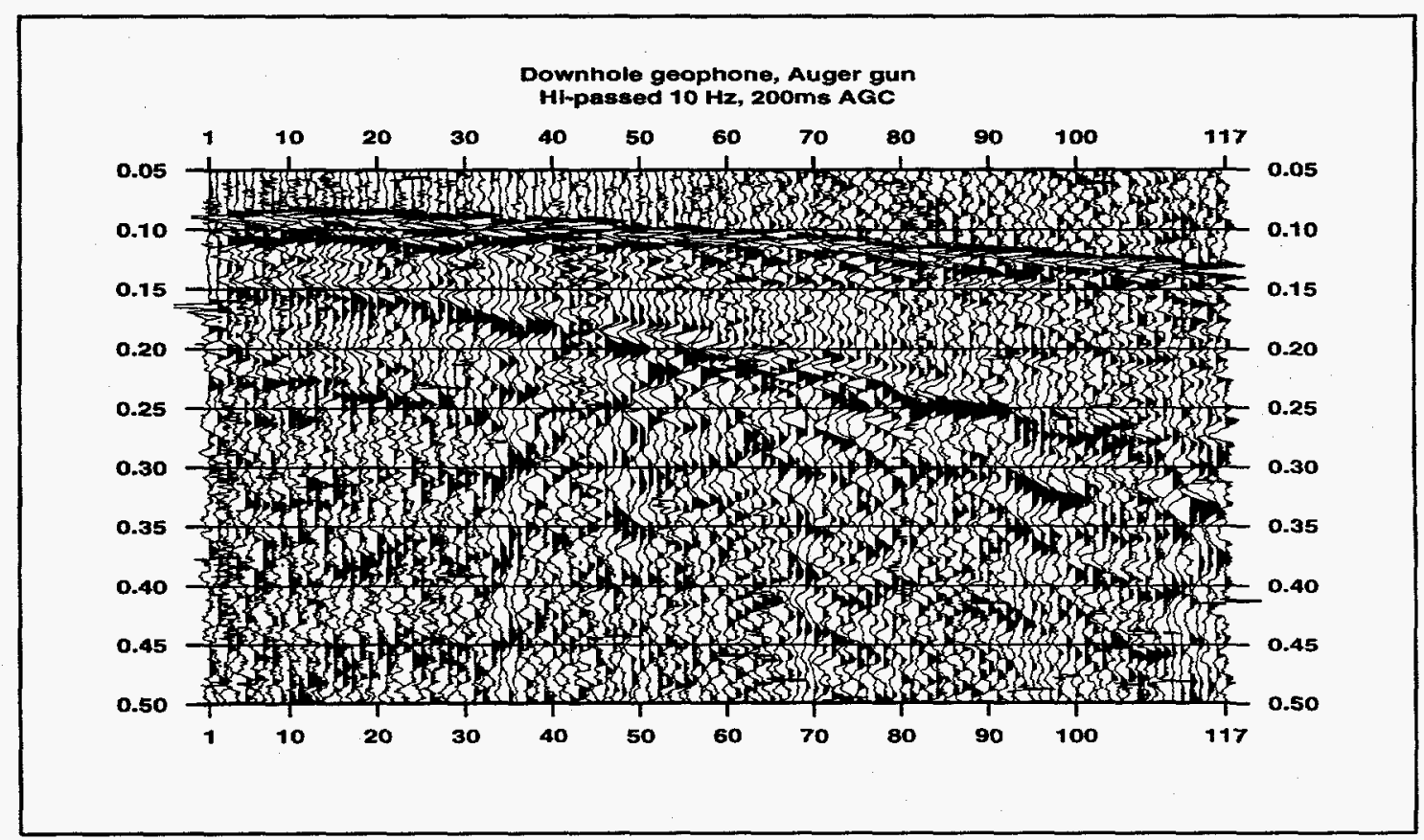

Figure 13d. Auger gun shots from all shot stations, recorded by the downhole vertical geophone in well 1943 at the west end of the geophone spread. 

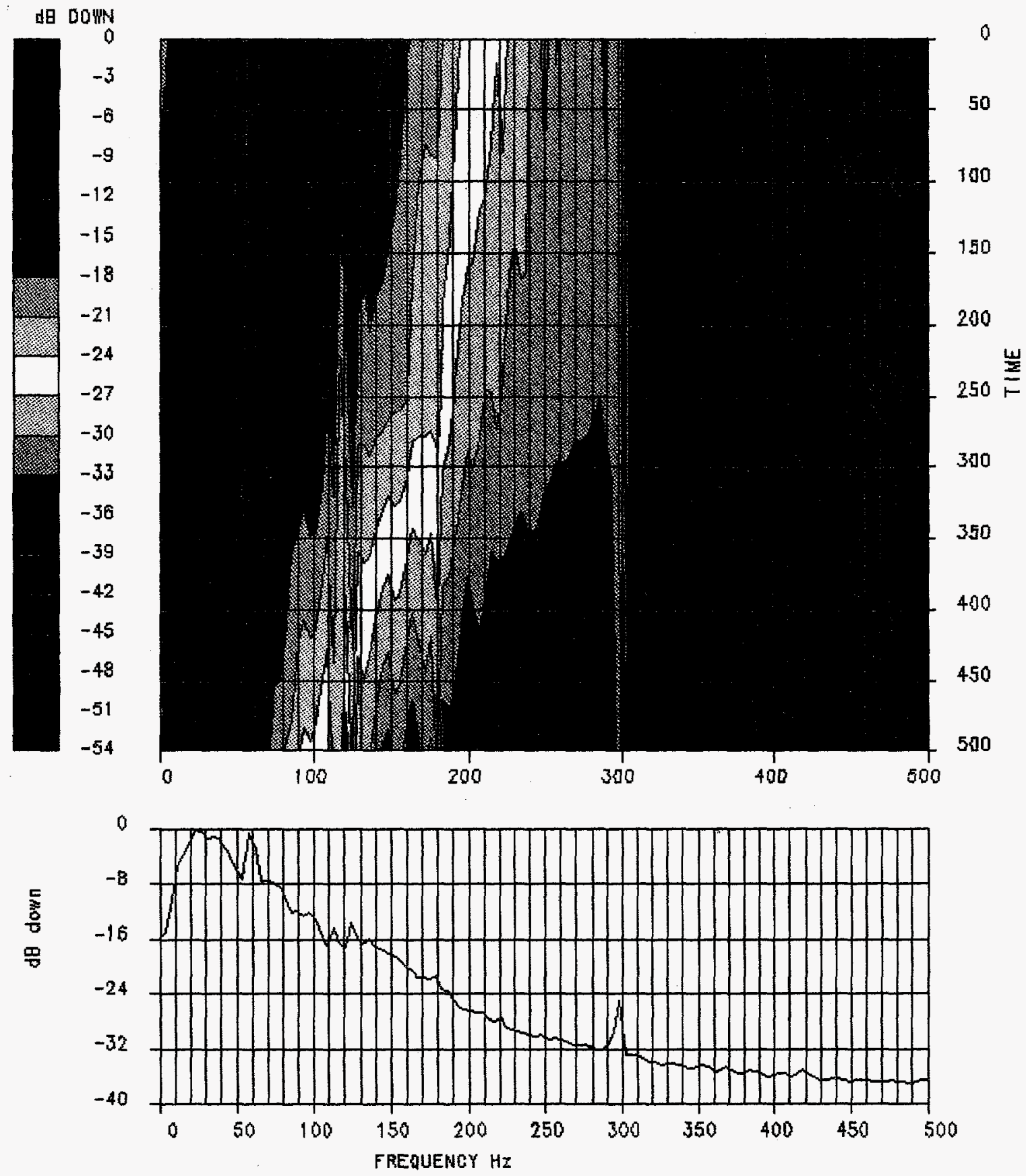

Figure 13e. Spectrum of unfiltered shots recorded by the downhole geophone with the auger gun source. The color display shows how the frequency content varies with time, and an average spectrum for the entire record is shown at the bottom. 


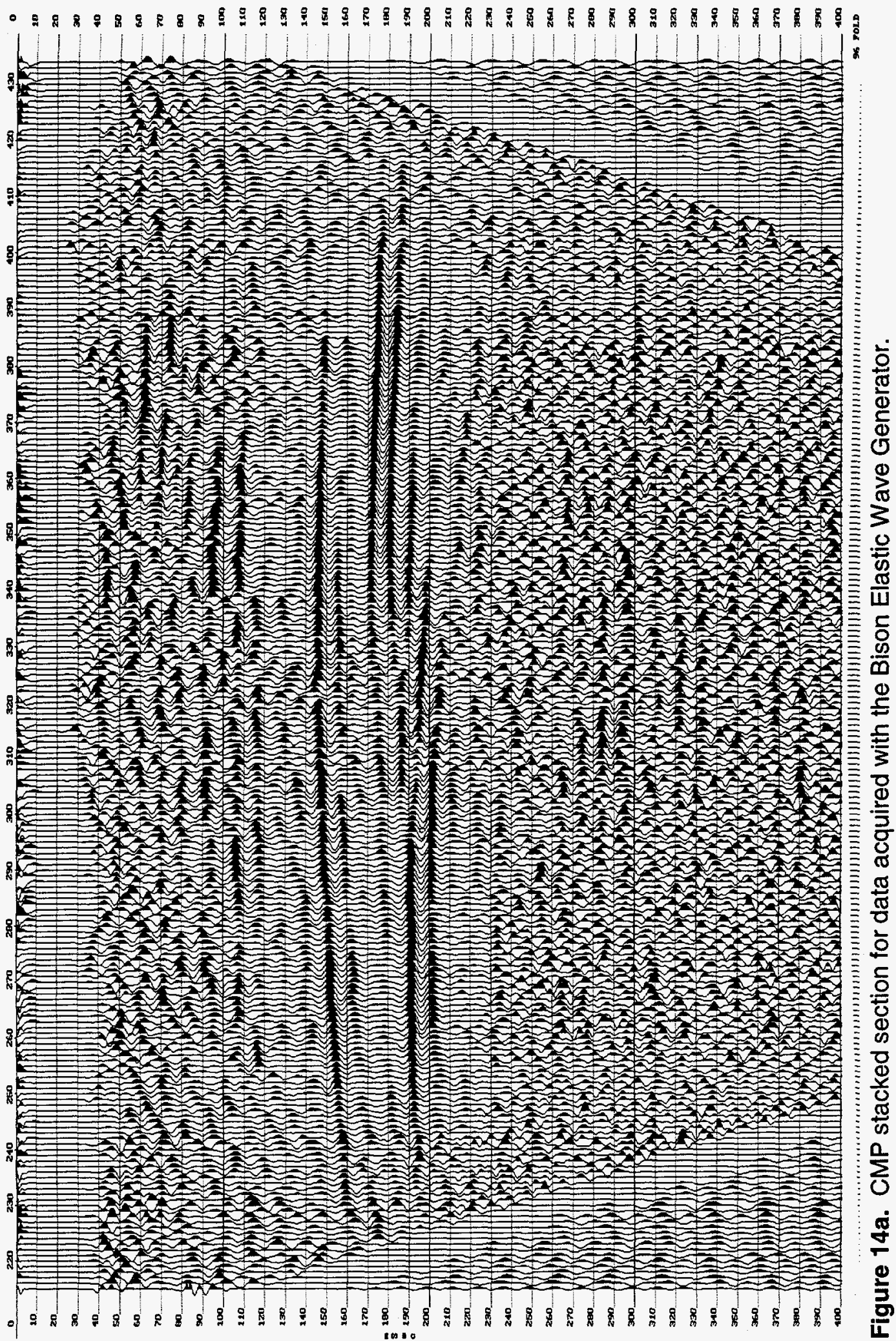




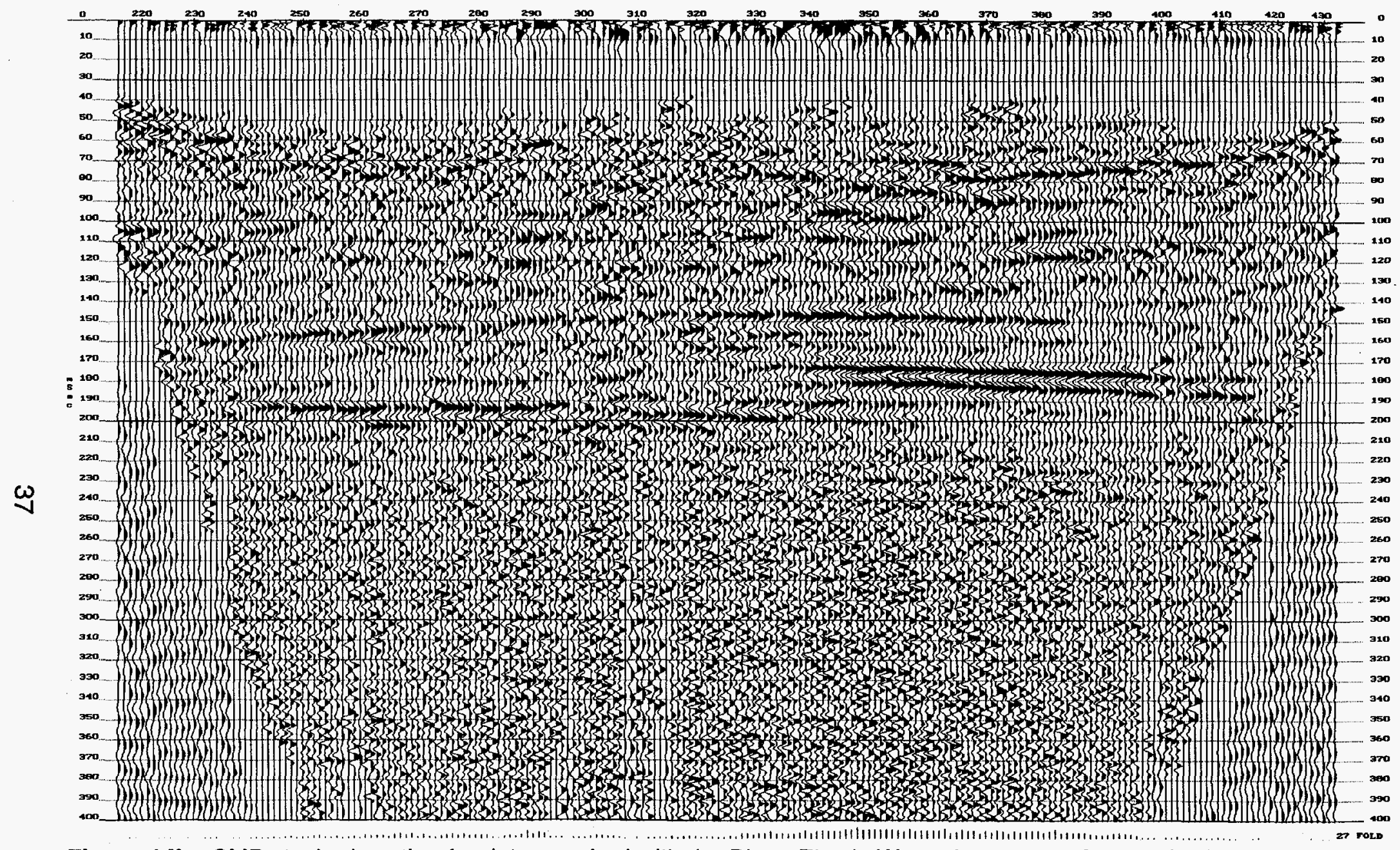

Figure 14b. CMP stacked section for data acquired with the Bison Elastic Wave Generator. Stretch AGC and spiking deconvolution have been applied to the data before stacking. 


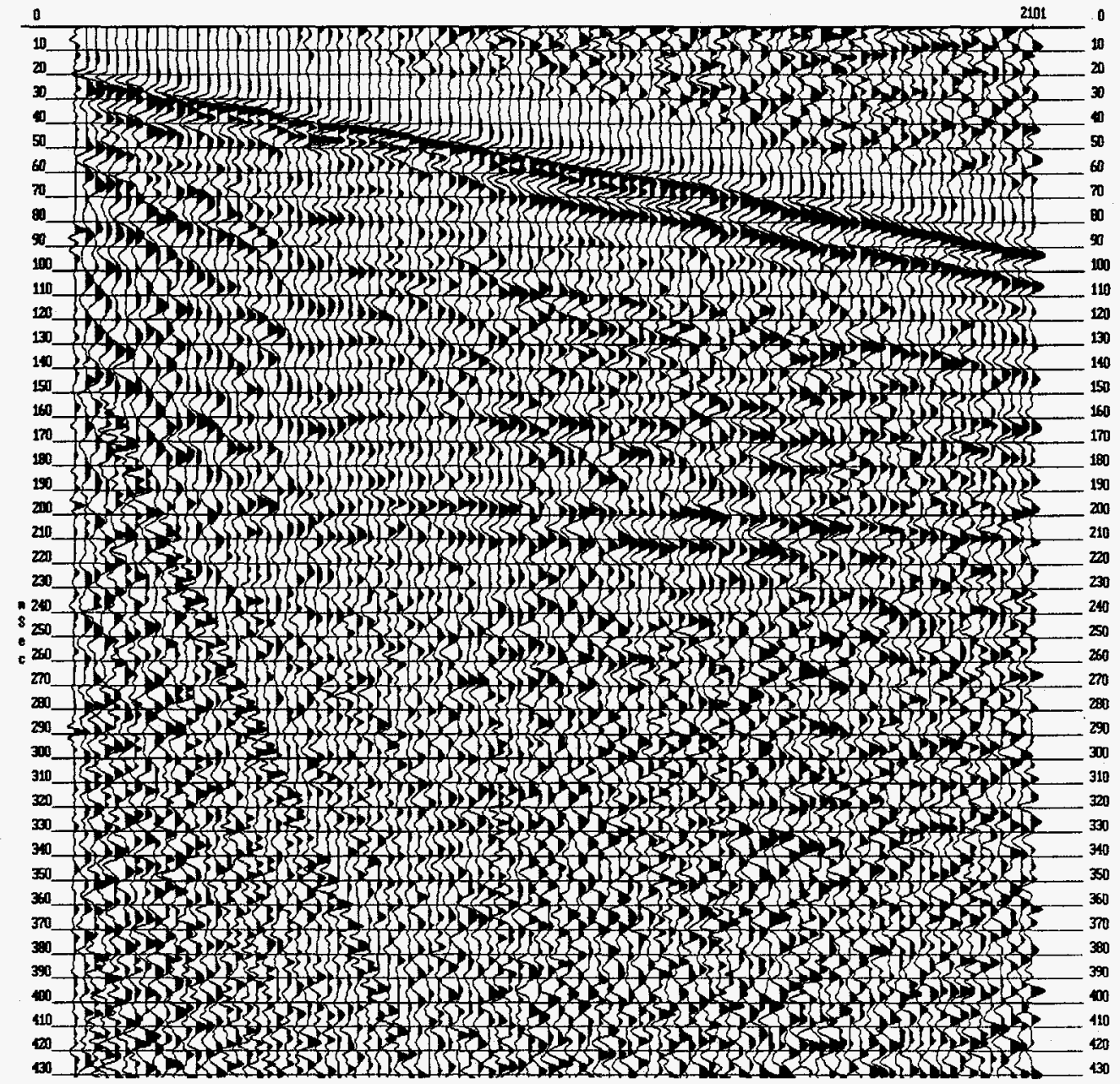

Figure 14c. Shot gather for one shot of the Bison Elastic Wave Generator. 


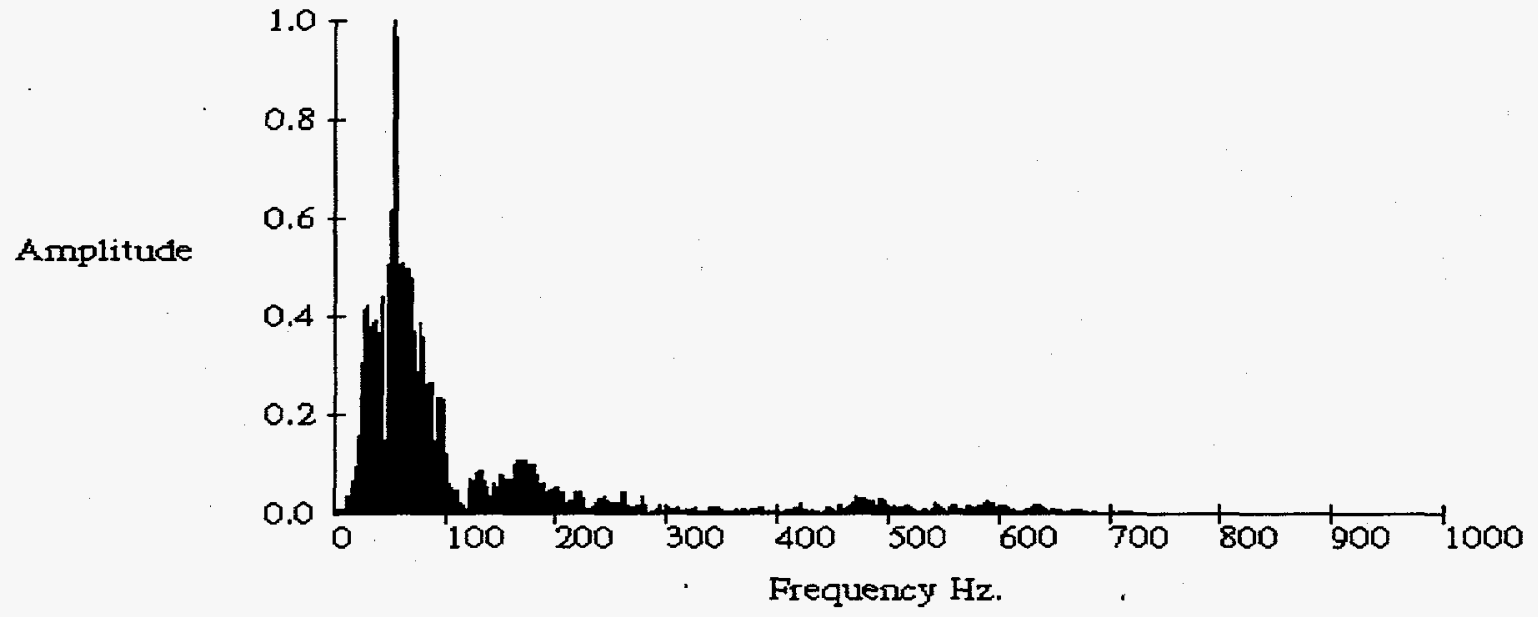

Figure 14d. Spectrum of trace 45, shot 2101 (Figure 14c) for the EWG.

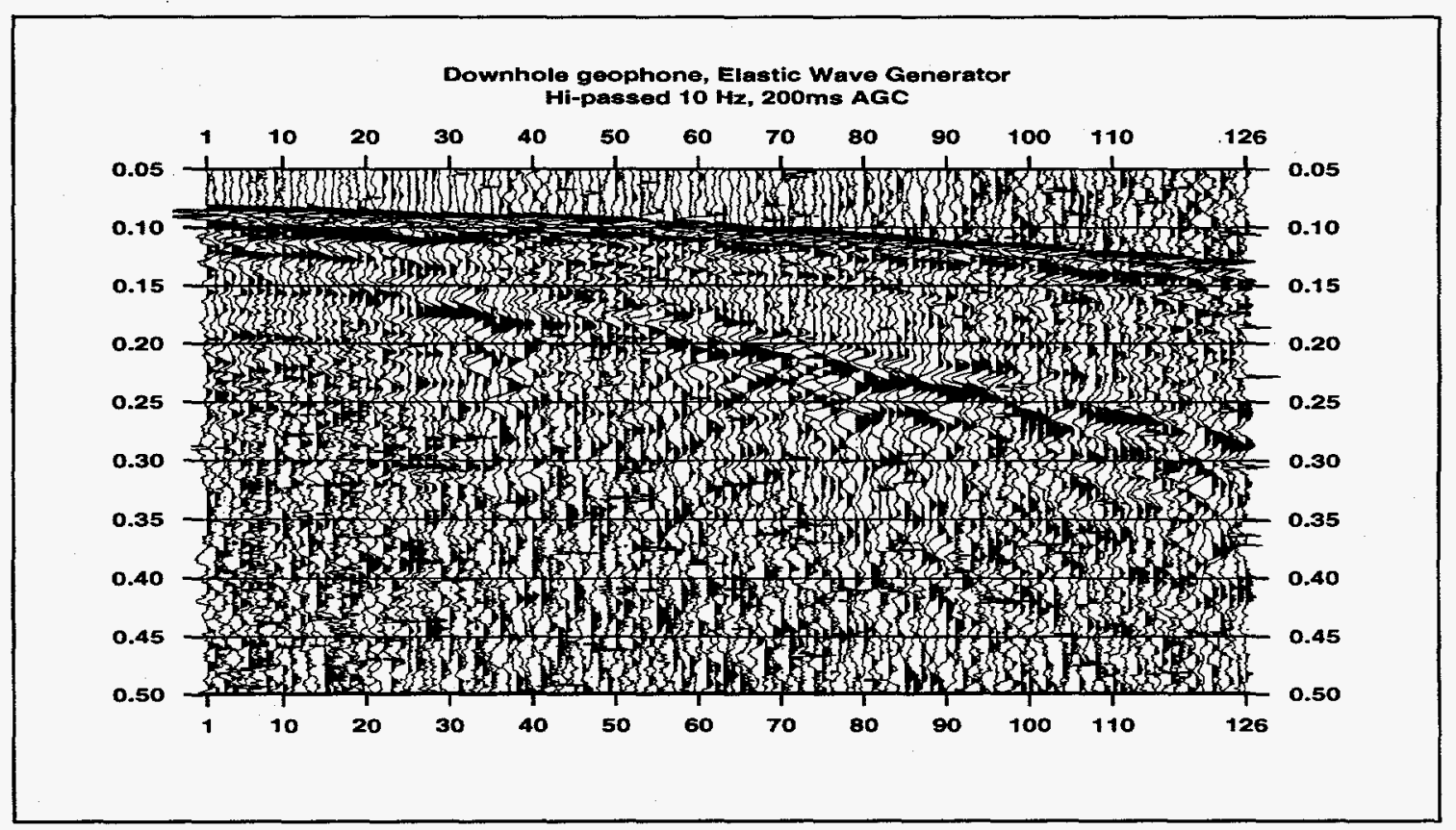

Figure 14e. EWG shots from all shot stations, recorded by the downhole vertical geophone in well 1943 at the west end of the geophone spread. 

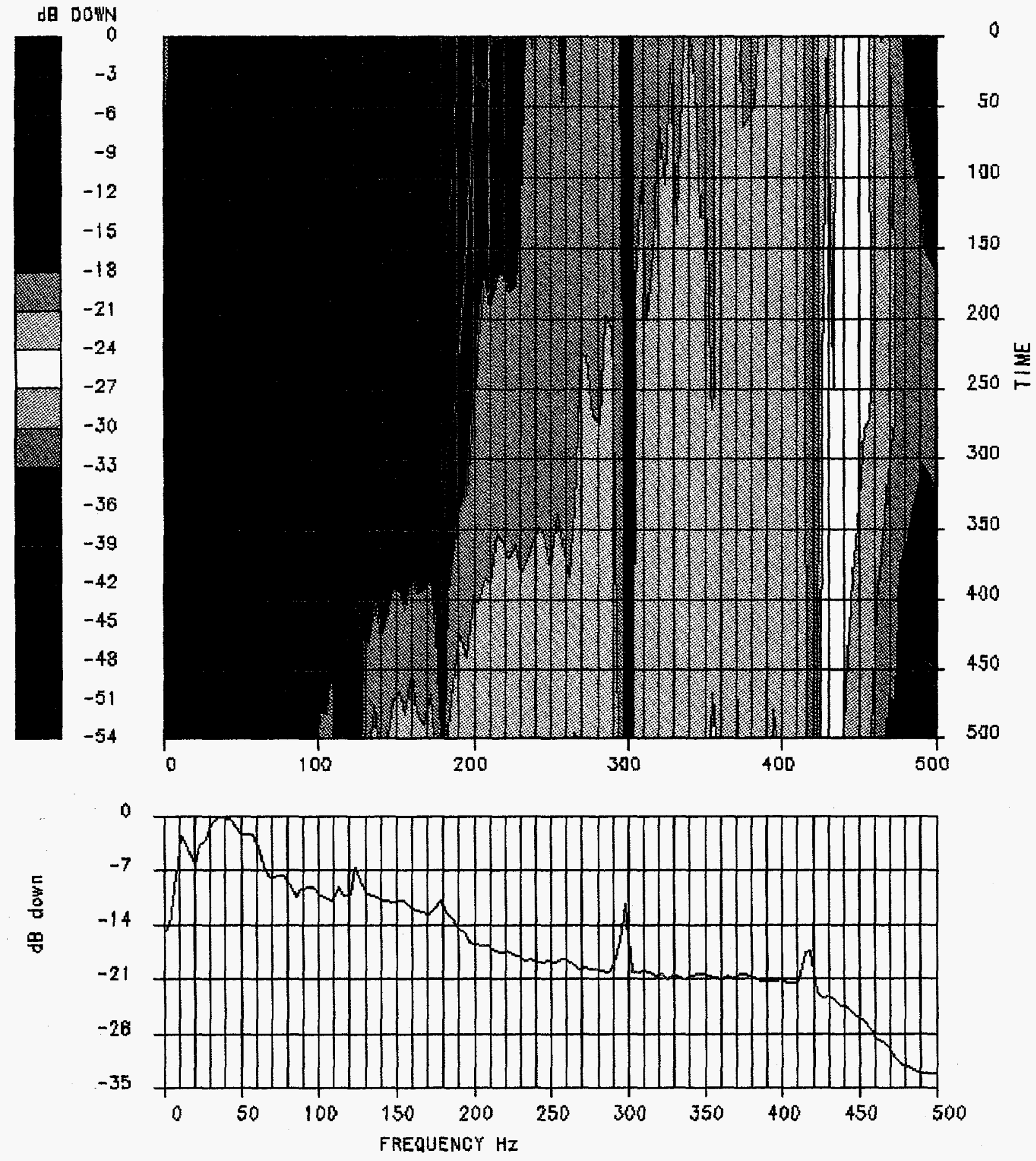

Figure 14f. Spectrum of unfiltered shots recorded by the downhole geophone with the EWG source. The color display shows how the frequency content varies with time, and an average spectrum for the entire record is shown at the bottom. 


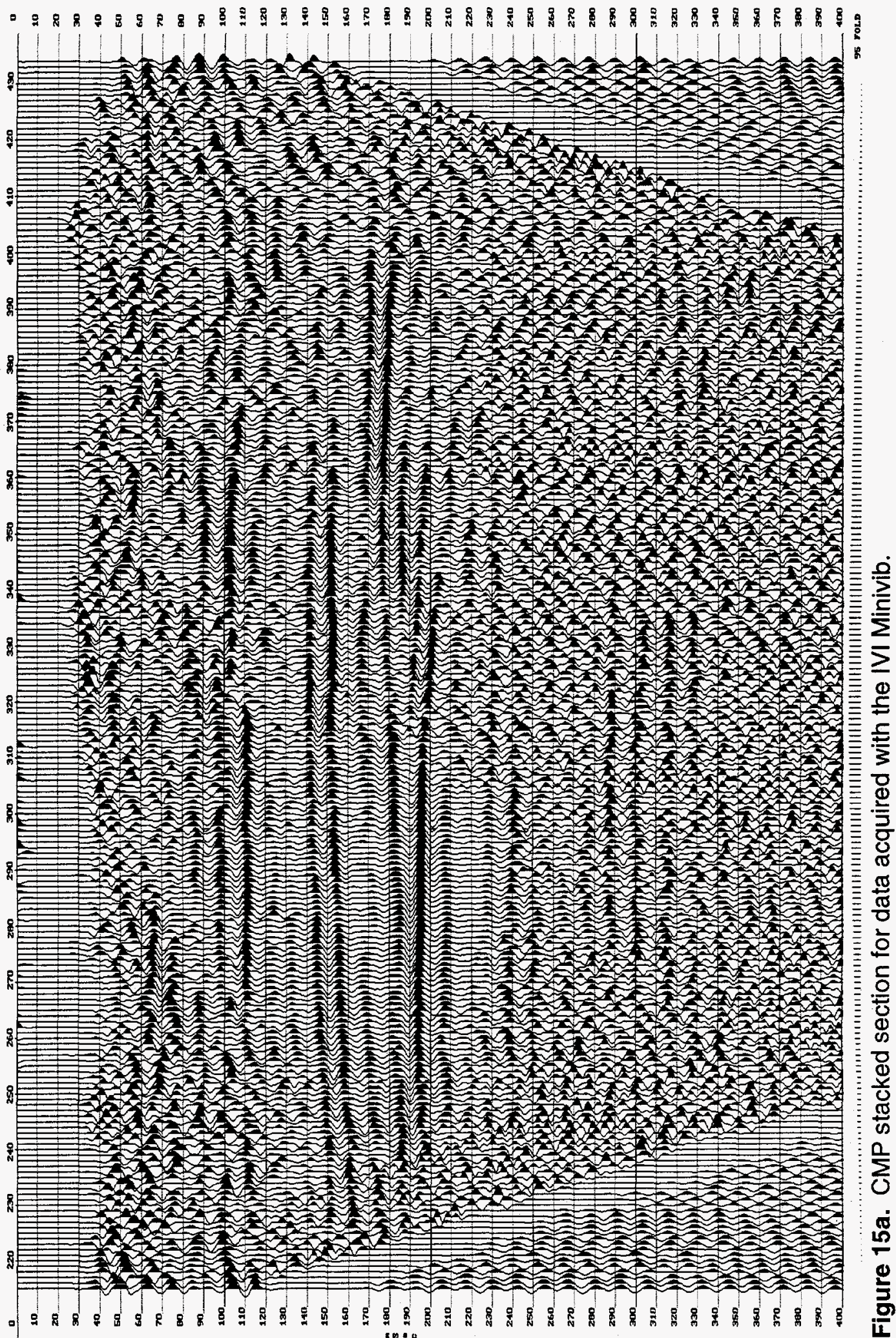




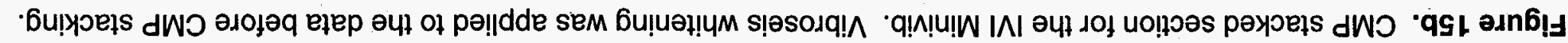

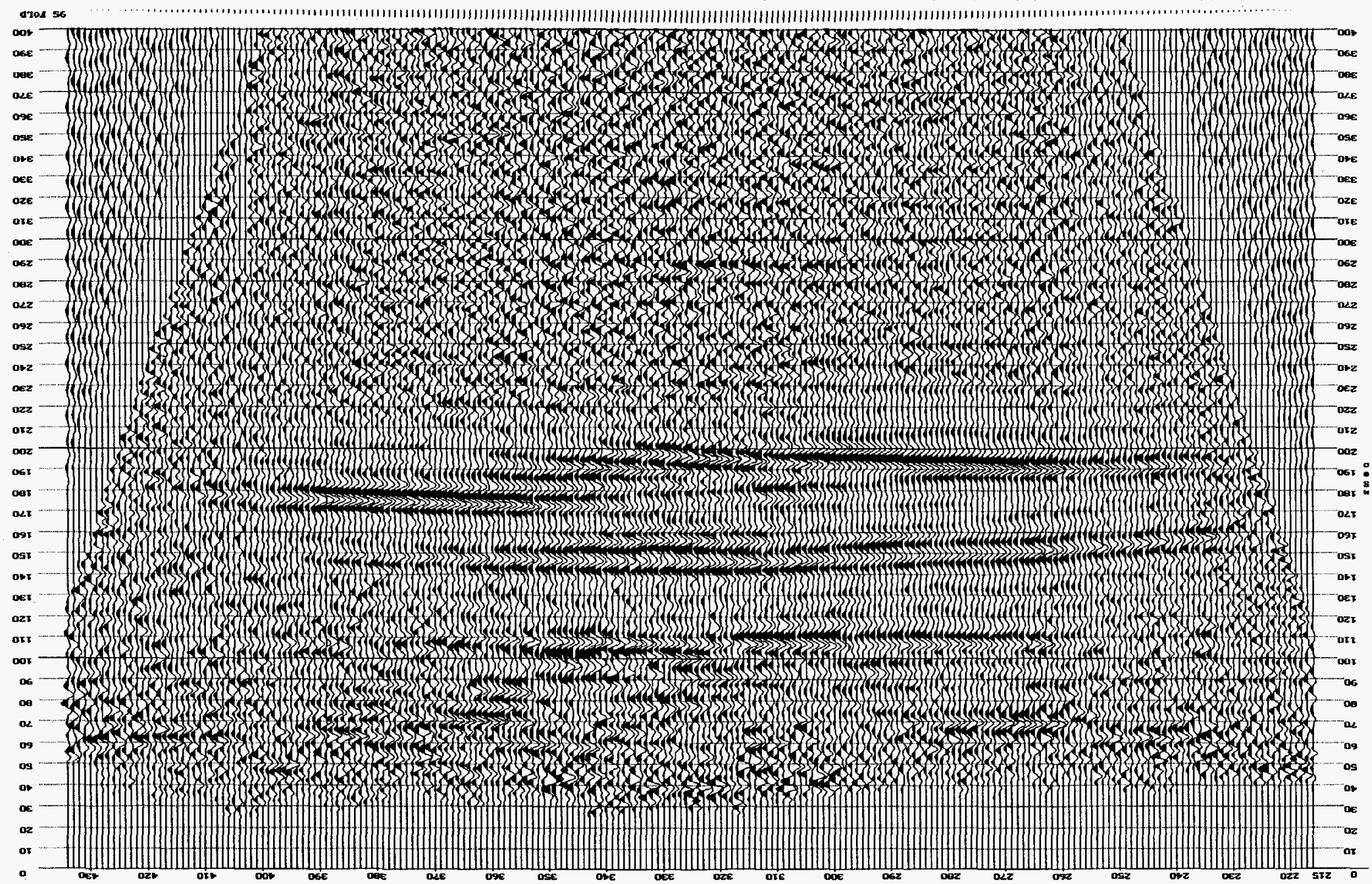




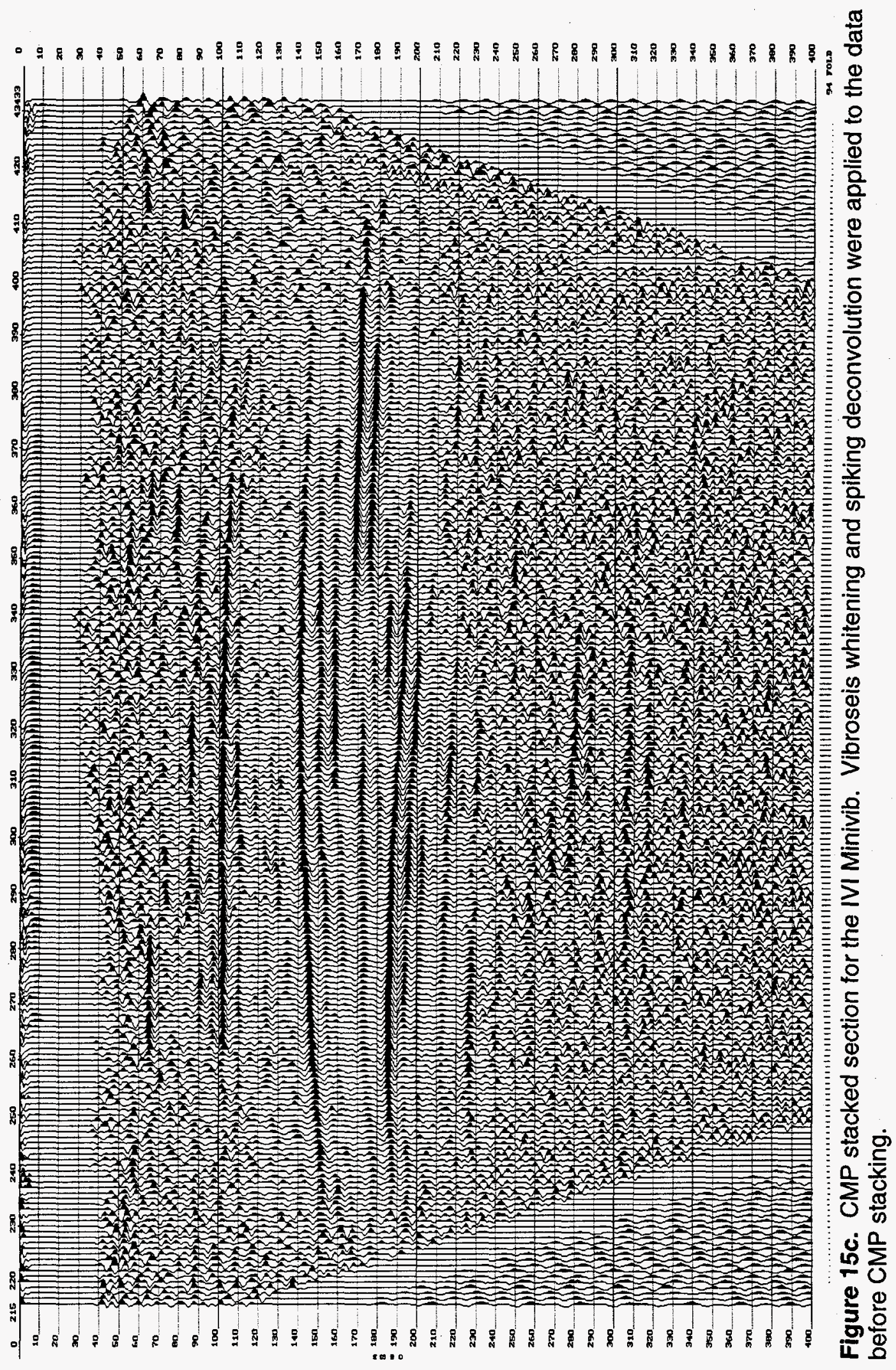




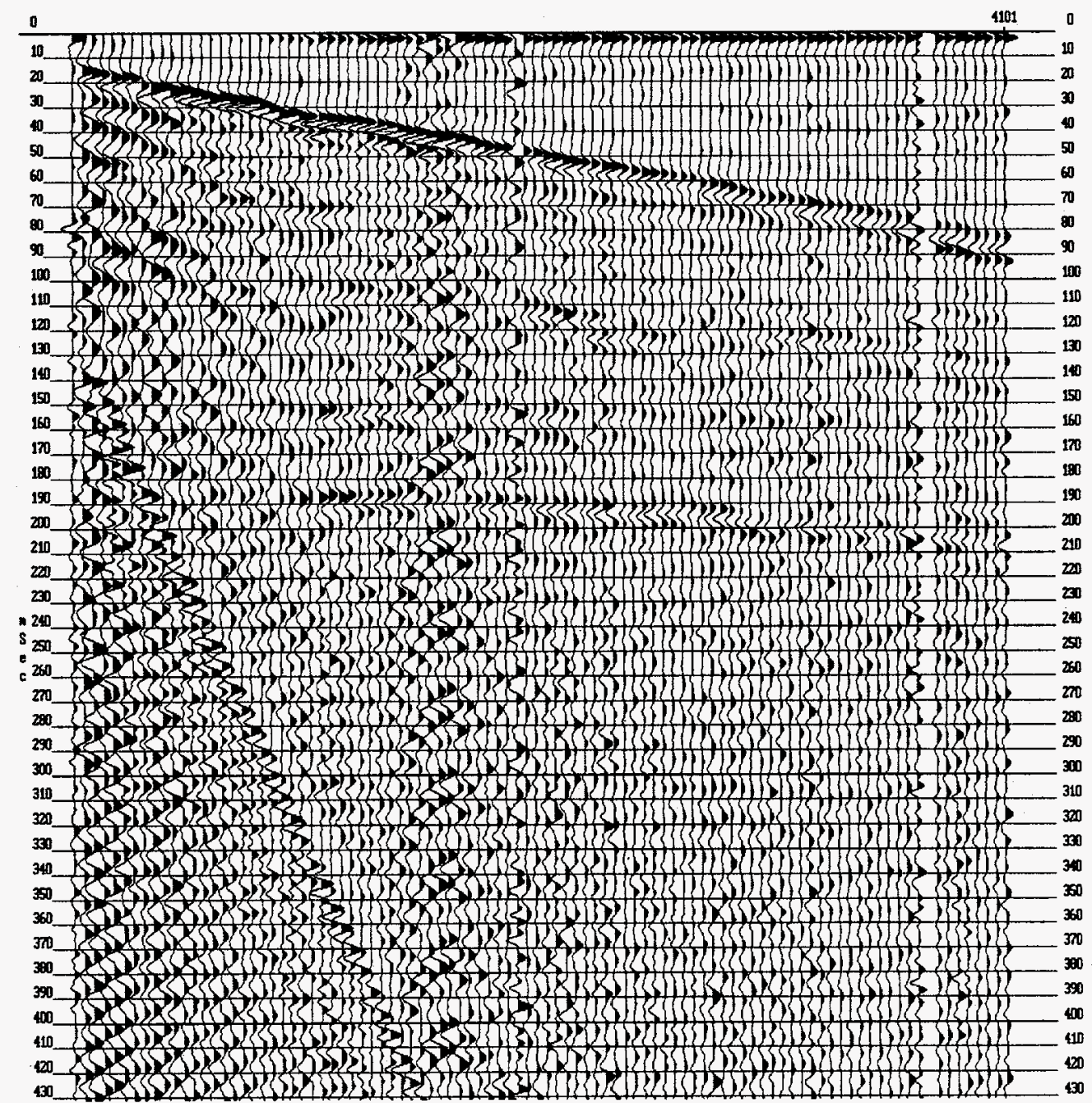

Figure 15d. Shot gather for one shot for the IVI Minivib. 


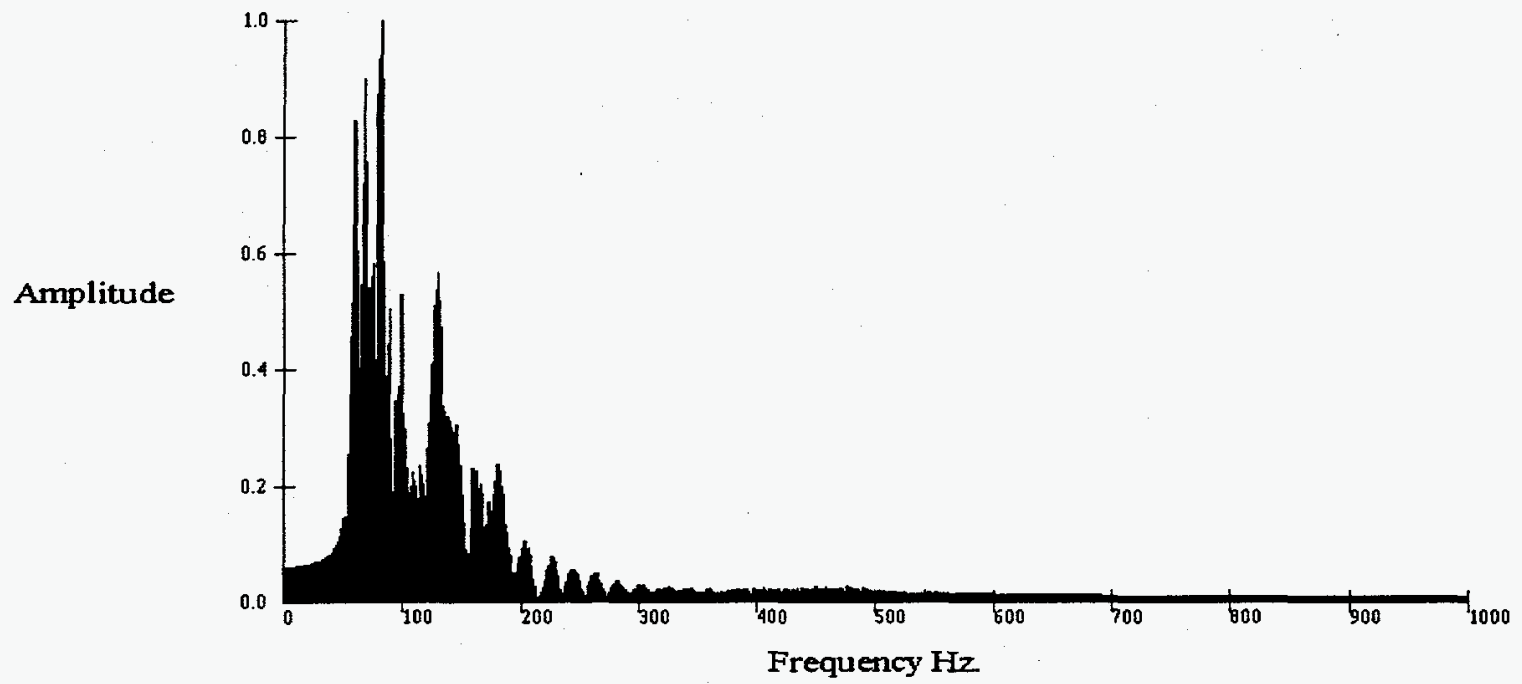

Figure 15e. Spectrum of trace 51, shot 4101 (Figure 15d) of the Minivib.

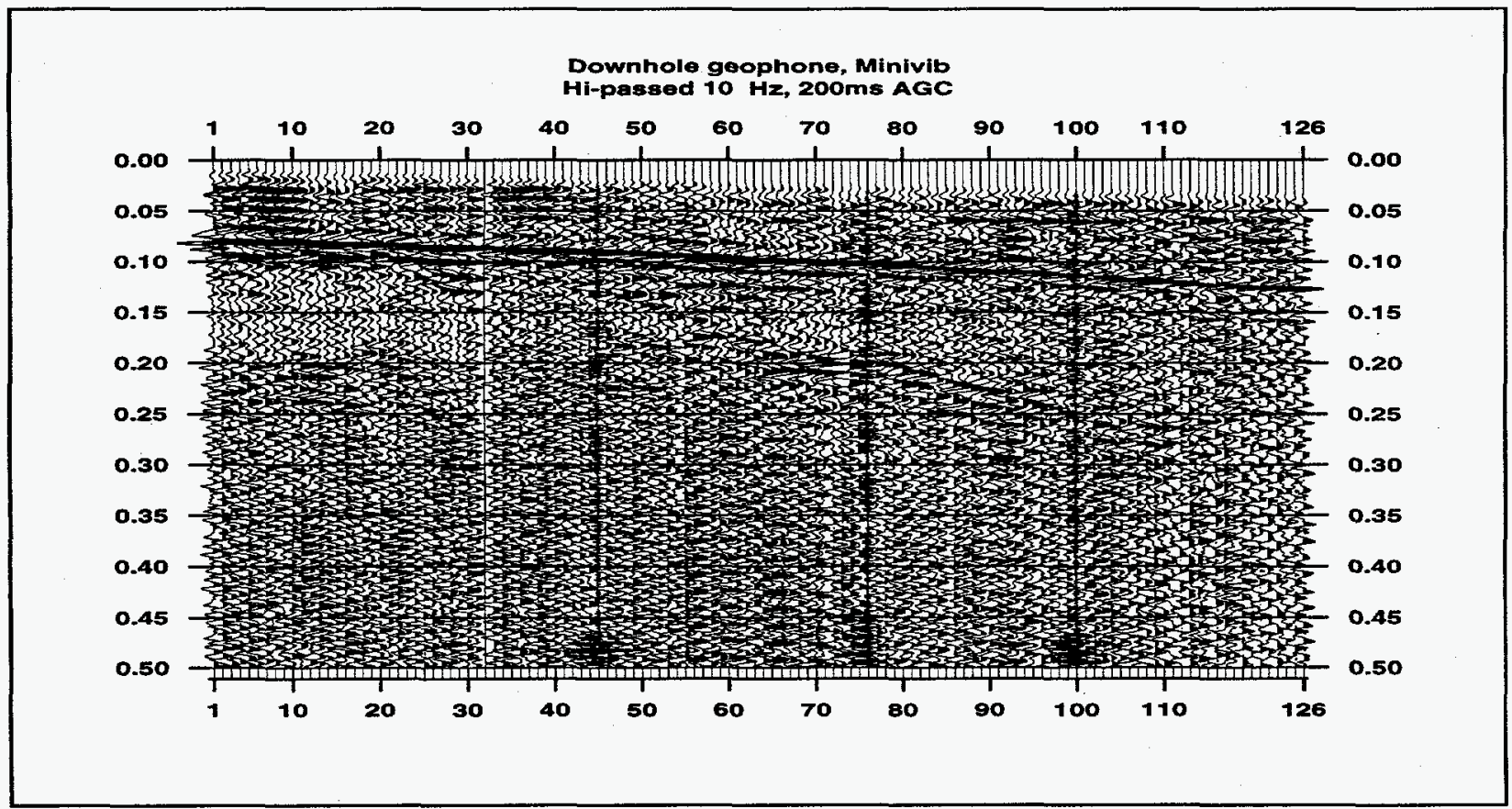

Figure 15f. Minivib shots from all shot stations, recorded by the downhole vertical geophone in well 1943 at the west end of the geophone spread. 


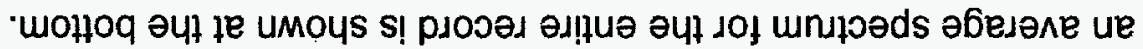

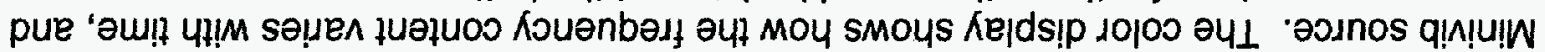

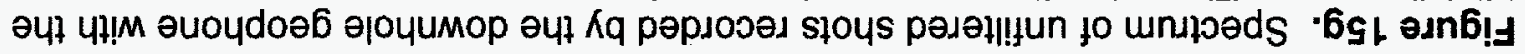
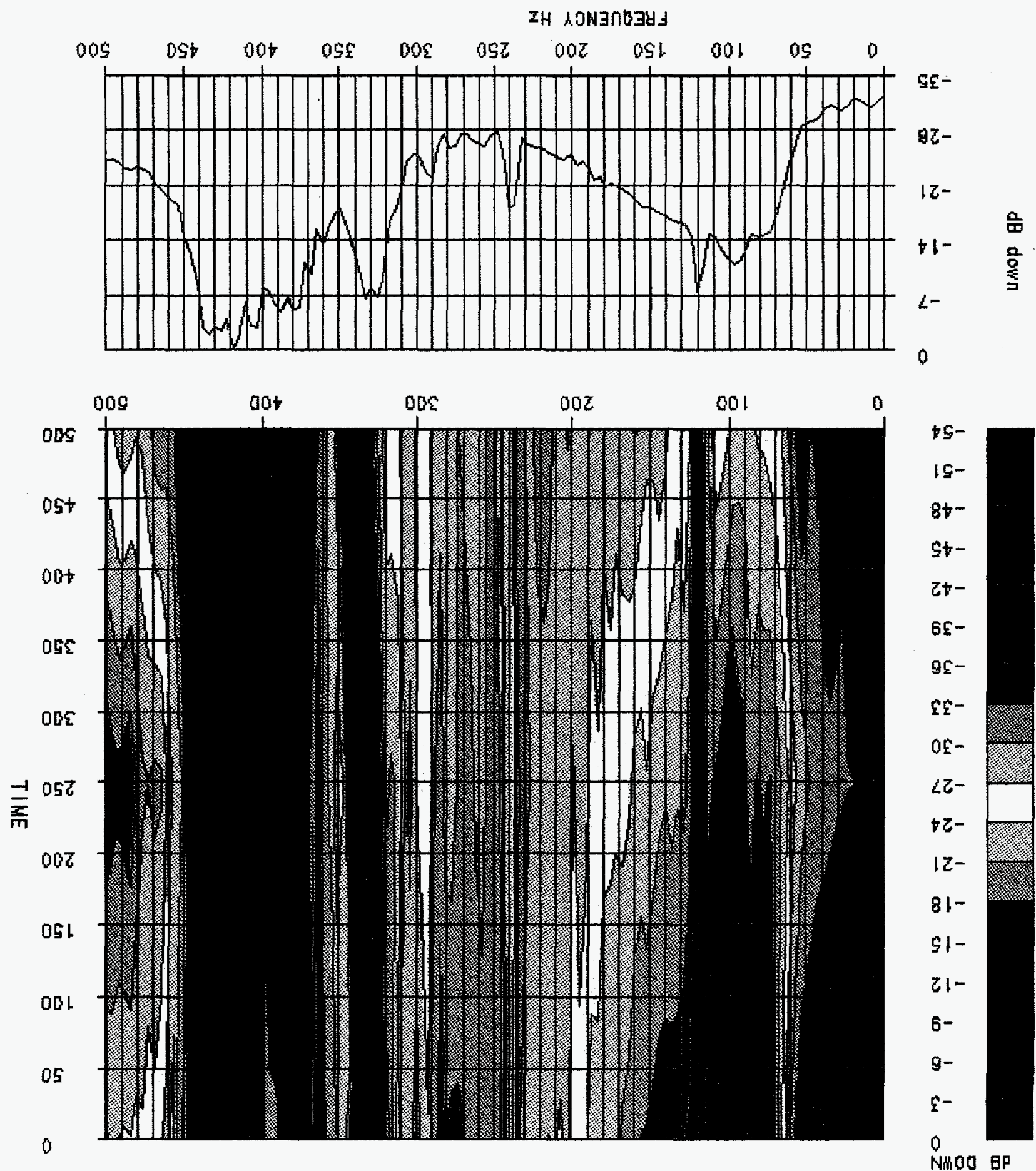


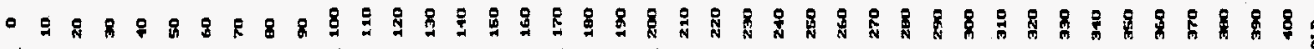

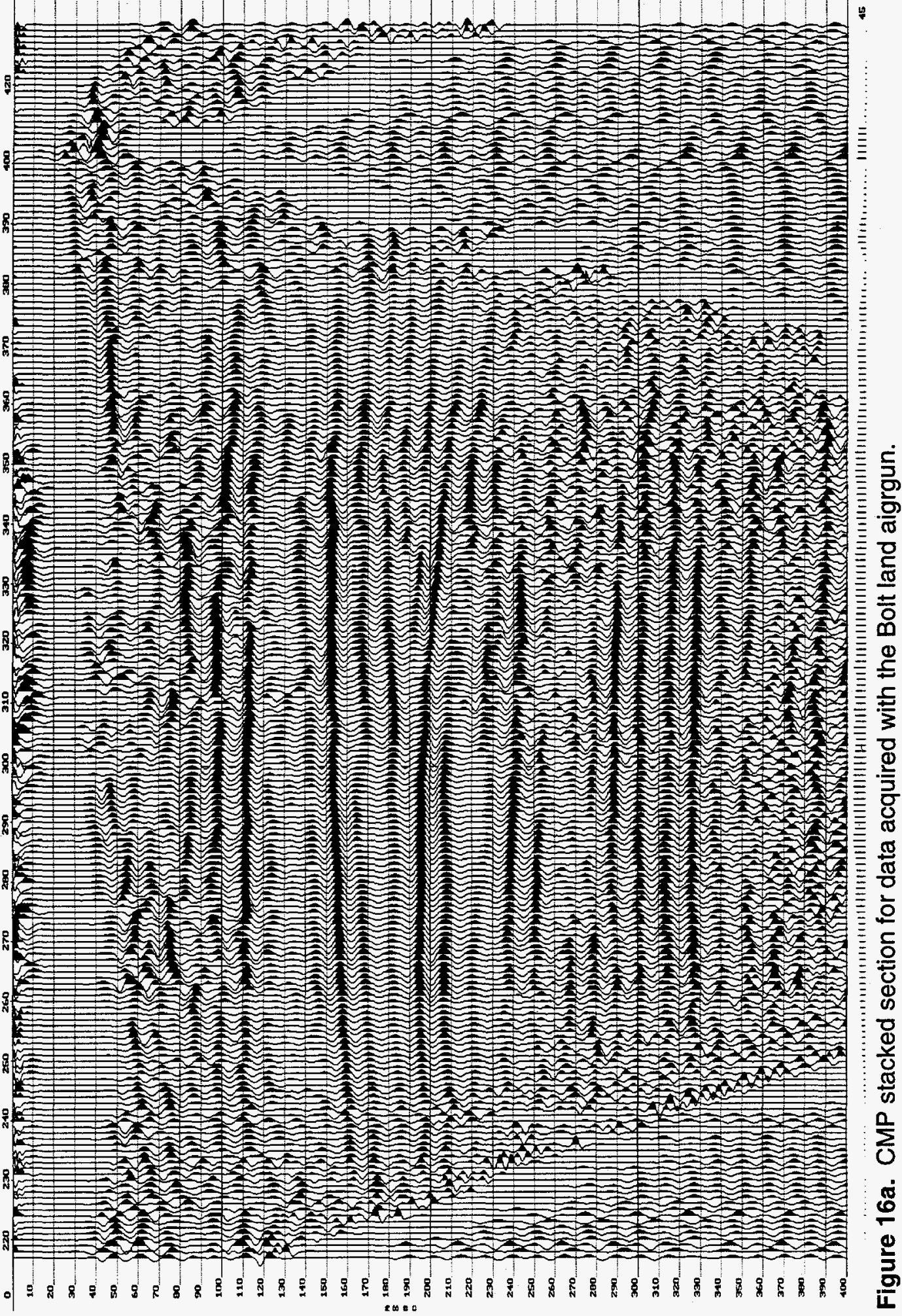




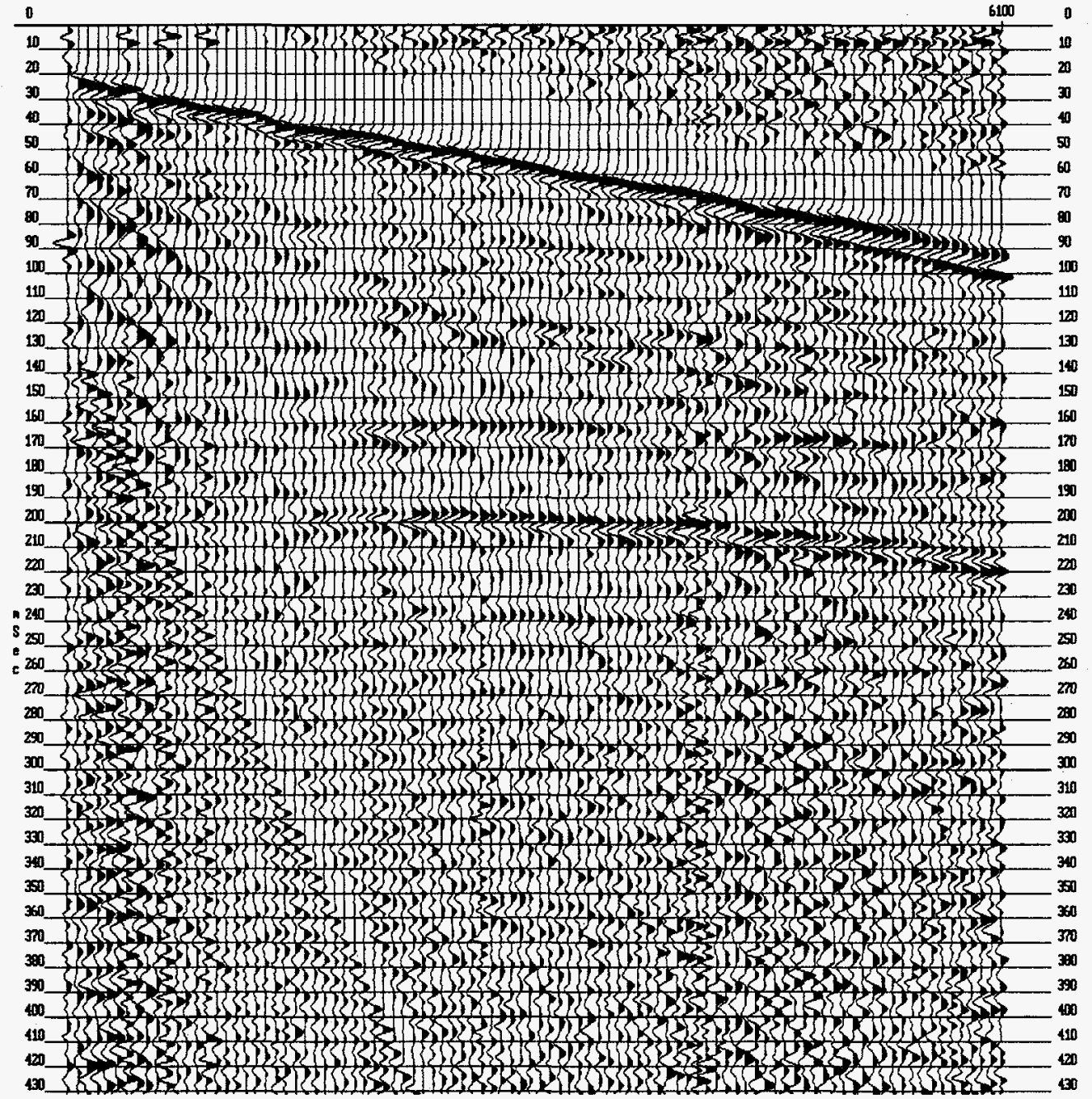

Figure 16b. Shot gather for one shot for the Bolt airgun. 


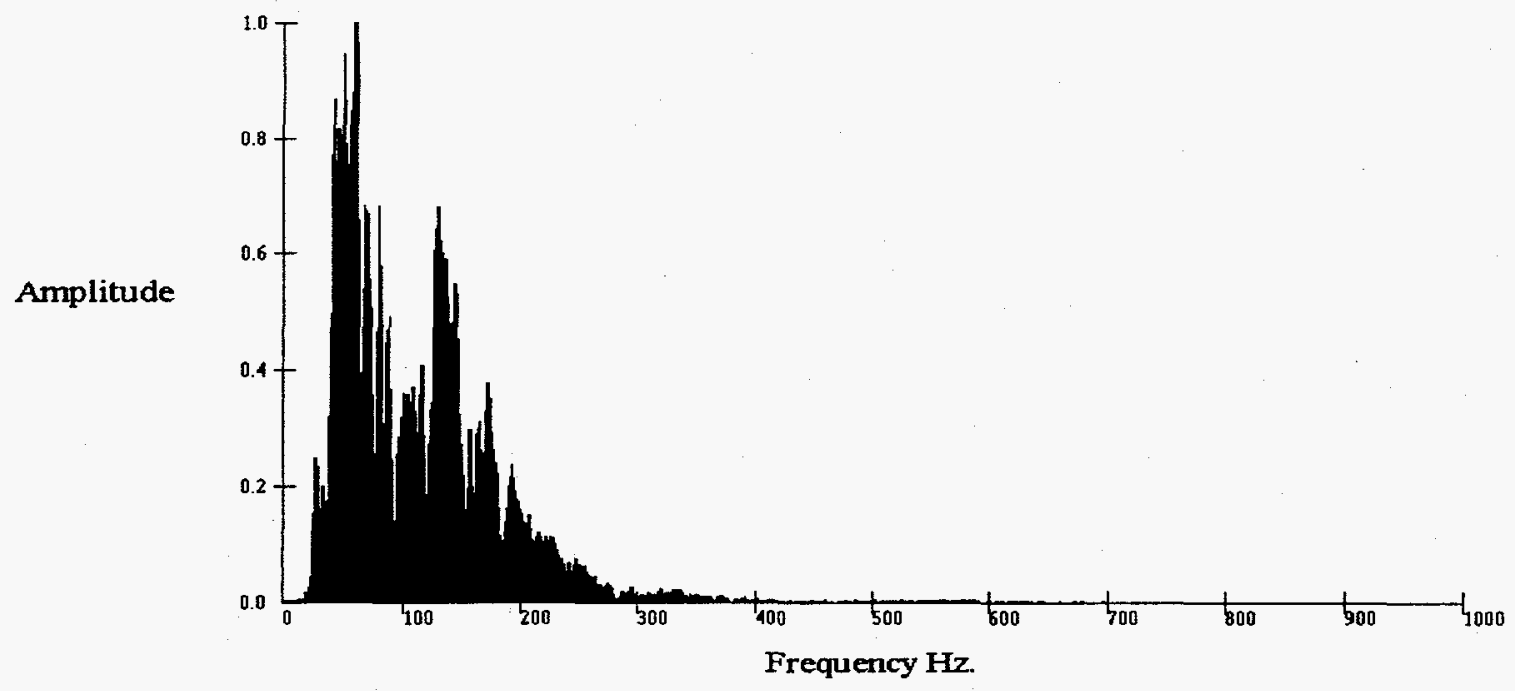

Figure 16c. Spectrum of trace 49, shot 6100 (Fig. 16b) for the airgun.

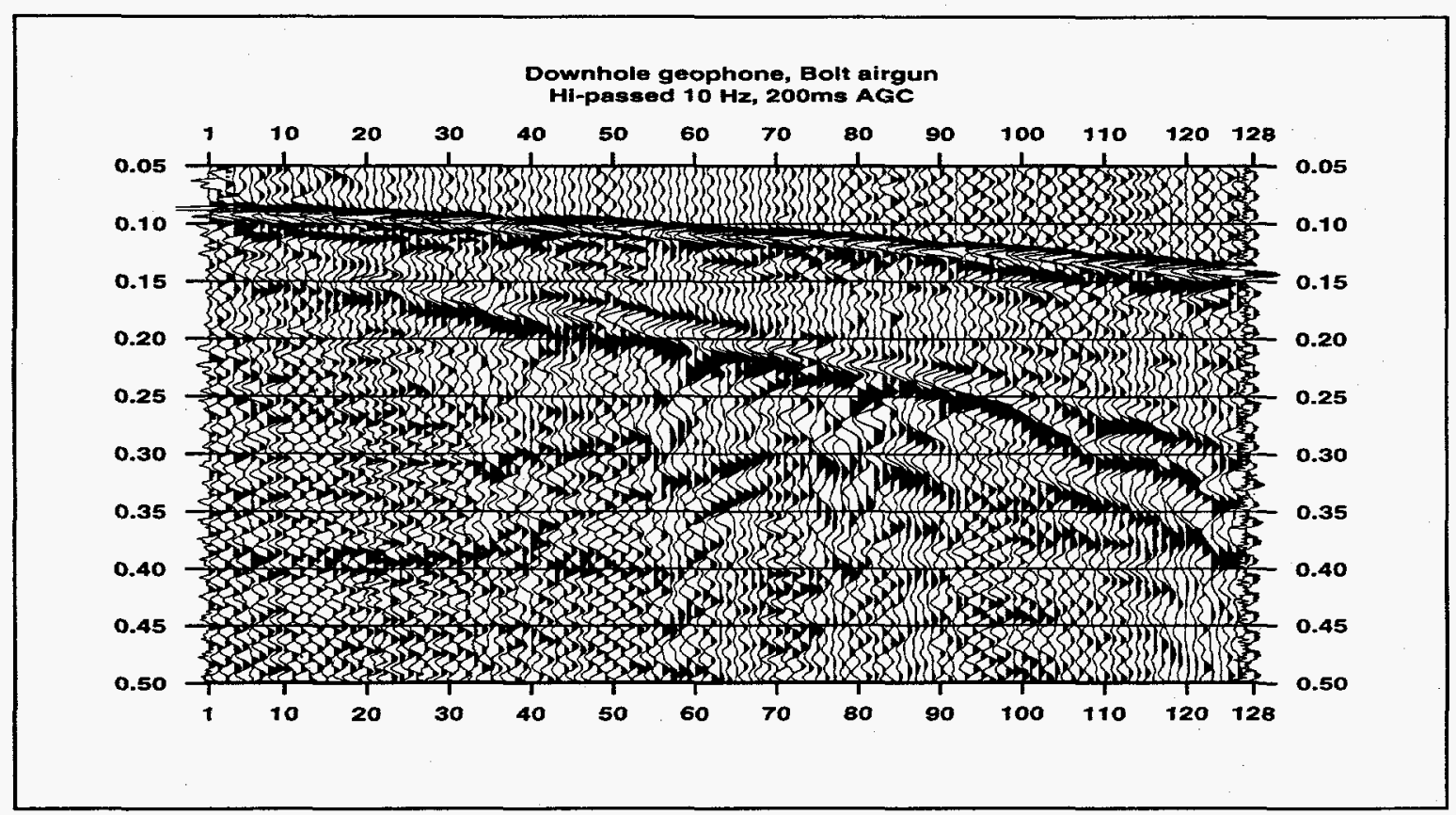

Figure 16d. Airgun shots from all shot stations, recorded by the downhole vertical geophone in well 1943 at the west end of the geophone spread. 


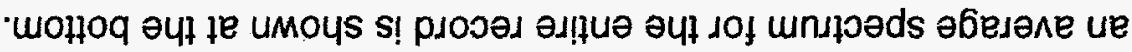

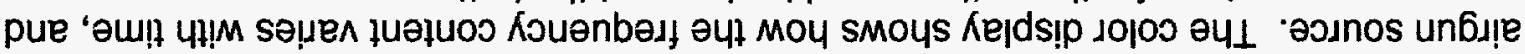

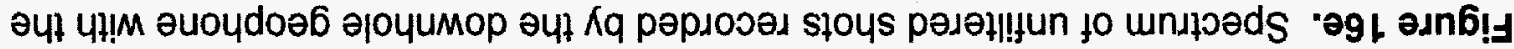

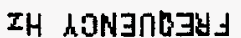
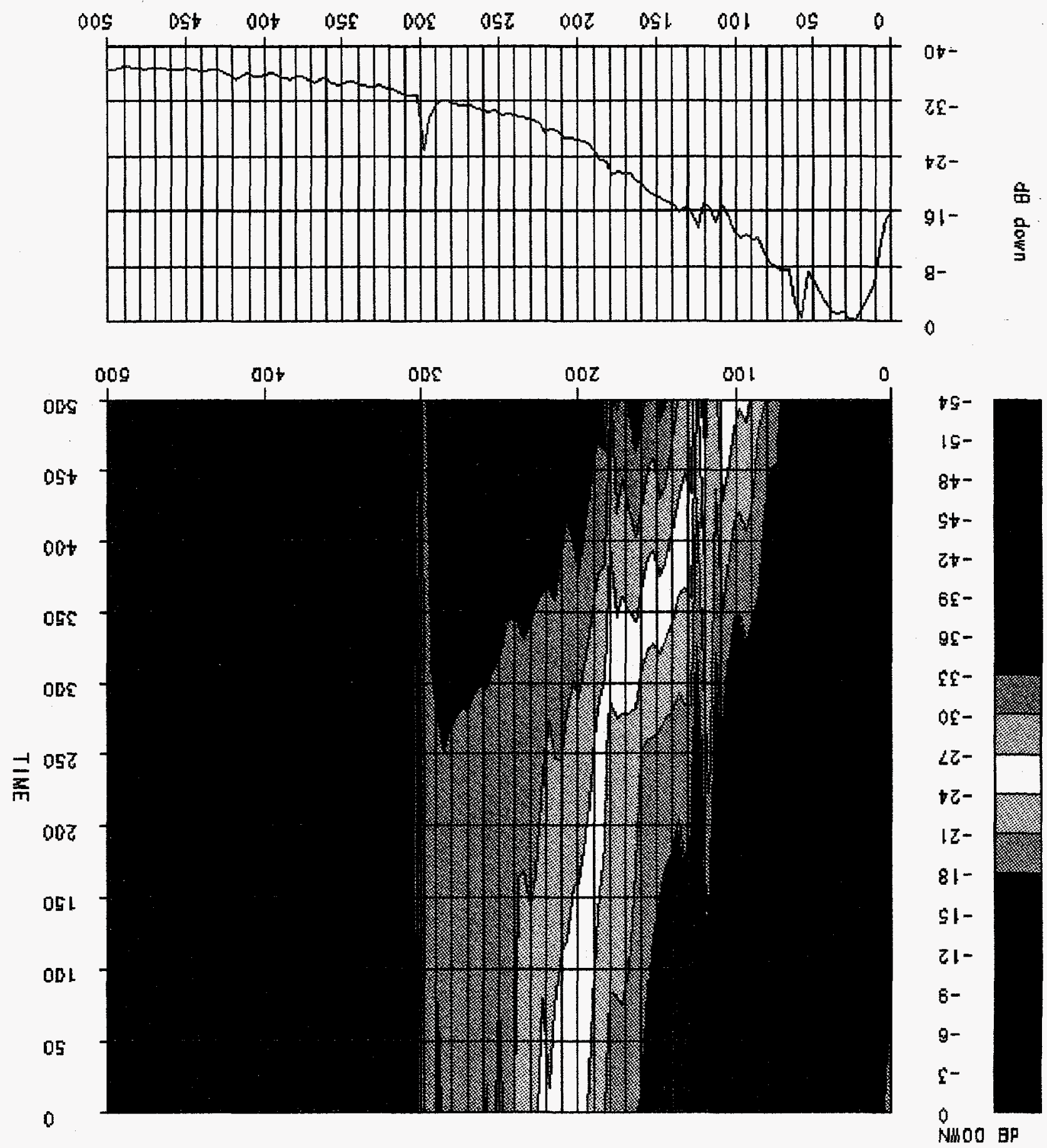


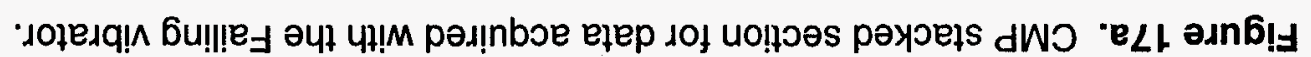

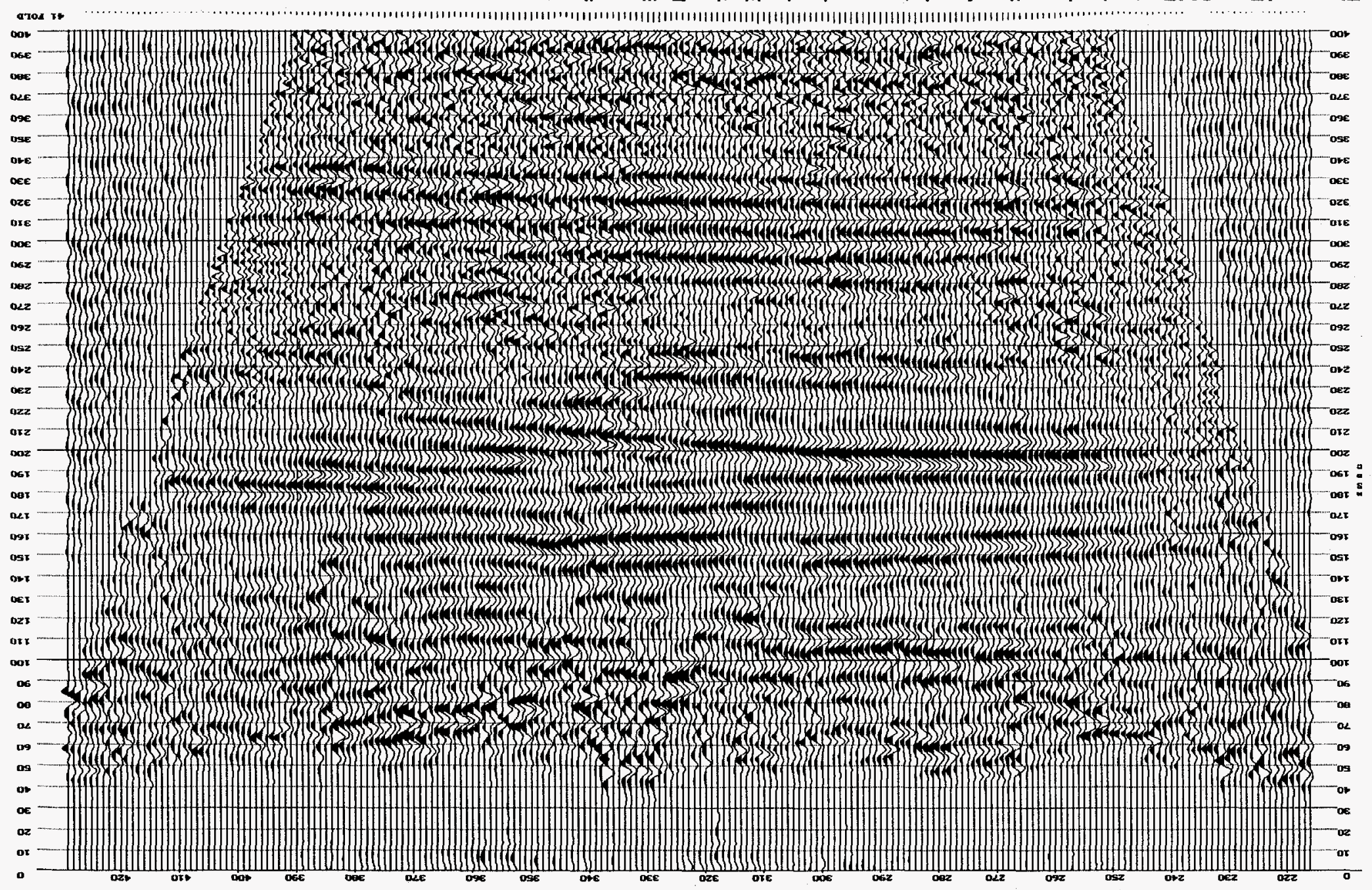




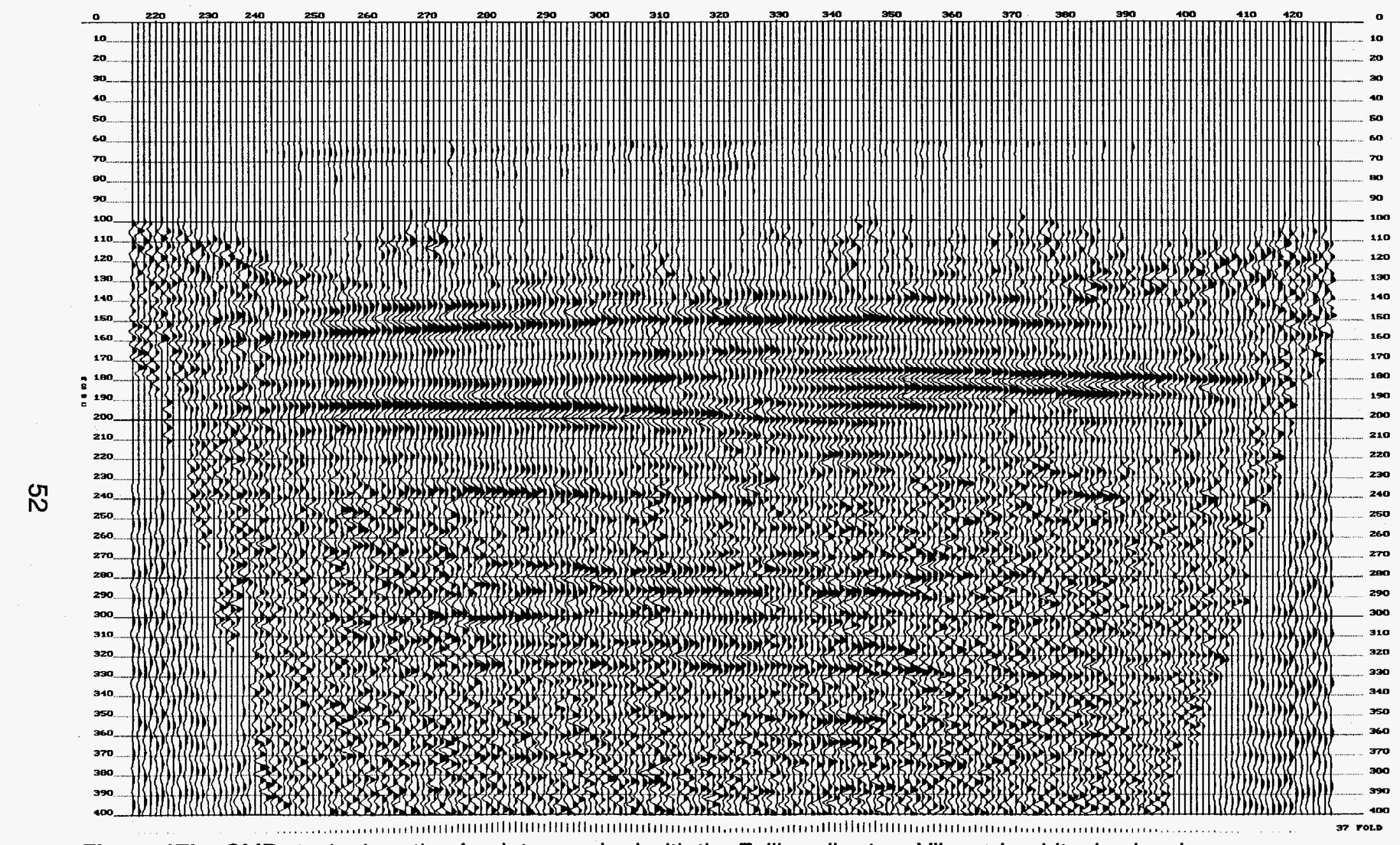

Figure 17b. CMP stacked section for data acquired with the Failing vibrator. Vibroseis whitening has been applied to the data before stacking. 


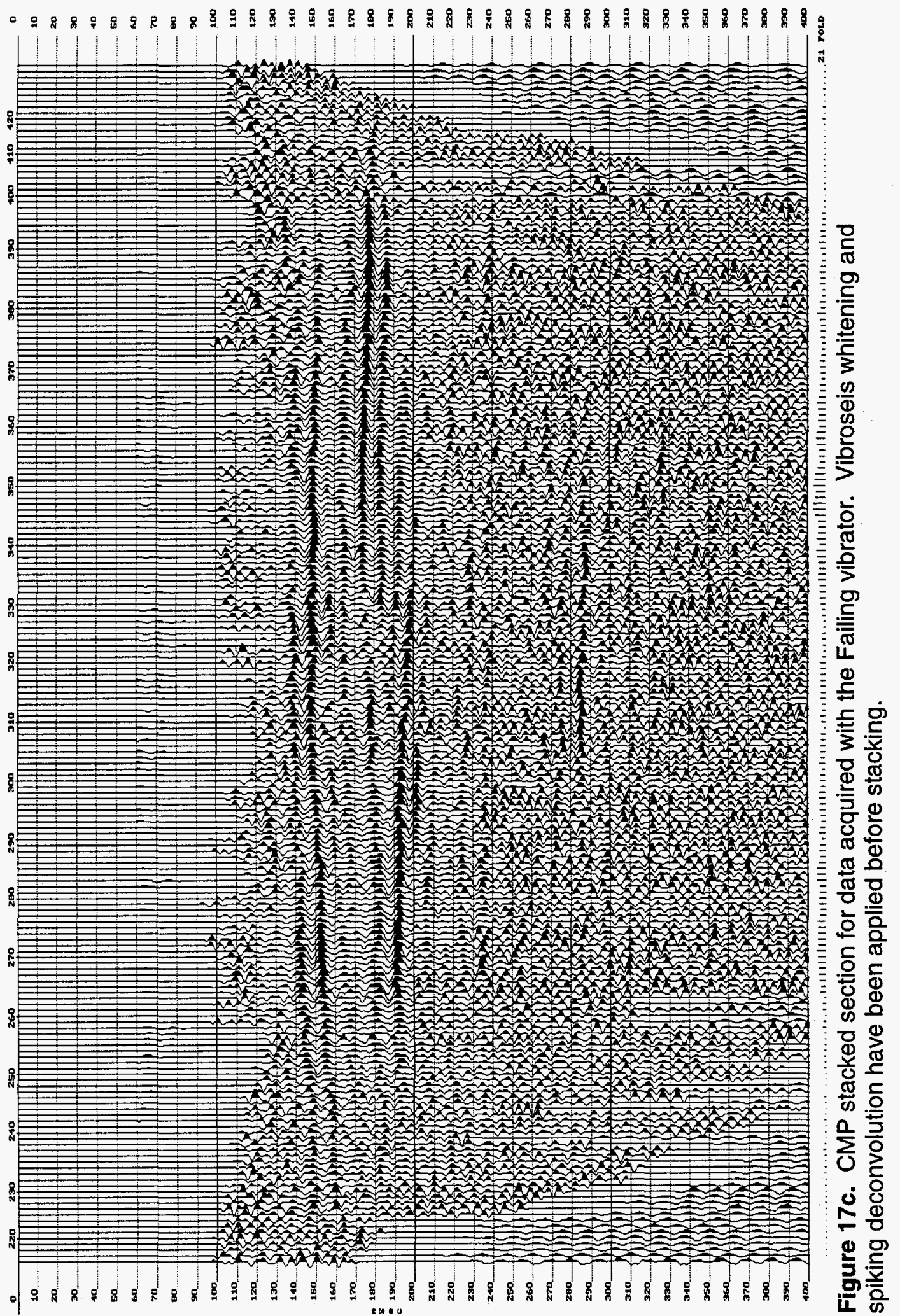




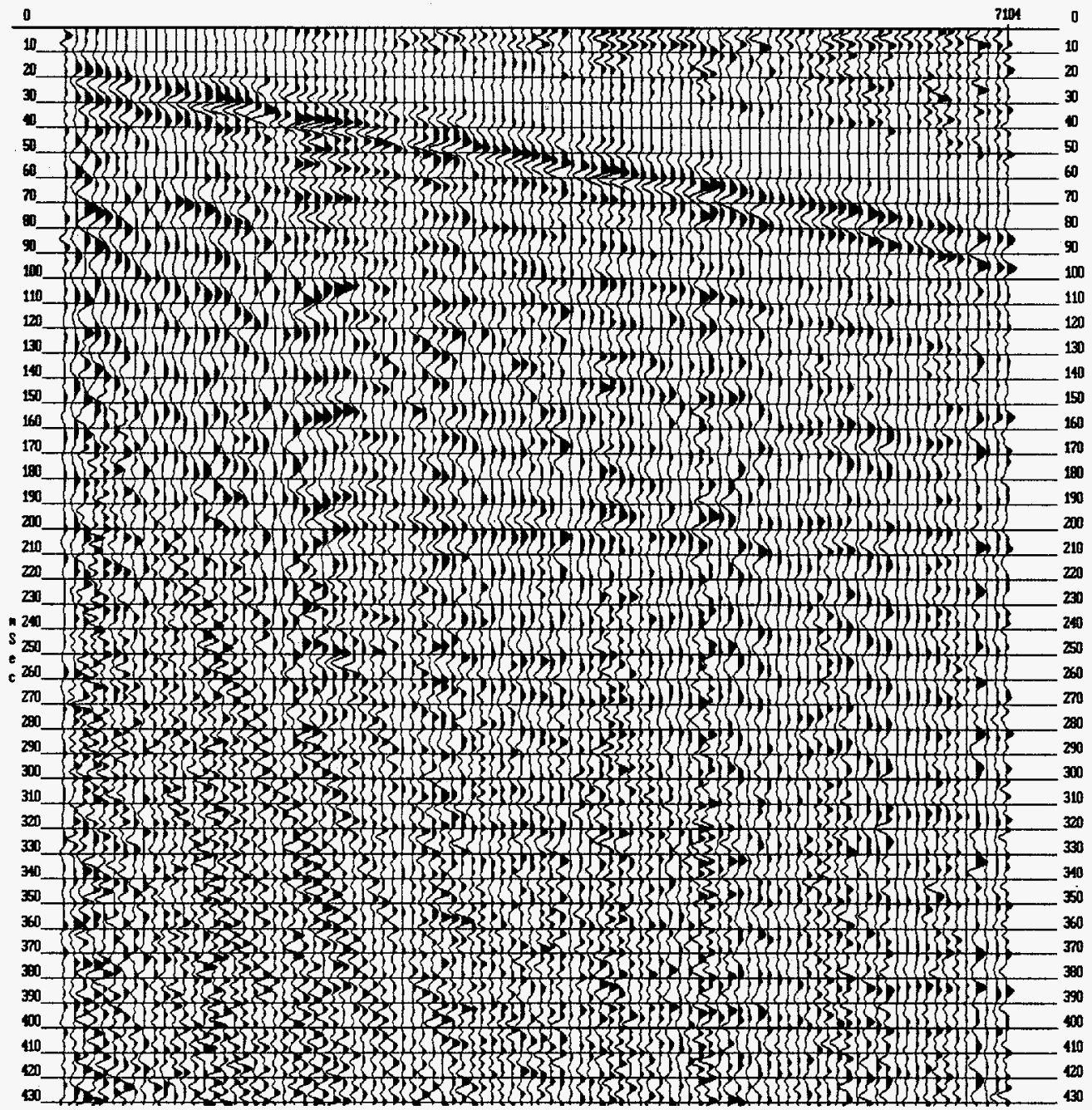

Figure 17d. Shot gather for one shot for the Failing vibrator. 


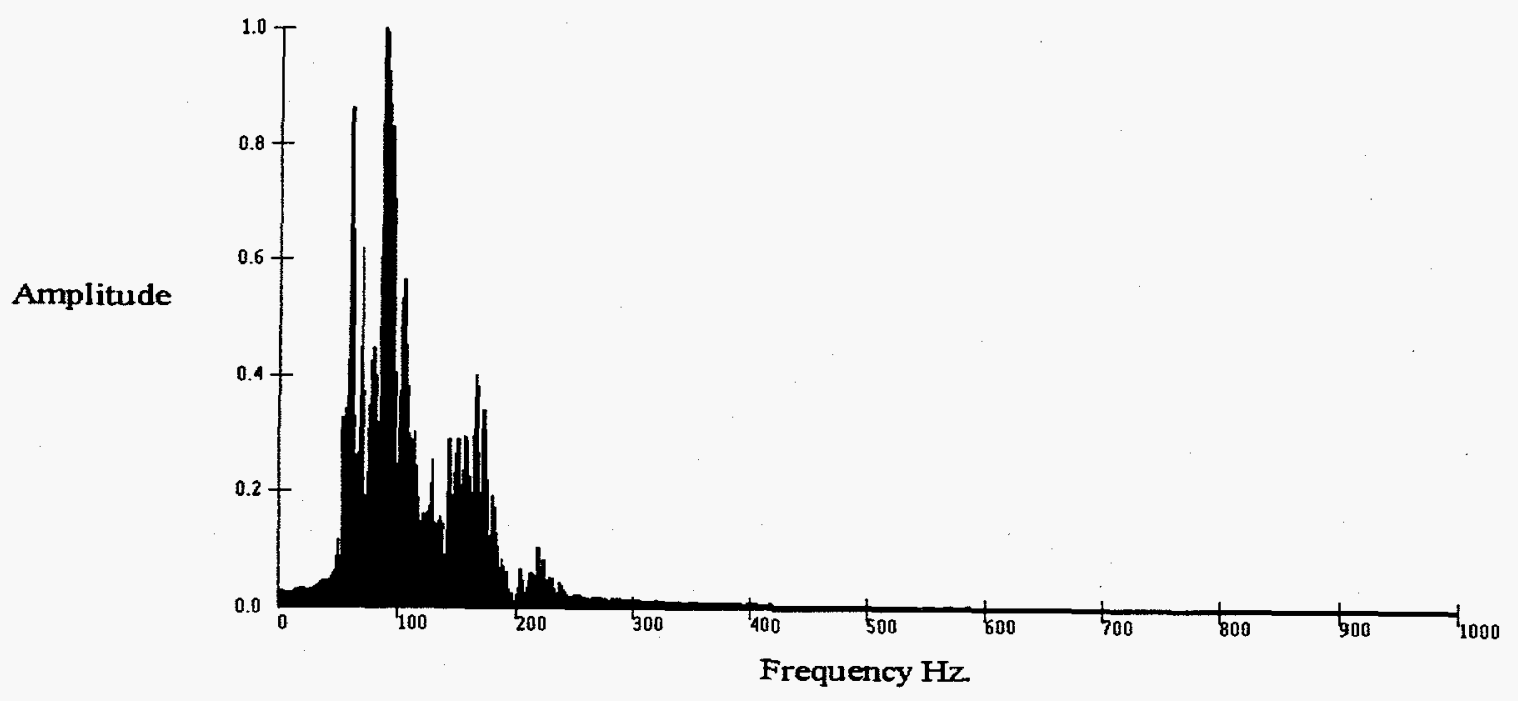

Figure 17e. Spectrum of trace 38, shot 7104 (Fig. 17b) for the Failing vibrator

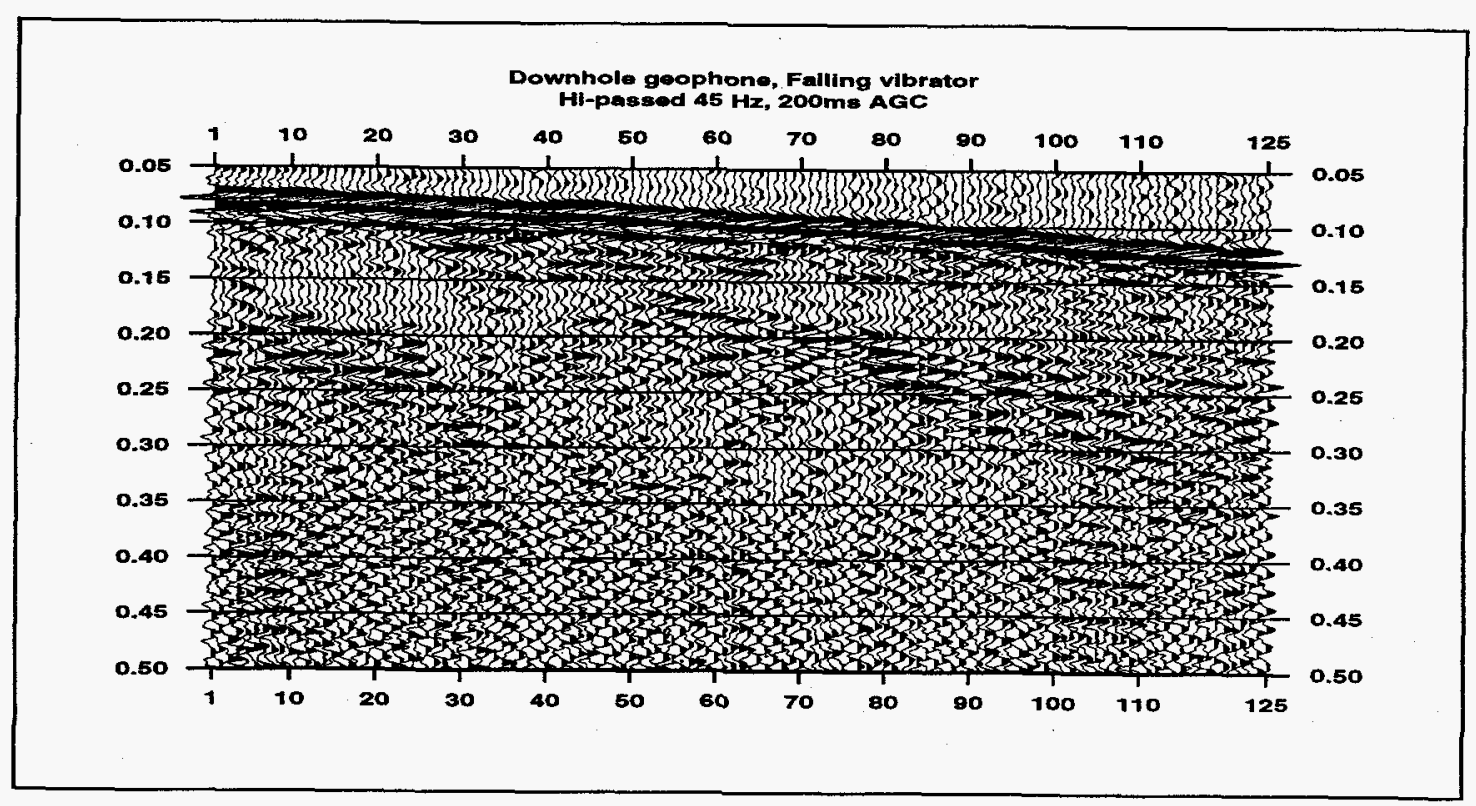

Figure 17f. Failing vibrator shots from all shot stations, recorded by the downhole vertical geophone in well 1943 at the west end of the geophone spread. 

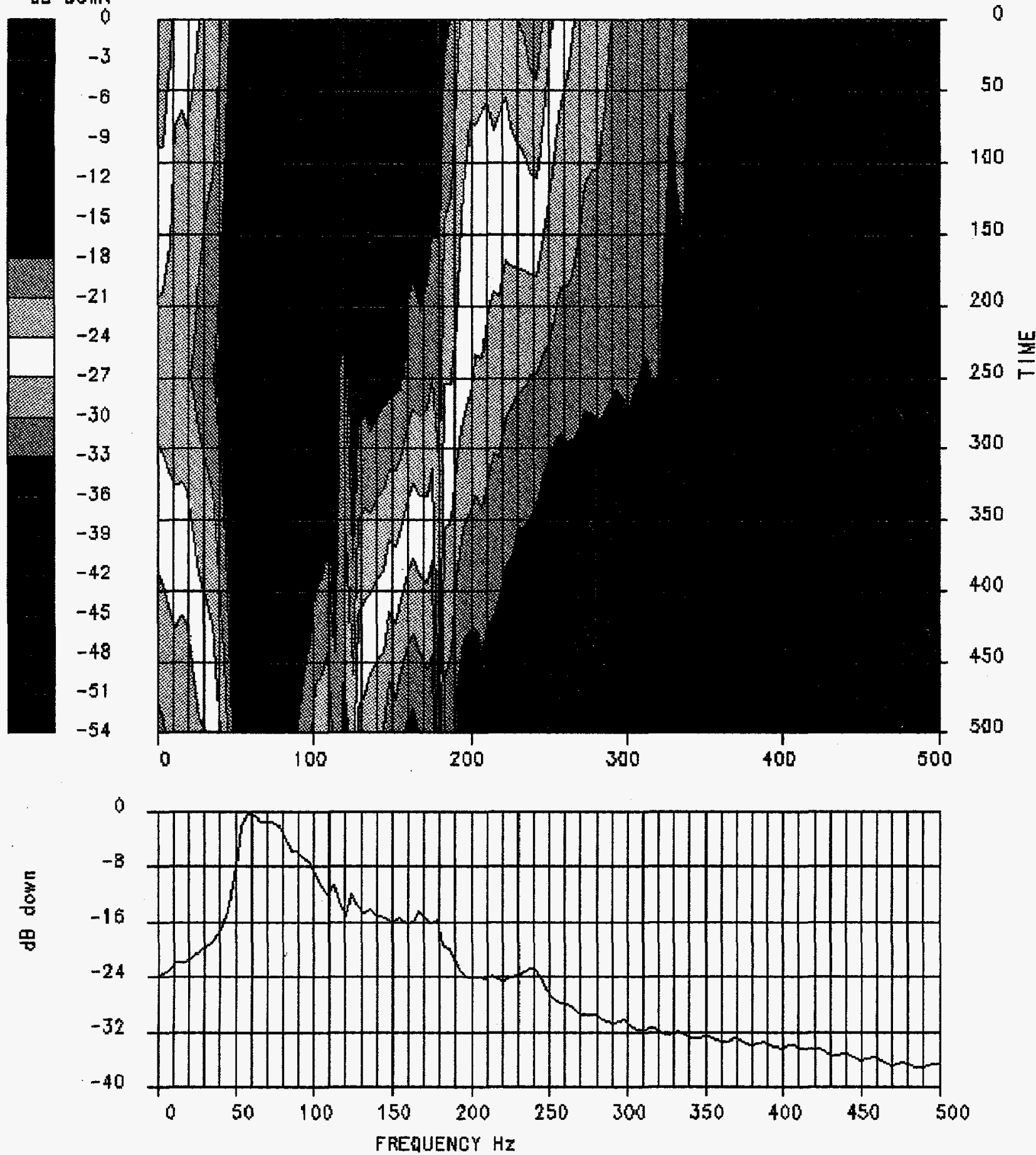

Figure 17g. Spectrum of unfiltered shots recorded by the downhole geophone with the Failing vibrator source. The color display shows how the frequency content varies with time, and an average spectrum for the entire record is shown at the bottom. 


\subsection{HYDROPHONE DATA}

The string of 48 hydrophones in well 1920 recorded tube waves that propagated upward and downward from at least two depths in the well. Hydrophone data provide a means of discriminating between hydraulically conductive (active) and nonconductive fractures. A sample hydrophone record is shown in Figure 18 for the EWG source and the nearest offset, 52.5 feet. Similar tube waves were observed for all sources at all source offsets from the well. The likely cause of the tube waves is shown in Figure 19. The pressure of the seismic pulse on hydraulically conductive fractures causes water to be squirted into the well, sending a pressure pulse that propagated both upward and downward in the well from its point of intersection with the fracture. Our interpretation of these tube waves are corroborated by well logging results, which locate fractures and fracture zones from thermal logs, caliper logs, and gamma logs. The corresponding well logs for this well are shown in Figure 5. Signatures in the caliper, gamma, residual temperature, fluid resistivity, and tube wave amplitude logs all indicate fracturing at 275 $\mathrm{ft}$. depth. Tube wave amplitude (in well logs) and fluid reisitivity logs indicate another fracture at 388 feet. These correlate with the source depths of tube waves in the hydrophone data. Other fractures or fracture zones indicated from individual well logs (e.g. $240 \mathrm{ft}, 400 \mathrm{ft}$ ) do not have corresponding tube waves in the hydrophone data. We conclude that hydrophone measurements may provide an inexpensive and effective means for discriminating between fractures that are hydraulically conductive and those that are nonconductive, particularly when combined with well log data.

The hydrophone data could also be processed using vertical seismic profiling methods to provide a cross-sectional image of the structures around the borehole. This could provide information for use in conjunction with well logs to constrain possible fracture orientations at a greater distance from the well (tens of feet as opposed to a few feet) than can be achieved by well logs alone. The data have yet not been processed to allow this type of analysis. 


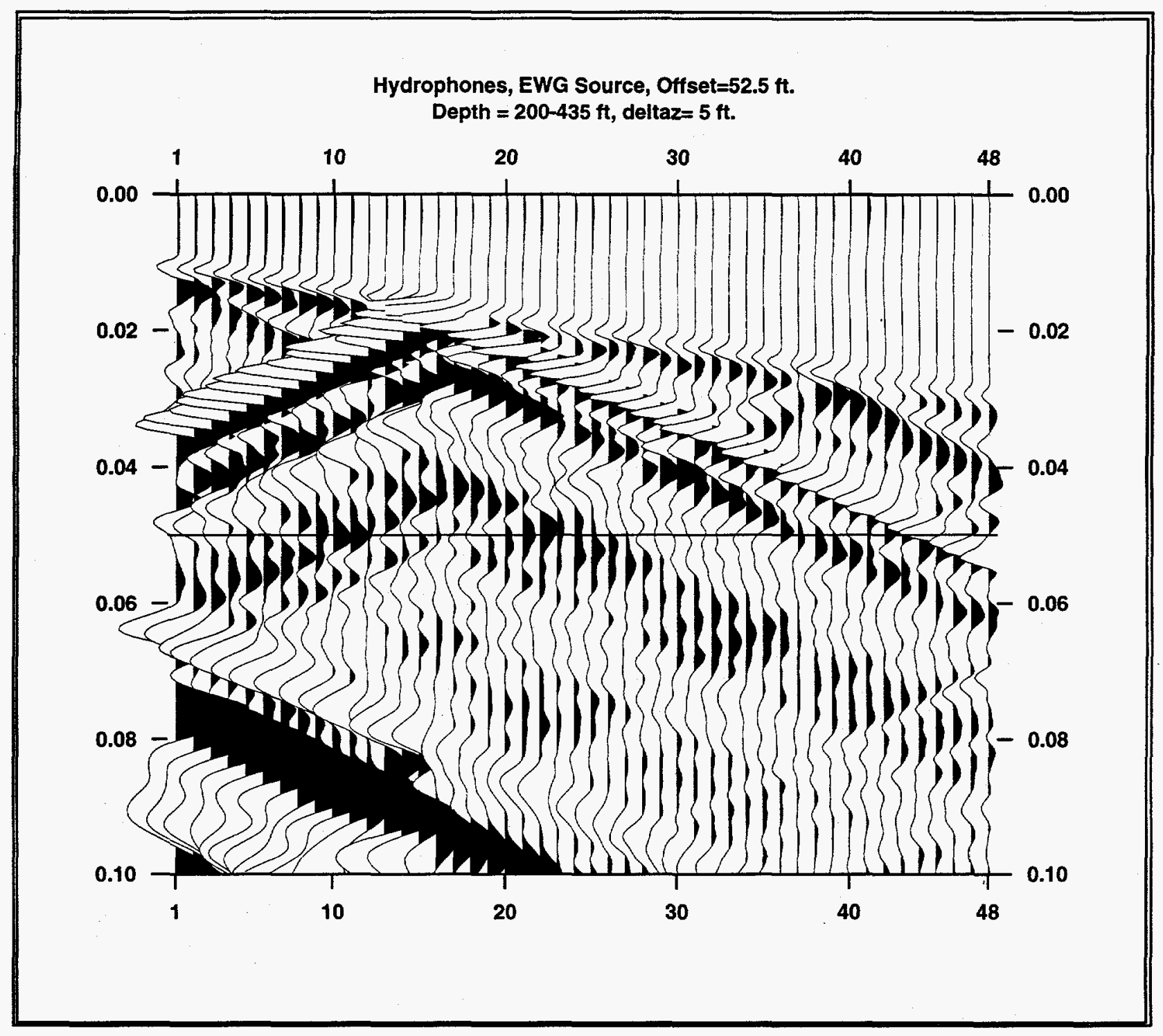

Figure 18. Hydrophone record from Well 1920 near the center of the surface line, for the nearest shot (52.5 ft away) with a Bison EWG source. The direct waves travelling from the source to the hydrophones arrive at times ranging from 0.01 seconds at the 200 feet depth to 0.03 seconds at 435 feet depth. Waves which start at the direct waves at hydrophones \# 16 $(280 \mathrm{ft})$ and \#38 (385ft) and arrive at later times on adjacent traces are "tube waves" which are caused by fluids being squirted into the borehole as a result of the pressure from the advancing seismic wave. They are indicative of fractures which are actively transmitting fluids, as opposed to fractures which might not transmit fluids. 


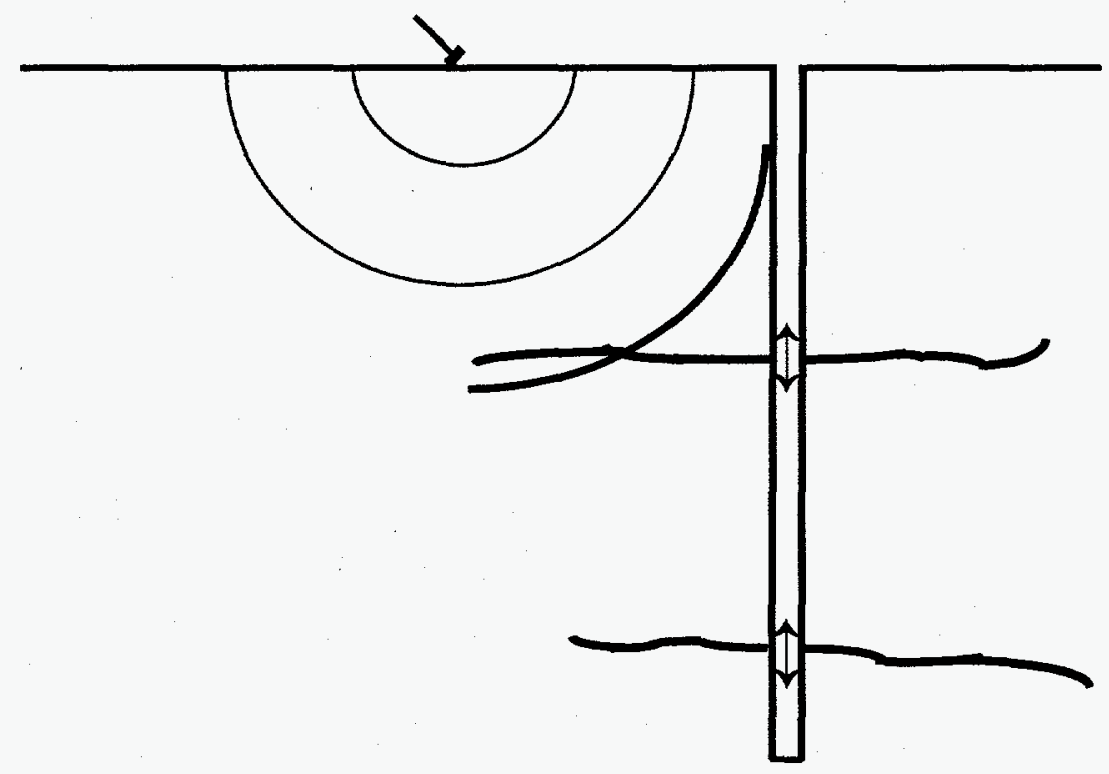

Figure 19. Diagram showing the process by which tube waves are generated in hydrophone data. When a seismic wave impinges on a fracture, it forces fluid into the borehole. This causes a pressure pulse to propagate both upward and downward from the fracture at a velocity which is slower than the velocity of seismic waves in rock. Recognition of these tube waves allows connected fractures to be identified. 


\section{CONCLUSIONS}

Eight non-invasive seismic sources were compared at a hazardous waste site on the Oak Ridge Reservation in November, 1993. Based on extrapolation of velocity well logs, a strong $200 \mathrm{~ms}$ reflection occurs at a depth of approximately $1300 \mathrm{ft}(400 \mathrm{~m})$. All of the sources, including the sledge hammer, generated sufficient energy to image portions of this reflection. The IVI Minivib provided the best image of the subsurface. Prewhitened data from this source were effective for imaging shallower depths than any of the other sources, while providing resolution of the $150 \mathrm{~ms}$ and $200 \mathrm{~ms}$ reflections that was as good as or better than any of the other sources. Among the impulsive sources, the Bison Elastic Wave Generator was most effective, but its lower dominant frequency and higher instantaneous energy resulted in poorer image quality for reflections shallower than 150 ms when compared with the Minivib, even when SAGC was applied in the early stages of processing. Because shallow reflections are interpretable at many depths in our test data, these test results can also be used in selection of sources for shallower surveys. 


\section{REFERENCES}

Bechtel National, Inc., CH2M Hill, Ogden, and Peer, 1992, Remedial Investigation Implementation Plan for Waste Area Grouping 10 at Oak Ridge National Laboratory, Oak Ridge, Tennessee, ORNL Environmental Restoration Report ES/ER-4N2\&D2, ORNL/ER/Sub/87$99053 / 6 / \mathrm{N} 2$.

Bechtel National, Inc., 1995, Site characterization summary report for Waste Area Grouping 10 wells at the Old Hydrofracture Facility, Oak Ridge National Laboratory, Oak Ridge, Tennessee, ORNL Environmental Restoration Report ORNL/ER-299, ORNL/ER/Sub/87-99053/78.

Doll, W.E. and Çoruh, C.,1995, Spectral whitening of impulsive and swept-source shallow seismic data, Technical Program: Expanded Abstracts with Author's Biographies, 1995 Annual SEG. Meeting, Houston, p. 398-401.

Gochioco, L.M., 1992, Modeling studies of interference reflections in thin-layered media bounded by coal seams: Geophysics, v. 57, p. 1209-1216.

Knapp, R.W. and Steeples, D.W., 1986, High-resolution common depth point seismic reflection profiling, instrumentation: Geophysics, v. 51, p. 276-282.

Knapp, R.W., 1990, Vertical resolution of thick beds, thin beds, and thin-bed cyclothems: Geophysics, v. 55, p. 1183-1190.

Matsubara, Yoshikazu, Toru Takahashi, Ranajit Ghose, and Yasuhiro Kaida, 1995, Very shallow subsurface imaging using a portable vibrator: Expanded Abstracts with Author's Biographies, 1995 Annual SEG Meeting, Houston, p. 415-418.

Miller, R.D., Pullan, S.E., Waldner, J.S., and Haeni, F.P., 1986, Field comparison of shallow seismic sources: Geophysics, 51, 2067-92.

Miller, R.D., Pullan, S.E., Steeples, D.W., and Hunter, J.A., 1992, Field comparison of shallow seismic sources near Chino, California: Geophysics, v. 57, p. 693-709.

Miller, R.D., Pullan, S.E., Keiswetter, D.A., Steeples, D.W., and Hunter, J.A., 1994, Field comparison of shallow P-wave seismic sources near Houston, Texas: Geophysics, v. 59, p. 1713-1728.

Park, C.B., R.D. Miller, D.W. Steeples, and R.A. Black, 1996, Swept impact seismic technique (SIST): Geophysics, v. 61, p. 1789-1803.

Sheriff, R.E.,1991, Encyclopedic dictionary of exploration geohysics, 3rd ed., Society of Exploration Geophysicists, Tulsa, OK, $376 \mathrm{pp}$.

Steeples, Don W. and Miller, R.D., 1990, Seismic reflection methods applied to engineering, environmental, and groundwater problems, in Geotechnical and Environmental Geophysics, Vol. 1: Review and Tutorial, S.H. Ward, ed., Society of Exploration Geophysicists, Houston, p. 1-30. 
Widess, M.B., 1973, How thin is a thin bed?: Geophysics, v. 38, p. 1176-1180. 


\section{FURTHER INFORMATION AND CONTACTS}

For more information on this study, you may contact William Doll at (423)-576-9930, or by email at d8e@ornl.gov. Richard Miller and Jianghai Xia may be contacted at the Kansas Geological Survey, 1930 Constant Ave, Lawrence, KS 66047, (913)-864-3965 or by email as

rmiller@kgs.ukans.edu and jxia@kgs.ukans.edu. The Program Manager for this study was A.S. Will III. 


\section{DISTRIBUTION}

1. B. J. Carr

2. J. H. Cushman

3-22. W. E. Doll

23. D. E. Fowler

24. C.S. Haase

25. R. D. Hatcher

26. S. G. Hildebrand

27. G.K. Jacobs

28. P. Kanciruk

29. R. H. Ketelle

30. J. Kuhaida

31. J. M. Loar
INTERNAL DISTRIBUTION

32. C. A. Motley

33. T. E. Myrick

34. S. J. Norton

35. J. E. Nyquist

36. D. E. Reichle

37. D. S. Shriner

38. Central Research Library

39-53. ESD Library

54-55. Laboratory Records Dept.

56. Laboratory Records, ORNL-RC

57. Y-12 Technical Library

58. ER Central Doc. Mgmt. Center -- RC

\section{EXTERNAL DISTRIBUTION}

59. M. Broido, Acting Director, Environmental Sciences Division, ER-74, Department of Energy, 19901 Germantown Road, Germantown, MD 20874

60. E. G. Cumesty, ORNL Site Manager, Department of Energy, Oak Ridge National Laboratory, P.O. Box 2008, Oak Ridge, TN 37831-6269

61. F. A. Donath, Director, Institute for Environmental Education, Geological Society of America, 1006 Las Posas, San Clemente, CA 92673

62. D. W. Freckman, Director, College of Natural Resources, 101 Natural Resources Building, Colorado State University, Fort Collins, CO 80523

63. P. A. Hofmann, U.S. Department of Energy Oak Ridge Operations, 30 Main Street, Oak Ridge, TN 37830

64. Michael C. McCracken, Director, Office of the U.S. Global Change Research Program, Code YS-1, 300 E Street, SW, Washington, DC 20546

65-69. R. D. Miller, Kansas Geological Survey, 1930 Constant Ave., Lawrence, KS 66047

70. A. Patrinos, Associate Director, Office of Health and Environmental Research, ER-70, Department of Energy, 19901 Germantown Road, Germantown, MD 20874

71. G. S. Sayler, Professor, 10515 Research Drive, Suite 100, The University of Tennessee, Knoxville, TN 37932-2567

72. Office of Assistant Manager for Energy Research and Development, U.S. Department of Energy Oak Ridge Operations, P.O. Box 2001, Oak Ridge, TN $37831-8600$

73-74. Office of Scientific and Technical Information, P.O. Box 62, Oak Ridge, TN 37831 